Distribution Categories:

Environmental Control Technology

and Earth Sciences (UC-11)

Nuclear Waste Management (UC-70)

ANL $-75-78$

ARGONNE NATIONAL LABORATORY

9700 South Cass Avenue

Argonne, Illinois 60439

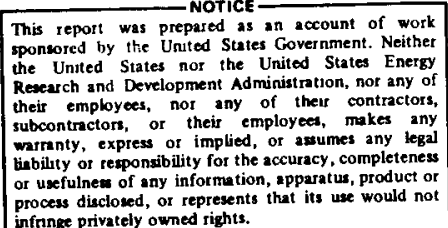

process disclosed, or represents
infinge privately owned rights.

\title{
CHARACTERIZATION OF PARTICULATE PLUTONIUM \\ RELEASED IN FUEL CYCLE OPERATIONS
}

by

W. B. Seefeldt, W. J. Mecham, and $M$. J. Steindler

Chemical Engineering Division

May 1976

Work performed under special contract No. 31-109-38-3213L

with the Electric Power Research Institute

DISTRIBUTICN $0:$ a: 


\section{DISCLAIMER}

This report was prepared as an account of work sponsored by an agency of the United States Government. Neither the United States Government nor any agency Thereof, nor any of their employees, makes any warranty, express or implied, or assumes any legal liability or responsibility for the accuracy, completeness, or usefulness of any information, apparatus, product, or process disclosed, or represents that its use would not infringe privately owned rights. Reference herein to any specific commercial product, process, or service by trade name, trademark, manufacturer, or otherwise does not necessarily constitute or imply its endorsement, recommendation, or favoring by the United States Government or any agency thereof. The views and opinions of authors expressed herein do not necessarily state or reflect those of the United States Government or any agency thereof. 


\section{DISCLAIMER}

Portions of this document may be illegible in electronic image products. Images are produced from the best available original document. 
-

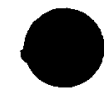


ABSTRACT. . . . . . . . . . . . . . . . . . . . . . 1

1. SUMMARY .......................... . 2

2. INTRODUCTION. . . . . . . . . . . . . . . . . . 4

3. CHARACTERIZATION OF ALTERNATIVE FUEL CYCLE CONCEPTS . • . . . . . . 5

3.1. Introduction. . . . . . . . . . . . . . . . . . 5

3.2. LWR-U Cycle . . . . . . . . . . . . . . . . 5

3.3. LWR-Pu Cycle. . . . . . . . . . . . . . . . . 5

3.4. LMFBR Cycle . . . . . . . . . . . . . . . 6

3.5. Reactor Park. . . . . . . . . . . . . . . 6

4. HISTORICAL REVIEW OF OPERATING EXPERIENCE WITH PLUTONIUM. . . . . . 7

4.1. Experiences Related to Government-Owned Facilities. . . . . 7

4.1.1. LASL Facilities . . . . . . . . . . . . . 8

4.2. Commercial Reprocessing Plant . . . . . . . . . . . 9

4.3. Commercial Fabrication Plants . . . . . . . . . . . . 12

4.4. Accident Evaluations. . . . . . . . . . . . . . 13

References for Section 4. . . . . . . . . . . . . 18

5. REGULATORY STANDARDS. . . . . . . . . . . . . . . . . . . 19

References for Section 5. . . . . . . . . . . . 22

6. PRINCIPLES OF AEROSOL BEHAVIOR. . . . . . . . . . . . . . . 23

6.1. Introduction. . . . . . . . . . . . . . . . 23

6.2. Surface Adhesion Forces and Coagulation of Aerosols . . . . 23

6.3. Basic Mechanisms for Collection of Airborne Particles . . . 26

6.4. Measurement of Aerosol Emissions. . . . . . . . . . . 32

References for Section 6. . . . . . . . . . . . 34

7. REVIEW OF MAJOR EXPERIMENTAL STUDIES RELATING TO PARTICLE SIZE

DISTRIBUTIONS AND EFFICIENCIES OF FIBER FILTERS . . . . . . . . . . 35

7.1. Analysis of Particle Size Distributions at Several AEC

Facilities. . . . . . . . . . . . . . 35

7.2. Experimental Studies of HEPA Performance. . . . . . . . . 43

7.3. HEPA Efficiency as a Function of Particle Size. . . . . . . 47

References for Section 7. . . . . . . . . . . . 51 
8. REVIEW OF ANALYSES OF NORMAL AND ACCIDENTAL RELEASES FROM

EX-REACTOR FUEL CYCLES . . . . . . . . . . . . . . . . . . . . 52

8.1. Introduction . . . . . . . . . . . . . . . 52

8.2. Theoretically Possible Major Accidents of Nuclear Fuel Cycle Plants . . . . . . . . . . . . . . . . . . . 53

8.2.1. Introduction . . . . . . . . . . . . . . 53

8.2.2. Reference Design Features to Minimize the Occurrence and Consequences of Accidents. . . . . . . . . 53

8.2.3. Dispersal and Release Mechanisms . . . . . . . . . 54

8.3. Routine and Accidental Releases of Plutonium in Purex Reprocessing Plants Estimated in a 1970 Siting Study . . . . . 55

8.3.1. Introduction . . . . . . . . . . . . . 55

8.3.2. Conclusions. . . . . . . . . . . . . . 57

8.3.3. Routine Plant Releases from Reprocessing Plants. . . . 57

8.3.4. Mechanisms of Particulate Formation. . . . . . . . 58

8.3.5. Plutonium Releases in Plant Accidents. . . . . . . 58

8.4. Risks of Effluents from Mixed-Oxide Fuel Fabrication Plants:

1973 PNL Study ..................... 59

8.5. Review of Accidental Releases of Truck Shipments of Plutonium;

A Risk Analysis by PNL . . . . . . . . . . . . . . . . 60

8.5.1. Introduction ................. 60

8.5.2. Basis of Analysis. . . . . . . . . . . . 62

8.5.3. Estimates of P1utonium Source Term . . . . . . . 62

8.6. AEC Generic Environmental Statements . . . . . . . . . . . 66

8.6.1. Environmental Survey of the Nuclear Fuel Cycle . . . 66

8.6.2. Generic Environmental Statement Mixed Oxide Fuel . . 67

8.6.3. AEC Generic Statement for LMFBR Program . . . . . 69

8.6.3.1. Fuel Fabrication . . . . . . . . . 69

8.6.3.2. Fuel Reprocessing. . . . . . . . . . 71

8.7. Allied Gulf Nuclear Fuel Processing Plant, Barnwell, S.C.. . . 71

8.8. Summary of Source Terms Data . . . . . . . . . . . . 72

References for Section 8 ............... 73

9. CONSTRUCTION OF SOURCE TERM MODELS FOR REFERENCE FUEL CYCLES . • . 74

9.1. Ventilation Design and General Filter Characteristics. . . . 74

9.2. Basic Ventilation Design . . . . . . . . . . . . . . 75 
9.2.1. Introduction . . . . . . . . . . . . 75

9.2.2. Glove Box Configuration. . . . . . . . . . . 75

9.2.3. Removal of Contaminants from Air in AEC Filters. . . 75

9.2.4. Safety and Other Considerations. . . . . . . . 76

9.3. Reference Penetration Data for HEPA Filters. . . . . . . . . 76

9.4. Particle Size Distributions of Effluents . . . . . . . . . . 77

9.5. Total Penetration Factors for Processing and Fabrication

Plants for Three Time Periods. . . . . . . . . . . . . 84

9.5.1. Plant Retention Based on Current Practice. . . . . . . 84

9.5.2. Plant Retention Based on Current Technology

Capability . . . . . . . . . . . . . . 84

9.5.3. Plant Retention Based on Future Technology

Developments .............. 85

9.6. Normalized Plutonium Flow for Fuel Cycles of Reference

Reactors . . . . . . . . . . . . . . . 86

9.7. Source Term for Normal Operations. . . . . . . . . . 87

9.8. Fractiona1 Release for the Shipment of Plutonium Dioxide . . . 88

9.9. Accidents in Fuel Cycle Facilities . . . . . . . . . . 88

9.9.1. General. . . . . . . . . . . . . . . 88

9.9.2. Fabrication Plants.............. . 89

9.9.3. Processing Plants. . . . . . . . . . . . 89

9.10. Conclusions . . . . . . . . . . . . . . . . 90

References for Section 9... . . . . . . . . . . 92

APPENDIX A - EXAMPLE OF METHOD USED TO CALCULATE FILTER PENETRATION AS AS A FUNCTION OF PARTICLE SIZE. . . . . . . . . . . . . 93

APPENDIX B - CALCULATION OF EXPECTED FRACTIONAL RELEASES FROM CUMULATIVE PROBABILITY DATA . . . . . . . . . . . . . 96 


\section{LIST OF FIGURES}

Section and No. Title Page

6.1. Characteristics of Particles and Particle Dispersoids . . . . . . . 24

6.2. Single-Fiber Model of Filtration . . . . . . . . . . . . 27

6.3. Particle Removal by Flow Interception . . . . . . . . . . . . 27

6.4. Particle Removal by Inertial Impaction. . . . . . . . . . . . 28

6.5. Particle Removal by Thermal Diffusion . . . . . . . . . . . 29

6.6. The Effects of Inertia, Diffusion, and Interception on the
Penetration-Velocity Curve. . . . . . . . . . . . 31

6.7. Series of Experiments Showing Decrease of Penetration of Fiber Filter at Submicron Diameters . . . . . . . . . . . . 31

7.1. Size Characteristics of Aerosol Containing ${ }^{238} \mathrm{Pu}$ and ${ }^{239} \mathrm{Pu}$ by Radiometric Analysis of All Impactor Samples at Location 00, a Research and Development Facility . . . . . . . . . . . 38

7.2. Size Characteristics of Aerosol Containing ${ }^{238} \mathrm{Pu}$ by Radiometric Analysis of All Impactor Samples at Location 04, a Research and Development Facility. . . . . . . . . . . . . . 38

7.3. Size Chacteristics of Aerosol Containing ${ }^{238} \mathrm{Pu}$ by Radiometric Analysis of All Impactor Samples at Location 08, a Fabrication Facility. . . . . . . . . . . . . . . . . . 39

7.4. Size Characteristics of Aerosol Containing ${ }^{239} \mathrm{Pu}$ by Radiometric Analysis of A11 Impactor Samples at Location 14, a Fabrication Facility. . . . . . . . . . . . . . . . . . . . 39

7.5. Size Characteristics of Aerosol Containing ${ }^{239} \mathrm{Pu}$ by Radiometric Analysis of All Impactor Samples at Location 11, A Chemical Recovery Facility . . . . . . . . . . . . . . . . . 40

7.6. Size Characteristics of Aerosol Containing ${ }^{238} \mathrm{Pu}$ and ${ }^{239} \mathrm{Pu}$. Lognormally Distributed Impactor Data from Location 00. . . . . . 41

7.7. Size Characteristics of Aerosol Containing ${ }^{238} \mathrm{Pu}$. Lognormally Distributed Impactor Data from Location 04. . . . . . . . . . . . 41

7.8. Size Characteristics of Aerosol Containing ${ }^{238} \mathrm{Pu}$. Lognorma11y Distributed Impactor Data from Location 08. . . . . . . . . . 42

7.9. Size Characteristics of Aerosol Containing ${ }^{239} \mathrm{Pu}$. Lognormally Distributed Impactor Data from Location 14. . . . . . . . . . 42

7.10. Size Characteristics of Aerosol Containing ${ }^{239} \mathrm{Pu}$. Lognormally Distributed Impactor Data from Location 11. . . . . . . . . . 43 
8.1. Accident Source Term of Plutonium Oxide Shipment Expressed as Cumulative Probability (per shipment) 25. Release Fraction. . 64

9.1. Penetration Data for First-Stage HEPA Filters Adopted for Reference ........ . . . . . . . . . . . 78

9.2. Penetration Data Adopted as Reference For Second and Third Stages of HEPA Filters . . . . . . . . . . . . . . . . . . 79

A.1. Reconstructed Particle Size Distributions for the First-Stage HEPA of LASL Run P4-3. . . . . . . . . . . . . . . . . . . 94 


\section{LIST OF TABLES}

Section and No.

Title

$\underline{\text { Page }}$

4.1. Plutonium in Gaseous Effluent from DP West Operations at LASL. . . 8

4.2. Alpha Effluent from CMR Operations at LASL . . . . . . . . . 9

4.3. Summary of Fuel Processed and Particulates Released During

Operation of Nuclear Fuel Services Facility. . . . . . . . . . . . 10

4.4. Concentration of Particulate Discharges from Nuclear Fue1

Services Facility During Processing of Fuel from Yankee Rowe

Reactor. . . . . . . . . . . . . . . . . . 11

4.5. Commercial Fabrication Plants. . . . . . . . . . . . . 12

4.6. Experimenta11y Determined Alpha-Emitters Released from P1utonium

Facilities . . . . . . . . . . . . . . . . 13

4.7. Major Plutonium Containment Accidents. . . . . . . . . . . . 14

4.8. Analysis of Causes of Abnormal Occurrences in Air-Cleaning

Systems for Nuclear Facilities . . . . . . . . . . . . 16

4.9. Regulatory Guides Related to Air-Cleaning Systems. . . . . . . . 17

6.1 The Coagulation Constant $\mathrm{K}\left(\mathrm{r}_{1}, \mathrm{r}_{2}\right)=\mathrm{K}_{\mathrm{o}} \mathrm{f}\left(10^{-10} \mathrm{~cm}^{3} \mathrm{sec}^{-1}\right) . . . .25$

6.2. Calculated Half-Times for Coagulation. . . . . . . . . . . 26

6.3. Relative Effectiveness of Filtration Mechanisms. . . . . . . 30

7.1. Facilities and Operating Conditions at Sampling Locations for

Determining Particle Size Distributions. . . . . . . . . . 35

7.2. Mean P1utonium Size Characteristics of Aerosols at Five AEC

Facilities Upstream from Air-Cleaning Facilities . . . . . . . 37

7.3. Aerosol Size Distributions and Filter Penetrations in HEPA Filter

Efficiency Experiments, Series A. . . . . . . . . 45

7.4. Aerosol Size Distributions and Filter Penetrations in HEPA Filter

Efficiency Experiments, Series B... . . . . . . . 46

7.5. HEPA Filter Performance Reported by LASL . . . . . . . . . . . 47

7.6. HEPA Filter Penetrations vs. Aerosol Particle Size for LASL

Series A and B Experiments . . . . . . . . . . . . . . . 49

8.1. Assumed Fissile Inventory and Calculated Accidental Releases

of Fissile Material in a Nuclear Fuel Fabrication Plant. . . . . . 56 
8.2. Upper Limit Accidenta1 Releases of Plutonium from Fue1 Reprocessing Plants in Relation to Plant Capacity . . . . . . . . . . . 58

8.3. Reference Isotopic Composition of Plutonium for PNL Study. . . . . 59

8.4. Annual Risk of an Individual in the Environs of a Plutonium Fuels Fabrication Facility . . . . . . . . . . . . . . .

8.5. Accident Release Fraction of Plutonium during Shipment is. Cumulative Probability . . . . . . . . . . . . . 63

8.6. Summary of Source Term Data from Environmental Reports . . . . . 72

9.1. Filter Penetration Data Used for Reference . . . . . . . . . 80

9.2. Particle Size Distributions of Effluents from Processing Plants for Air-Cleaning Systems Containing Two and Three HEPA Filters in Series . . . . . . . . . . . . . . . . 82

9.3. Particle Size Distributions of Effluents from Fabrication Plants for Air-Cleaning Systems Containing Two and Three HEPA Filters in Series. . . . . . . . . . . . . . . . . . . . .

9.4. Summary of Reference Values for Plutonium Releases in Processing and Fabrication Plants for Various Time Periods. . . . . . . . 86

9.5. Normalized Plutonium Flows in Three Reference Reactors . . . . . 87

9.6. Source Term for Normal P1utonium Releases from Three Ex-Reactor Cycles . . . . . . . . . . . . . . . . . . . 87

9.7. Estimated P1utonium Released during Shipment of Plutonium Oxide. . 88

9.8. Estimated P1utonium Contents of Effluents Upstream from Air-Cleaning System for Serious Accidents in Fabrication Plants . . . . . . . . 89

9.9. Estimated P1utonium Contents of Effluents Upstream from Air-Cleaning System for Serious Accidents in Processing Plants. . . . . . . . . 90

9.10. Normalized Plutonium Releases for Major Accidents in Fabrication and Processing Plants. . . . . . . . . . . . . . 90

9.11. Releases Expected from Normal and Accident Situations for Ex-Reactor Fuel Cycle Operations. . . . . . . . . . . . . . . 91 
CHARACTERIZATION OF PARTICULATE PLUTONIUM RELEASED

IN FUEL CYCLE OPERATIONS

by

W. B. Seefeldt, W. J. Mecham, and M. J. Steindler

\begin{abstract}
An estimate of the plutonium source terms is made for the fuel cycles of three reactor types on the basis of currently applied, currently available, and estimated future technology. The three reactors are $L W R-U, L W R-P u$, and $L M F B R$. The source terms are characterized as to quantity, form, and particle size distribution.

Historical operating data for existing plants and the state of the art of the technology of air cleaning are reviewed.
\end{abstract}




\section{SUMMARY}

An estimate was made from currently available information of the expected releases of plutonium (both quantities and size distributions) to the environment in ex-reactor fuel cycles. Three different fuel cycles were considered, corresponding to the three reactor types: (1) a light-water reactor fueled with slightly enriched uranium, (2) a light-water reactor operating with recycle plutonium, and (3) a liquid-metal fast-breeder reactor. In the corresponding reference fuel cycles, the relative plutonium processing rates are approximately $1: 2: 8$, respectively,

To make allowance for developing technology in effluent control, an estimate for each fuel cycle was made for three stages of technology:

(a) practices of air cleaning in plants presently operating; (b) current aircleaning technology as applied to proposed or hypothetical plants; and

(c) improved practices based on projected future applications and/or advanced technology. The plutonium source terms (i.e., releases) are reported as $\mu g$ $\mathrm{Pu} / \mathrm{GW}(\mathrm{e})-\mathrm{yr}$ of electrical power production, and include releases estimated for both normal operations and averaged accident conditions. The information reviewed indicated that the principal form of plutonium release would be airborne particulates, of a reasonably well characterized chemical form and particle-size distribution. The chemical form would depend on the material source and would be solid plutonium dioxide from solid fuel material and solid plutonium nitrate from the evaporation of droplets of process solution.

Literature was reviewed on experience in the shipping of plutonium and other hazardous materials, on the operation of existing reprocessing and fabrication plants, and on releases described in environmental statements for proposed and hypothetical plants. Literature on accident history and on projected accident behavior was included. Also reviewed were regulations of the Atomic Energy Commission, the Nuclear Regulatory Commission, and the Environmental Protection Agency.

Because the principal mode of release is airborne plutonium, particular attention was paid to the mechanisms of aerosol behavior and collection, and to the efficiency of standard HEPA fiber filters. The operation of fiber filters is such that increased particle-removal efficiency can be achieved by using several standard filters in series; particles are retained by adhesion on the surface of the fibers and not by being trapped in the interstices. The collection efficiency of fiber filters is strongly dependent on particle size and is at a minimum for particles with a diameter of the order of $0.4 \mu \mathrm{m}$. As a result of this characteristic, the particles penetrating the filter tend to be concentrated in a narrow range of about this size, that is, between about 0.2 and $0.6 \mu \mathrm{m}$ for fiber filters of the HEPA type. Experimental results indicate that a single-stage HEPA filter has a typical penetration fraction of less than $10^{-4}$ for the size of particles with maximum penetration. Particles smaller than $0.1 \mu \mathrm{m}$ and larger than $0.6 \mu \mathrm{m}$ are filtered out more effectively.

Because of the intrinsic high efficiency of HEPA filters, the practical limits of effectiveness of a filter system are determined by the leaktightness of installation and by the continuing maintenance checks on filter and seal integrity. The principal factor determining the releases during normal operations are expected to be the requirements imposed by regulatory authorities. Releases as a result of accidents, which are not under process 
control, are determined by the safety features of overall plant design and especially the features of the air cleaning and confinement systems.

The numerical estimates of plutonium source terms in this report are based on our selection of the best available plant data in the literature as cited in references of Section 9 for existing plants, for plants under construction, and for state-of-the-art proposed plants. Basic performance data for HEPA filters with respect to collection efficiency were derived from LASL tests summarized in Section 7. Factors of judgment were applied to allow for degradation in service and to alternative reference designs with an additional stage of filtration.

In normal shipment of plutonium, the regulations specify complete containment. The expected releases for accidents were based on a PNL study of the risk of plutonium shipment.

It was found that air cleaning in existing fuel cycle facilities for light water reactors with enriched uranium fuel is not capable of meeting proposed EPA emission limits of $0.5 \mathrm{mCi} / \mathrm{GW}(\mathrm{e})-\mathrm{yr}$ of combined ${ }^{239} \mathrm{Pu}$ and other alpha-emitting transuranic nuclides. Substantially improved air cleaning is needed for such plants.

On the basis of equal fractions of plutonium released in equivalent fuel cycle facilities, the plutonium discharges [per GW(e)-yr of generated power] for light water reactors with plutonium recycle is about twice that for light water reactors with uranium fuel, and the release for LMFBRs is about four times that for light water reactors with plutonium recycle. 


\section{INTRODUCTION}

At present, considerable controversy exists about the acceptability of the future public hazard from plutonium releases in an expanding nuclear power industry. All of the currently operating nuclear power reactors are generating plutonium. It is proposed to utilize this plutonium in the anticipated expansion of the nuclear industry during the next two or three decades by recycling it to the thermal reactors that produced it, or by using it as fuel in new fast breeder reactors. Large quantities of plutonium have been handled without significant public injury during the past three decades, mostly in large-scale governmental operations and small-scale research operations. There is no such experience with large-scale operations in competitive, investor-owned business organizations.

In order to predict the impact of increased participation of plutonium in nuclear power generation, it is desirable to provide estimates of the amount and form of plutonium that may be released from operations that are part of the ex-reactor fuel cycle. Under normal circumstances, the ex-reactor fuel cycle includes mining, milling, fuel material preparation, fuel element fabrication, storage, shipping, reprocessing, and waste handling and disposal. The physical and chemical attributes of the materials of the ex-reactor fuel cycle depend on the particular type of reactor fuel and operation, e.g., LWR-U or LWR-Pu. Since the present focus is on plutonium, operations that deal only with uranium are not considered here. Further, little attention is given to waste disposal operations largely because the major release of plutonium in these operations is from stored materials over a long term.

The objective of this work is to provide a summary of available information that characterizes the source term for the releases of plutonium from the external fuel cycle. As used here, the source term includes the quantity of plutonium released per unit of fuel cycle throughput, the physical form and particle size distributions of plutonium associated with normal operations and with accidents, and the weighting of these factors by their probability of occurrence. The source terms described are those for releases of solid plutonium compounds dispersed in a gaseous medium. The major focus is on plutonium dioxide dispersed in air.

The scope of the work includes a historical assessment of the commercial nuclear industry, light water reactors with and without the recycle of plutonium, liquid metal fast breeder reactors, and the impact of power parks. The scope also includes a review of the state of fundamental knowledge of the mechanics of aerosol formation, agglomeration characteristics, and the mechanisms of particle interception. 


\section{CHARACTERIZATION OF ALTERNATIVE FUEL CYCLE CONCEPTS}

\subsection{Introduction}

This report considers four basic fuel cycle concepts which are identified as:

(1) The Light Water Reactor-Uranium (LWR-U) cycle,

(2) The Light Water Reactor-Plutonium (LWR-Pu) cycle,

(3) The LMFBR cycle, and

(4) A reactor park concept that incorporates LWR-Pus and LMFBRs.

The fuel cycle operations for each concept are described below.

\section{2. $\quad \underline{L W R-U \text { Cycle }}$}

The reference LWR-U cycle provides for the fueling of LWRs only with slightly enriched uranium, which may be either virgin or recycle. Since no plutonium is involved in fueling LWR-Us, the fabrication of finished fuel assemblies is not considered in this review. In this cycle, plutonium bearing spent fuel is shipped and then processed for the recovery and subsequent recycle of uranium. Plutonium is recovered and stored, and high-level wastes are treated for disposal. Recycle uranium is converted to $\mathrm{UF}_{6}$, re-enriched, converted to $\mathrm{UO}_{2}$, and fabricated into fuel assemblies. These operations are performed at three sites categorized as follows: (1) processing and conversion to $\mathrm{UF}_{6}$, (2) enrichment, and (3) conversion to $\mathrm{UO}_{2}$ and refabrication.

Plutonium is converted to $\mathrm{PuO}_{2}$ at the processing plant and is subsequently shipped to a storage facility.

High-level wastes that may contain small quantities of transuranium compounds are converted to solids at the processing plant and are shipped to a disposal site.

Plutonium is thus present in three shipments: (1) spent fuel from the reactor to the processing plant, (2) solid oxide from the processing plant to storage, and (3) high-level waste (containing only small quantities of plutonium) from the processing plant to the disposal site.

\subsection{LWR-Pu Cycle}

The LWR-Pu cycle differs from the PWR-U cycle in that the separated plutonium at the processing plant undergoes operations designed to recycle it back to a reactor. The plutonium is converted to oxide at the processing plant to meet NRC shipping requirements. At a fabrication facility designed for plutonium handling, plutonium and slightly enriched uranium are fabricated into mixed-oxide fuel assemblies that are subsequently shipped to a reactor. The other portions of the cycle are basically the same as those for the LWR-U cycle, except that less uranium enrichment is required. 


\subsection{LMFBR Cycle}

The core, axial blankets, and radial blankets discharged from an LMFBR are processed together for the separation of uranium, plutonium, and fission products. Uranium and plutonium are each converted to oxide at the processing plant. Each is shipped to one or both of two separate fabrication plants (which may be at the same location)--the uranium for fabrication of axial and radial blanket assemblies at one plant or for fabrication of core assemblies at the second plant, and the plutonium for fabrication of core assemblies, also at the second plant. It is assumed that excess plutonium not needed for the fabrication of reload assemblies is processed and fabricated into mixedoxide core assemblies for use in other reactors. The high-level waste is converted to solid form at the processing plant and is shipped to a disposal site. Four different shipments of uranium and plutonium are made in the ex-reactor cycle.

\subsection{Reactor Park}

The reference reactor park consists of a mixture of LMFBRs and LWR-Pus such that the only fuel material needed for the park is natural or depleted uranium. Near the reactors is a processing plant that is capable of accepting spent fuel from both types of reactors and of effecting separation of uranium, plutonium, and fission products. Also on site are several fabrication facilities: one for the fabrication of the uranium blanket assemblies for LMFBRs and of uranium-only assemblies for the LWR-Pus, a second for the fabrication of mixed-oxide assemblies for LWR-Pus, and a third for the fabrication of mixed-oxide assemblies for LMFBR cores. A fuel cycle facility may consist of separate structures, each for the performance of one or more functions, or a single structure. In the reactor park concept, the material shipped is restricted principally to incoming depleted uranium and the small amount of plutonium (excess or shortage) needed to correct imbalances between the two reactor types present. Solidified high-level wastes may be shipped offsite for disposal. 


\section{HISTORICAL REVIEW OF OPERATING EXPERIENCE WITH PLUTONIUM}

\subsection{Experiences Related to Government-Owned Facilities}

During a thirty-year period, the Atomic Energy Commission has been producing plutonium and fabricating it into forms suitable for weapons. A great deal of experience has been accumulated in performing the many operations between the stage at which fuel is discharged from the plutonium-producing reactors and the stage at which it has reached its final form. These operations include processing for the separation of plutonium, conversion to oxide and fluoride, reduction to metal, consolidation, and metal fabrication. In addition to these basic operations, large-scale scrap recovery has been done at facilities for recovering plutonium. Since the facilities are widely separated--e. g., Hanford, Rocky Flats, Savannah River, Los Alamos, etc.-large-scale shipping operations have also been required.

Data on the scale of the operations and the total particulate discharges from these facilities are unavailable, but guesses can be made based on the approximate numbers of stockpiled weapons. If it is assumed that 10,000 weapons have been fabricated, that each requires on the order of $10 \mathrm{~kg}$ of plutonium, and that processing and fabrication efficiences are on the order of $50 \%$ then $200,000 \mathrm{~kg}$ of plutonium have been processed. This quantity is further increased if it is assumed that periodic refabrication is required. If the size of shipments is on the order of $100 \mathrm{~kg}$ and if material in intermediate forms is shipped four times, the number of shipments can be estimated to be of the order of 8000 , or an average of about one shipment per day. This crude estimate serves to illustrate the potentially extensive experience available.

In addition, nuclear weapons are continuously airborne as part of the U. S. military defense and as part of the U. S. contribution to NATO defenses. The total number of air- and ground-miles accumulated in performing this function must be substantial, although actual figures are not available.

Two accidents involving nuclear weapons have been reported. 1 The first, referred to as the Palomares, occurred January 16, 1966, along the coast of Spain. It resulted from the in-flight explosion of a B-52 bomber while it was engaged in in-flight refueling. The explosion released four plutoniumbearing weapons, three of which impacted on the ground and one of which landed in water. 'i'wo weapons were recovered intact, one from land and one from the sea. The high-explosive components of the other two weapons detonated on impact and dispersed plutonium over 1200 acres. The radii of the areas where levels of ground contamination exceeded $500 \mu \mathrm{g} / \mathrm{m}^{2}$ were $80 \mathrm{~m}$ and $60 \mathrm{~m}$ for the two weapons.

A second accident, also involving a B-52 bomber, occurred at North Star Bay, near Thule in Greenland on January 21, 1968. The cause was an on-board fire which necessitated bail-out of the crew. On impact of the bomber, the fuel ignited and four plutonium-bearing weapons burned. The debris and flaming fuel were scattered along a path about $700 \mathrm{~m}$ long. It was estimated that $99 \%$ of the plutonium was contained on the surface, and that some was carried downwind in a smoke cloud. 
Extensive cleanup operations were performed for each of the two events, and large quantities of contaminated material were shipped back to the U. S. Exposures of operating or other personnel were apparently not severe, since no exposure incidents have been reported.

The experiences in process operations, fabrication, and shipping apparently have been good, although no detailed information is available. As is discussed in Section 7, studies have been reported on characterizing airborne plutonium discharges from several facilities by particle size distribution, but not by quantity. The data on particle size distributions are useful in helping to identify the significant characteristics of particulate discharges from commercial fuel cycle facilities.

\subsubsection{LASL Facilities}

The off-gas treatment facilities for two LASL operations were upgraded in about 1973. The two facilities are identified as DP West and the CMR laboratories. The new facilities and a record of the improvement of plutonium levels in the effluent were recently described. ${ }^{2}$

The DP West facilities involve glove box operations with kilogram quantities of ${ }^{239} \mathrm{Pu}$ and several-hundred-gram quantities of ${ }^{238} \mathrm{Pu}$. The off-gas systems were progressively upgraded through the years, and a particularly intense effort was initiated following the 1969 Rocky Flats fire. Prior to the changes, the exhaust of each glove box was passed through one stage of HEPA filters located near the glove box and was subsequently given an additional stage of HEPA filtration in a building (146) provided for this purpose. In early 1973, an additional bank of HEPA filters was installed in a second building (324). A capability for efficiency testing with DOP was also provided.

In late 1972, the room exhaust system for DP West was also upgraded to a system that contained roughing filters and one stage of HEPAs. The discharge data for the process and room air systems (shown in Table 4.1) indicate the substantial improvements obtained.

TABLE 4.1. Plutonium in Gaseous Effluent from DP West Operations at LASL $^{2}$

\begin{tabular}{cccr}
\hline & \multicolumn{3}{c}{ Pu Discharged $(\mu \mathrm{Ci})$} \\
\cline { 2 - 4 } Year & $\begin{array}{c}\text { Process Air } \\
\text { System }\end{array}$ & $\begin{array}{c}\text { Room Air } \\
\text { System }\end{array}$ & Total \\
\hline 1971 & 500 & 12,500 & 13,000 \\
1972 & 300 & 55,000 & 55,000 \\
1973 & 13 & 1 & 14 \\
1974 (4 months) & 0.08 & 1 & 1.1 \\
\hline
\end{tabular}


The CMR laboratories are used for research and development activities involving gram to 100-gram quantities of the two plutonium isotopes. Prior to system improvements, exhaust air was passed through single banks of Aerosolve 95 filters (stated to be 80 to $85 \%$ efficient for $0.3-\mu \mathrm{m}$ DOP particles) and two sets of dry glove fiber filter pads. The new system, operable in late 1973, consists of roughing filters and two banks of HEPA filters. Table 4.2 shows that the effluent activity was reduced 99.2 to $99.7 \%$.

TABLE 4.2. Alpha Effluent from CMR Operations at LASL $^{2}$

\begin{tabular}{cccc}
\hline & \multicolumn{3}{c}{ Pu Discharged $(\mu \mathrm{Ci})$} \\
\cline { 2 - 4 } Month/Year & Wing 7 & Wing 5 & Wing 2 \\
\hline & 70 & 68 & 378 \\
$9 / 73$ & 49 & 30 & 435 \\
$10 / 73$ & 19 & 179 & 379 \\
$11 / 73$ & $0.09^{\mathrm{a}}$ & 62 & 416 \\
$12 / 73$ & 0.00 & 71 & 105 \\
$1 / 74$ & 0.9 & 134 & 12 \\
$2 / 74$ & 0.04 & $0.1^{\mathrm{a}}$ & $0.4^{\mathrm{a}}$ \\
$3 / 74$ & 0.10 & 0.07 & 0.03 \\
$4 / 74$ & 1.00 & 0.20 & 0.03 \\
$5 / 74$ & 0.43 & 0.36 & 1.90 \\
$6 / 74$ & 0.51 & 0.46 & 2.40 \\
Avg before change & 46 & 90.6 & 287.5 \\
Avg after change & 0.38 & 0.238 & 0.952 \\
\hline
\end{tabular}

$a_{\text {HEPA filters installed. }}$

\subsection{Commercial Reprocessing Plant}

To date, only one commercial facility has been constructed and operated for the processing of nuclear fuels: the Nuclear Fuels Services (NFS) facility at West Valley, New York. The plant was operated from 1966 through 1971, then terminated operations pending plant expansion and improvement. In that period, a total of 624 MT (metric tons) of fuel was processed representing a total burnup of $3.8 \times 10^{6} \mathrm{MWd}^{3}$ In addition, $95.5 \mathrm{~kg}$ of plutonium from SEFOR was processed and recovered. Of the total, 379 MT was fue1 from the NPR (New Production Reactor) (average burnup, $2039 \mathrm{MWd} / \mathrm{MT}$ ) and 245.1 MT was largely from commercial power reactors (average burnup, 12, 359 MWd/MT). The total amount of plutonium handled was $1884 \mathrm{~kg}$. A breakdown by year is shown in Table 4.3.

The particulate discharge during the seven years of operation was reported to total 2.16 curies. ${ }^{3}$ Reference 3 provides no breakdown of the fraction of total particulate that is either plutonium or total alpha. However, such data was obtained by HEW (Department of Health, Education, and 
TABLE 4.3. Summary of Fuel Processed and Particulates Released During Operation of Nuclear Fuel Services Facility

\begin{tabular}{|c|c|c|c|c|c|c|c|c|c|}
\hline \multirow[b]{2}{*}{ Year } & \multirow[b]{2}{*}{$\begin{array}{c}\text { Fuel } \\
\text { Processed } \\
(\text { MTU })^{a}\end{array}$} & \multirow[b]{2}{*}{$\begin{array}{c}\mathrm{Pu} \\
\text { Content } \\
(\mathrm{kg})^{\mathrm{a}}\end{array}$} & \multirow[b]{2}{*}{$\begin{array}{l}\text { Average } \\
\text { Burnup } \\
\text { (MWd/MT) }\end{array}$} & \multirow[b]{2}{*}{$\begin{array}{c}\text { Estimated } \\
\text { Pu } \\
\text { Specific } \\
\text { Activity } \\
\text { (Ci/g) }\end{array}$} & \multicolumn{5}{|c|}{ Particulate Discharged } \\
\hline & & & & & $\begin{array}{c}\text { Total } \\
\mathrm{Ci}^{\mathrm{a}}\end{array}$ & $\underset{\alpha(\mathrm{mC} i)^{b}}{\text { Total }}$ & $\mathrm{Pu}(\mathrm{mg}) \mathrm{C}$ & $\begin{array}{l}\mathrm{mCi}(\alpha) / \\
\mathrm{GW}(\mathrm{e})-\mathrm{yr}\end{array}$ & $\begin{array}{l}\text { Fraction } \\
\text { of } \mathrm{Pu} \\
\text { Released }\end{array}$ \\
\hline 1966 & 145.2 & 245.9 & 3,374 & 0.157 & 0.15 & 0.94 & 6.03 & 2.2 & $2.4 \times 10^{-8}$ \\
\hline 1967 & 102.5 & 285.1 & 6,827 & 0.200 & 0.45 & 2.84 & 14.2 & 4.6 & $5.0 \times 10^{-8}$ \\
\hline 1968 & 136.5 & 270.2 & 2,814 & 0.168 & 1.1 & 6.93 & 41.2 & 20.6 & $15.3 \times 10^{-8}$ \\
\hline 1969 & 135.9 & 490.7 & 7,521 & 0.232 & 0.12 & 0.76 & 3.26 & 0.8 & $0.7 \times 10^{-8}$ \\
\hline 1970 & 37.3 & 175.5 & 11,109 & 0.276 & 0.18 & 1.13 & 4.11 & 3.1 & $2.3 \times 10^{-8}$ \\
\hline 1971 & $\begin{array}{c}67.1 \\
0 \\
\end{array}$ & $\begin{array}{r}320.8 \\
95.5 \\
\end{array}$ & 11,814 & 0.236 & 0.16 & 1.01 & 4.28 & 1.4 & $1.0 \times 10^{-8}$ \\
\hline TOTAL & 624.5 & $1,883.7$ & 6,089 & & 2.16 & 13.6 & 73.1 & Avg 4.2 & Avg $3.9 \times 10^{-8}$ \\
\hline
\end{tabular}

$a_{\text {Reference } 3 .}$

${ }^{b}$ Conversion factor obtained from data in Table 4.4 .

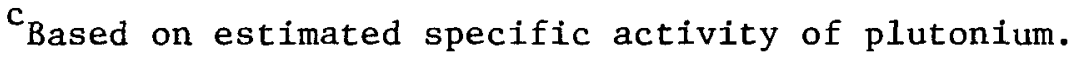


Welfare) investigators who made measurements at the plant during June of 1969 when 20 MT of fuel from the Yankee Rowe Reactor was processed. ${ }^{4}$ This was one of the hotter fuels processed--its average burnup was 20,500 MWd/MT. The results are shown in Table 4.4. For the three periods for which alpha data are reported, the fraction of total particulate that was alpha ranged from $5.05 \times 10^{-3}$ to $7.3 \times 10^{-3}$. The value of $6.45 \times 10^{-3}$, together with estimates of specific activity based on burnup, was used to convert the NFS reported data to weight quantities of plutonium. The results of these calculations are shown in Table 4.3 The imprecision of the estimate due to the presence of other alpha-emitting nuclides is recognized.

TABLE 4.4. Concentration of Particulate Discharges from Nuclear Fuel Services Facility During Processing of Fuel from Yankee Rowe Reactor ${ }^{6}$

\begin{tabular}{cccc}
\hline & \multicolumn{3}{c}{ Concentration $\left(\mu \mathrm{Ci} / \mathrm{cm}^{3}\right) \pm 3 \sigma$} \\
\cline { 2 - 4 } Period & $\begin{array}{c}\text { Gross } \alpha \\
\times 10^{-14}\end{array}$ & $\begin{array}{l}\text { Gross } \beta \\
\times 10^{-12}\end{array}$ & Ratio, $\frac{\alpha}{\alpha+\beta}$ \\
\hline June 5 to 12,1969 & $2.8 \pm 0.3$ & $3.8 \pm 0.1$ & $7.3 \times 10^{-3}$ \\
June 12 to 19,1969 & $6.5 \pm 0.7$ & $1.0 \pm 0.5$ & $6.45 \times 10^{-3}$ \\
June 19 to 26,1969 & $6.6 \pm 0.4$ & $1.3 \pm 0.5$ & $5.05 \times 10^{-3}$ \\
July 3 to 10,1969 & a & $2.0 \pm 0.1$ & ---
\end{tabular}

${ }_{A} A$ heavy black deposit on the filter made gross alpha measurement impracticable.

A total weight of about $73 \mathrm{mg}$ of plutonium was released, which corresponds to an average release fraction of $3.9 \times 10^{-8}$ of the total plutonium processed during the 6-yr period. Yearly values ranged from $0.7 \times 10^{-8}$ in 1969 to $15.3 \times 10^{-8}$ in 1968 .

The recently announced proposed regulations of the EPA ${ }^{5}$ provide plutonium particulate discharge limits for the entire fuel cycle of $0.5 \mathrm{mCi} /$ GW(e)-yr of electrical power generation. NFS data, converted to these units, are shown in Table 4.3. The average value for the $6 \mathrm{yr}$ of operation is 4.2 $\mathrm{mCi} / \mathrm{GW}(\mathrm{e})-\mathrm{yr}$.

If NFS had processed fuel having a burnup of $30,000 \mathrm{MWd} / \mathrm{MT}$ (with a Pu content of $8.56 \mathrm{~kg} / \mathrm{MT}$ ), the plutonium release rate would have been about 8.9 $\mathrm{mCi}(\alpha) / \mathrm{GW}(\mathrm{e})-\mathrm{yr}$ of electrical power generation. This value was calculated on the basis of a specific activity of $0.7 \mathrm{Ci}(\alpha)$ per gram of plutonium and a plant release fraction of $3.9 \times 10^{-8}$. 


\subsection{Commercial Fabrication Plants}

There are six commercially operated fuel fabrication facilities having a capability of handling reasonably large quantities of plutonium. All of them are characterized as being pilot scale; none is suitable for supporting a large-scale commercial plutonium-recycle industry. Their total annual production capacity has been estimated to be 50-75 MT/yr.

Table 4.5 identifies the facilities, their plutonium possession limits, and estimated capacities. ${ }^{7}$ Kerr-McGee and NUMEC are manufacturing fuel for the Fast Flux Test Reactor. Table 4.6 1ists experimentally determined alpha particulate discharges, both as concentrations in the stack gas and as annual releases. ${ }^{7}$ The numbers are not correlated with quantities of plutonium handled; hence, calculation of release fractions is not possible. Although LASL (an ERDA facility) does not perform operations comparable to those in the commercial facilities, it does handle several metric tons of plutonium per year. ${ }^{7}$ If it is assumed that two metric tons per year are handled and that the plutonium specific activity is $0.09 \mathrm{Ci} / \mathrm{g}$, the fraction released would be $7.2 \times 10^{-11}$. This fraction, much smaller than that for NFS, possibly reflects that solids are being handled (instead of solutions as at NFS) and/or that the air cleaning systems are more efficient.

TABLE 4.5. Existing Mixed-Oxide Fabrication Facilities ${ }^{7}$

\begin{tabular}{llcc}
\hline \multicolumn{1}{c}{ Company } & \multicolumn{1}{c}{ Location } & $\begin{array}{c}\text { Pu Possession } \\
\text { Limit (kg) }\end{array}$ & $\begin{array}{c}\text { Estimated } \\
\text { Production } \\
\text { Capacity } \\
\text { (MT/yr) }\end{array}$ \\
\hline Exxon Nuclear & Richland, Wash. & 100 & 15 \\
General Electric & Pleasanton, Calif. & 15 & 3 \\
Kerr-McGee & Crescent, Okla. & 360 & $5-10$ \\
NumEC & Apollo, Pa. & 2000 & 20 \\
$\begin{array}{l}\text { Westinghouse } \\
\text { Nuclear Fuel } \\
\text { Services }\end{array}$ & Cheswick, Pa. & 120 & $10-15$ \\
\hline
\end{tabular}


TABLE 4.6. Experimentally Determined Alpha-Emitters Released from Plutonium Facilities ${ }^{7}$

\begin{tabular}{lcc} 
& \multicolumn{2}{c}{ Alpha-Particulate Discharge } \\
\cline { 2 - 3 } Facility & $\begin{array}{c}\text { Stack Gas } \\
(\mu \mathrm{C} \text { i } / \mathrm{m} 1)\end{array}$ & $\begin{array}{c}\text { Annual } \\
(\mu \mathrm{C} i)\end{array}$ \\
\hline Kerr-McGee & $4 \times 10^{-14}$ & 30 \\
NUMEC & $<0.6 \times 10^{-14}$ & Not available \\
Westinghouse & $<5.4 \times 10^{-14}$ & 11 \\
LASL & $20.5 \times 10^{-14}$ & 13 \\
\hline
\end{tabular}

Additional data about the discharges from the Westinghouse (Cheswick) facility has been furnished in the PSAR for the Westinghouse Recycle Plant at Anderson, South Carolina. ${ }^{8}$ Discharges from three locations were sampled: fume hoods at $4060 \mathrm{cfm}$, wet-dry glove boxes at $3000 \mathrm{cfm}$, and the analytical laboratory at $7300 \mathrm{cfm}$. The normal sampling rate was $1 \mathrm{~m}^{3} / \mathrm{hr}$ and the sampling interval was $24 \mathrm{hr}$. These conditions yield an activity threshold of $5.4 \times 10^{-14} \mu \mathrm{Ci}(\alpha) / \mathrm{ml}$. Most of the time, activity levels were at or below the threshold for the three locations. The highest count rate recorded was for a sample from the analytical laboratory that corresponded to an effluent concentration of $3.2 \times 10^{-13} \mu \mathrm{Ci} / \mathrm{ml}$. The threshold value, $5.4 \times 10^{-14} \mu \mathrm{Ci} / \mathrm{ml}$, is listed in Table 4.6 .

No data was found, during the review, on the particle size distributions of particulate discharges from the commercial facilities. Data on chemica1 characteristics was similarly lacking.

\subsection{Accident Evaluations}

Accidents in plutonium-handling facilities and more general failures in nuclear air-cleaning systems have been summarized and evaluated in two recent review articles. 9,10

An analysis was made of 13 major plutonium-handling accidents that occurred in more than thirty years. 9 Although the 13 accidents do not include all accident-experience data, the incidents were selected as major ones for which documentation is available and which are representative of plutonium hazards in general and of glove box operations in particular. The accidents are summarized in Table 4.7. The predominance of Rocky Flats accidents in this table is due to the availability of this information to the author and to the exceptional hazard of finely divided plutonium metal. Plutonium solutions and plutonium oxide are distinctly less hazardous. 
TABLE 4.7. Major Plutonium Containment Accidents ${ }^{9}$

\begin{tabular}{|c|c|c|c|c|}
\hline Date & $\begin{array}{l}\text { Damage } \\
\text { Category }\end{array}$ & Location & Manner and Amount of $\mathrm{Pu}$ Release & Explanation \\
\hline $11 / 16 / 51$ & $\begin{array}{l}\text { Criticality } \\
\text { Excursion in } \\
\text { Criticality } \\
\text { Test }\end{array}$ & $\begin{array}{l}\text { Richland, } \\
\text { Wash. }\end{array}$ & $\begin{array}{l}\text { Pressure buildup inside a vessel } \\
\text { containing Pu solution caused the } \\
\text { solution to spray into room. No } \\
\text { environmental release. }\end{array}$ & $\begin{array}{l}\text { Too-rapid withdrawal of a safety } \\
\text { rod resulted in criticality and } \\
\text { boiling surge. No ventilation } \\
\text { system damage. }\end{array}$ \\
\hline $12 / 4 / 51$ & Fire & $\begin{array}{l}\text { Hanford, } \\
\text { Wash: } \\
\text { Research } \\
\text { Facility }\end{array}$ & $<4 \mathrm{~g}$; some $\mathrm{Pu}$ outside of facility. & $\begin{array}{l}\text { Spontaneous ignition of combustible } \\
\text { waste in storage [Apparently no } \\
\text { ventilation system provided.] }\end{array}$ \\
\hline $1 / 55$ & Fire & $\begin{array}{l}\text { GE } \\
\text { Install. } \\
\text { at Hanford, } \\
\text { Wash. }\end{array}$ & No $P u$ outside of facility. & $\begin{array}{l}900 \mathrm{~g} \text { of metal Pu residues caught } \\
\text { fire. [Ventilation system role } \\
\text { not clear.] }\end{array}$ \\
\hline $9 / 55$ & Fire & $\begin{array}{l}\text { Rocky } \\
\text { Flats } \\
\text { plant, } \\
\text { Col. }\end{array}$ & $\begin{array}{l}2.3 \mathrm{\mu g} \text { in air exhaust, none } \\
\text { detected in environment. }\end{array}$ & $\begin{array}{l}800 \mathrm{~g} \text { Pu metal-containing } \\
\text { briquette spontaneously ignited } \\
\text { and burned completely in a } \\
\text { glove box. }\end{array}$ \\
\hline $9 / 57$ & Fire & $\begin{array}{l}\text { Rocky } \\
\text { Flats } \\
\text { plant, } \\
\text { Col. }\end{array}$ & $\begin{array}{l}\text { Emerging smoke (after the ventila- } \\
\text { tion system was shut off) contained } \\
\text { negligible } \mathrm{Pu} \leq 4 \times 10^{-9} \mathrm{~g} \mathrm{Pu} / \mathrm{g} \text { of } \\
\text { vegetation found in vicinity, but } \\
\text { this is considered below hazardous } \\
\text { levels. }\end{array}$ & $\begin{array}{l}22 \mathrm{~kg} \text { of } \mathrm{Pu} \text { in metal form } \\
\text { spontaneously ignited in a glove } \\
\text { box. After } 15 \mathrm{~min} \text {, ventilation } \\
\text { was stopped. }\end{array}$ \\
\hline $3 / 31 / 59$ & $\begin{array}{l}\text { Chemical } \\
\text { Explosion }\end{array}$ & $\begin{array}{l}\text { Pu Metal } \\
\text { Machining, } \\
\text { Richland, } \\
\text { Wash. }\end{array}$ & $\begin{array}{l}\text { No significant contamination out- } \\
\text { side the laboratory room; glove } \\
\text { box breached, room contamination } \\
\text { up to } 26,000 \mathrm{~d} / \mathrm{s} /(\mathrm{min})\left(\mathrm{cm}^{2}\right) \text {. }\end{array}$ & $\begin{array}{l}\text { Explosion, apparently from air and } \\
\text { possibly an organic solvent from } \\
\text { sparks from Pu metal machining. }\end{array}$ \\
\hline $4 / 15 / 59$ & Fire & $\begin{array}{l}\text { Los Alamos } \\
\text { Scientific } \\
\text { Laboratory, } \\
\text { New Mexico }\end{array}$ & $\begin{array}{l}\text { Heavy Pu contamination of the room, } \\
\text { some outside on the ground to } \\
20,000 \mathrm{dis} /(\mathrm{mln})\left(\mathrm{cm}^{2}\right) \text {. }\end{array}$ & $\begin{array}{l}\text { Welding repair of metal near an } \\
\text { asbestos filter allowed spark to } \\
\text { ignite Pu dust (possibly metal Pu) } \\
\text { collected on a filter from 5-yr } \\
\text { Pu production Buring of } \\
\text { combustible material on the filter } \\
\text { resulted in destroying the filter } \\
\text { completely. }\end{array}$ \\
\hline $11 / 59$ & Explosion & $\begin{array}{l}\text { Oak Ridge } \\
\text { Nat. Lab., } \\
\text { Tenn. }\end{array}$ & $\begin{array}{l}150 \mathrm{~g} \mathrm{Pu} \text { in aqueous solution was } \\
\text { ejected from the equipment into } \\
\text { the cell. } 0.6 \mathrm{~g} \text { was blown through } \\
\text { the cell door. Outside local } \\
\text { contamination was extensive. Cell } \\
\text { ventilation filters removed } 1.5 \mathrm{~g} \\
\text { and did not allow release via this } \\
\text { path to the plant stack. }\end{array}$ & $\begin{array}{l}\text { A chemical explosion occurred in } \\
\text { an evaporator inside a shielded } \\
\text { cell. }\end{array}$ \\
\hline $5 / 11 / 61$ & $\begin{array}{l}\text { Over- } \\
\text { pressurized } \\
\text { Container }\end{array}$ & $\begin{array}{l}\text { Mramisburg, } \\
\text { Oh10 }\end{array}$ & $\begin{array}{l}\text { Room contaminated by leak through } \\
\text { glove box vent. No environmental } \\
\text { contamination. }\end{array}$ & $\begin{array}{l}\text { A leak in a vacuum connection to } \\
\text { a scrubber for the glove box } \\
\text { operation resulted in the scrubber } \\
\text { venting to the room A } 238_{\mathrm{Pu}} \\
\text { precipitate was being dried in the } \\
\text { glove Dox }\end{array}$ \\
\hline $10 / 27 / 64$ & $\begin{array}{l}\text { Chemical } \\
\text { Explosion }\end{array}$ & $\begin{array}{l}\text { Miamisburg, } \\
\text { Oh1o }\end{array}$ & $\begin{array}{l}\text { Pu escaped from the glove box, and } \\
\text { extensive contamination of the } \\
\text { building resulted from the spread } \\
\text { of } \sim 1 / 2 \mathrm{~g} \text { of } 238 \mathrm{Pu} \text {. }\end{array}$ & $\begin{array}{l}17 \mathrm{~g} \text { of }{ }^{238} \mathrm{Pu} \text { was being processed } \\
\text { in a glove box having a methanol- } \\
\text { air atmosphere. It is belleved } \\
\text { that a hot plate lgnited the } \\
\text { atmosphere and led to an explosion } \\
\text { which pressurized the glove box } \\
\text { and tore six gloves from the glove } \\
\text { ports. }\end{array}$ \\
\hline $1 / 20 / 65$ & $\begin{array}{l}\text { Over- } \\
\text { pressurized } \\
\text { Container }\end{array}$ & $\begin{array}{l}\text { Livermore, } \\
\text { California }\end{array}$ & $\begin{array}{l}\text { Some Pu discharged through the } \\
\text { stack. No contamination was } \\
\text { detected outside the building }\end{array}$ & $\begin{array}{l}\text { Pu-contaminated gas was released } \\
\text { to a ventilated hood and was } \\
\text { discharged to the atmosphere } \\
\text { through a high stack }\end{array}$ \\
\hline $10 / 15 / 65$ & Fire & $\begin{array}{l}\text { Rocky } \\
\text { Flats } \\
\text { plant, } \\
\text { Col. }\end{array}$ & $\begin{array}{l}\text { Activity outside the bullding was } \\
\text { less than } 250 \text { counts } /(\mathrm{min})\left(\mathrm{cm}^{2}\right) \text {, } \\
\text { contamination of the building } \\
\text { extensive relative to } 8-\mathrm{hr} \\
\text { concentration limit. }\end{array}$ & $\begin{array}{l}\text { Oily Pu metal chips and lathe } \\
\text { turnings caught fire from a spark } \\
30 \mathrm{~g} \text { of Pu was widely dispersed in } \\
\text { the bullding, apparently as very } \\
\text { fine aerosol }\end{array}$ \\
\hline $5 / 11 / 69$ & Fire & $\begin{array}{l}\text { Rocky } \\
\text { Flats } \\
\text { plant, } \\
\text { Col. }\end{array}$ & $\begin{array}{l}\text { Some contamination of the roof, } \\
\text { but no clear evidence of external } \\
\text { contamination from the very large } \\
\text { fire, partiy because the Pu back- } \\
\text { ground around the plant was high } \\
\text { as a result of earlier Pu storage. }\end{array}$ & $\begin{array}{l}\text { A fire swept through a production } \\
\text { bullding, causing about } \$ 50 \\
\text { million damage. The filters } \\
\text { apparently caught all the } \\
\text { contaminants released during the } \\
\text { fire. }\end{array}$ \\
\hline
\end{tabular}


The author's conclusion was that in all plutonium incidents to date, the plutonium release from containment was very low--below that which constituted any apparent health risk. Even in the case of an accident (at Oak Ridge) in which $150 \mathrm{~g}$ of an aerosol of plutonium (probably very finely divided) was dispersed explosively into a cell, on 1 y $0.6 \mathrm{~g}$ escaped through an open cell door and there was only minor spread of plutonium contamination outside the cell.

More striking was the example of the fire May 11, 1969, at Rocky Flats. Here, a much larger quantity of plutonium burned inside a production building, and the containment of the building and its exhaust system was such that only a minute amount escaped.

There are several reasons for the exceptionally good containment record of plutonium aerosols. Hunt's view ${ }^{9}$ is that the two most important reasons are the following. First, the process of burning plutonium produces particles which (for most of the mass burned) tend to be so large that they settle out quickly in the vicinity of the original release. Other dispersion mechanisms tend to operate similarly. It should be noted that many particle-sizing studies measure only the characteristics of the airborne fraction of a plutonium release. Such studies cannot be directly used to assess the probable dispersion of plutonium when a given total quantity of plutonium is released. Second, the particles that are small enough to be efficiently airborne tend to become attached to any fixed surfaces (even the smoothest ones) with which they may come in contact; this is particularly so for the smallest size fraction. The attached particles may, of course, be subsequently resuspended, but resuspension probabilities are small, even for large surface disturbances. This contact adhesion of particulate plutonium is the basis of air cleaning and filtration, which, however, are not analyzed in this review. ${ }^{9}$

Another review article is concerned with the performance and problems of air-cleaning systems. 10 Fifty-five selected abnormal events were considered and analyzed for failures of various sorts. A summary of the failures by categories along with their immediate causes is given below in Table 4.8, which is taken from the report. ${ }^{10}$ As shown in Table 4.8, a large proportion of failures (about 65\%) appear to be due to errors by personne1 responsible for the operation and maintenance of air-cleaning equipment. This situation, together with the importance of air cleaning as an engineered safeguard, has led to publication by the AEC and the NRC of regulatory guides (listed in Table 4.9). 
TABLE 4.8. Analysis of Causes of Abnormal Occurrences in Air-Cleaning Systems for Nuclear Facilities 10

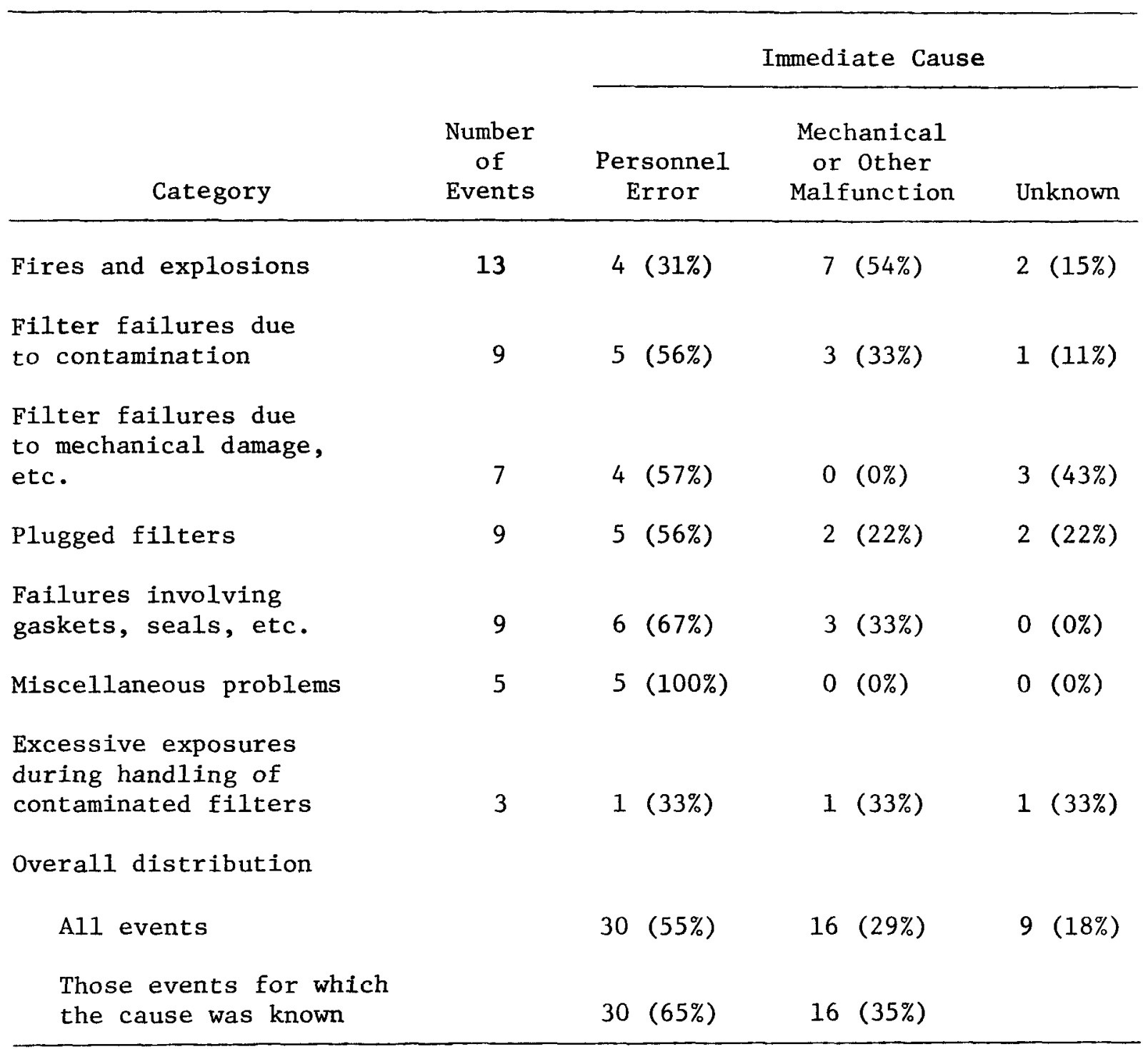


TABLE 4.9. Regulatory Guides Related to Air-Cleaning Systems

Guide No.

Title

1.7 Control of Combustible Gas Concentrations in Containment Following a Loss of Coolant Accident

1.42 Interim Licensing Policy on As-Low-As-Practicable for Gaseous Radioiodine Releases from Light-Water-Cooled Nuclear Power Reactors

1.52 Design, Testing, and Maintenance Criteria for Atmosphere Cleanup System Air Filtration and Adsorption Units of Light-Water-Cooled Nuclear Power Plants

1.70.2 Additional Information--Air Filtration Systems and Containment Sumps for Nuclear Power Plants

1.78 Assumptions Used for Evaluating the Habitability of a Nuclear Power Plant Control Room During a Postulated Hazardous Chemical Release

3.2 Efficiency Testing of Air-Cleaning Systems Containing Devices for Removal of Particles

3.7 Monitoring of Combustible Gases and Vapors in Plutonium Processing and Fuel Fabrication Plants

3.12 General Design Guide for Ventilation Systems of Plutonium Processing and Fuel Fabrication Plants

3.16 General Fire Protection Guide for Plutonium Processing and Fuel Fabrication Plants

3.20 Process Off-Gas Systems for Fuel Reprocessing Plants

3.32 General Design Guide for Ventilation Systems for Fuel Reprocessing Plants

8.8 Information Relevant to Maintaining Occupational Radiation Exposure as Low as Practicable (Nuclear Reactors)

a Calculation of Releases of Radioactive Materials in Liquid and Gaseous Effluents from Pressurized-Water Reactors (PWRs)

a Calculation of Releases of Radioactive Materials in Liquid and Gaseous Effluents from Boiling-Water Reactors (BWRs)

a Division 4 Regulatory Guide under development. 


\section{References for Section 4}

1. H. S. Jordan, Release of Plutonium to the Atmosphere, Plutonium Information Meeting for an Ad Hoc Subcommittee of the Advisory Committee on Reactor Safeguards, January 4 and 5, 1974, CONF-740115, pp. 16-29.

2. R. G. Stafford, J. C. Gallimore, Jr., R. N. Mitche11, W. J. Maraham, and W. D. McNeese, Ventilation Design Modifications at Los Alamos Scientific Laboratory Major P1utonium Operational Areas, Proceedings of the Thirteenth AEC Air Cleaning Conference, San Francisco, Cal., August 12-15, 1974, CONF-740807, pp. 353-371.

3. Safety Analysis Report, NFS Processing Plant, West Valley, New York, Docket Number 50-201, pp. I-2-1 to I-2-9 (1973).

4. J. A. Cochran, D. G. Smith, P. J. Magno, and B. Shleien, An Investigation of Airborne Radioactive Effluent from an Operating Nuclear Fuel

Reprocessing Plant, U. S. Department of Health, Education, and Welfare, Report BRH/NERHL 70-3 (July 1970).

5. Proposed EPA Rules 40 CFR Part 190, Fed. Regist. 40(104), 23420-23425 (May 29, 1975).

6. J. A. Cochran et al., op. cit., p. 4.

7. Generic Environmenta1 Statement Mixed Oxide Fue1, USAEC Report WASH-1327, Vo1. 3, P. IV D-7 (August 1974).

8. Preliminary Safety Analysis Report, Westinghouse Recycle P1ant, DOCKET-70-1432, p. 10 A-1.

9. D. C. Hunt, Restricted Release of Plutonium--Part 1. Observational Data, Nuc1. Saf. 12(2), 85-89 (1971).

10. D. W. Moeller, Problems in Air-Cleaning Systems, Nuc1. Saf. 16 (4), 469-481 (1975). 


\section{REGULATORY STANDARDS}

The basic standards for protection against radiation from activities under licenses issued by the Nuclear Regulatory Commission are included in 10 CFR Part 20 of the Code of Federal Regulations. Paragraph 20.106 states that "(a) a licensee sha1l not possess, use, or transfer licensed material so as to release to an unrestricted area radioactive material in concentrations which exceed the limits specified in Appendix B, Table II of this part. . . For purposes of this section concentrations may be averaged over a period not greater than one year. . . (d). . . Table II of this part shall apply at the boundary of the restricted area. . . . the concentration at the boundary may be determined by applying appropriate factors for dilution, dispersion, or decay between the point of discharge and the boundary." Applicable values from Appendix B, Table II, 10 CFR Part 20, for the plutonium isotopes are:

Concentration $(\mu \mathrm{Ci} / \mathrm{m} 1)$

\begin{tabular}{cccccc} 
& \multicolumn{3}{c}{ Air } & & \multicolumn{2}{c}{ Water } \\
\cline { 2 - 3 } \cline { 5 - 6 } Isotope & Soluble & Insoluble & Soluble & Insoluble \\
\hline Pu-238 & $7 \times 10^{-14}$ & $1 \times 10^{-12}$ & $5 \times 10^{-6}$ & $3 \times 10^{-5}$ \\
-239 & $6 \times 10^{-14}$ & $1 \times 10^{-12}$ & $5 \times 10^{-6}$ & $3 \times 10^{-5}$ \\
-240 & $6 \times 10^{-14}$ & $1 \times 10^{-12}$ & $5 \times 10^{-6}$ & $3 \times 10^{-5}$ \\
-241 & $3 \times 10^{-12}$ & $1 \times 10^{-9}$ & & $2 \times 10^{-4}$ & $1 \times 10^{-3}$ \\
-242 & $6 \times 10^{-14}$ & $1 \times 10^{-12}$ & $5 \times 10^{-6}$ & $3 \times 10^{-5}$ \\
-243 & $6 \times 10^{-8}$ & $8 \times 10^{-8}$ & $3 \times 10^{-4}$ & $3 \times 10^{-4}$ \\
-244 & $6 \times 10^{-14}$ & $1 \times 10^{-12}$ & $4 \times 10^{-6}$ & $1 \times 10^{-5}$ \\
\hline
\end{tabular}

Operating experience of power reators has indicated that actual discharges are less than the limits stated above. Based on that experience, the Commission prepared quantitative guidance for design objectives and limiting conditions for operation of reactors to meet the criterion of "as low as practicable." This guidance, identified as Appendix I of 10 CFR Part 50, was recent1y adopted. In May 1974, the Commission indicated that it was studying the possible extension of the "as low as practicable" concept to the effluents from the ex-reactor fuel cycle, including those from fuel reprocessing facilities and plutonium mixed-oxide fuel fabrication plants. To date, such guidance has not been published in the Federal Register.

On May 29, 1975, the Environmental Protection Agency issued proposed rules for environmental radiation standards which would assure protection of the general public from unnecessary radiation exposures and radioactive materials in the general environment resulting from the normal operations of facilities comprising the uranium fuel cycle. ${ }^{2}$ specifically excluded at this time are facilities based on the recycle of plutonium or thorium. These 
standards indicate the direction that environmental controls are taking, and it is expected that the proposed rules will form the basis of future regulations that would be applicable to ex-reactor cycles involving plutonium, e.g., plutonium recycle in LWRs, LMFBRs, etc.

The standards as proposed apply to the entire ex-reactor cycle; they do not apply to the individual operations of the cycle. The allocation of discharges to each facility falls under the jurisdiction of the Nuclear Regulatory Commission.

The key part of the proposed regulations that bears relevance to this study appears in paragraph 190.10 of $40 \mathrm{CFR}$ :

". . . (b) The total quantity of radioactive materials entering the general environment from the entire uranium fuel cycle, per gigawattyear of electrical energy produced by the fuel cycle, shall contain less than. . . 0.5 millicuries combined of plutonium-239 and other alpha-emitting transuranic radionuclides with half-lives greater than one year."2

In proposing these regulations, the EPA has taken into account the current technology of methods of reducing the plutonium content of discharges to the environment. By diligent application of that technology to the design and operation of facilities, this limit is believed to be reasonably achievable.

The Nuclear Regulatory Commission has issued a series of Regulatory Guides intended to provide guidance to licensees for meeting the requirements of $10 \mathrm{CFR}$. Those identified as pertinent to this study are:

Regulatory Guide No.

3.2

3.10

3.12

3.18

3.20
Title

Efficiency Testing of Air-Cleaning Systems Containing Devices for Removal of Particles

Liquid Waste Treatment System Design Guide for Plutonium Processing and Fuel Fabrication Plants

General Design Guide for Ventilation Systems of P1utonium Processing and Fuel Fabrication Plants

Confinement Barriers and Systems for Fuel Reprocessing Plants

Process Off-gas Systems for Fuel Processing Plants 
Regulatory Guide 3.2 refers to an ANSI standard that is acceptable for the efficiency testing of air-cleaning systems: ANSI N 101.1-1972, "American National Standard--Efficiency Testing of Air-Cleaning Systems Containing Devices for Removal of Particles." The standard provides for a uniform method of in-place testing of air-cleaning devices in such a manner that any penetration of the device by test aerosol (dioctyl phthalate) or any leakage of the test aerosol around the devices is included in the results. Performance criteria are not part of the standard.

Guidance for performance is included in Regulatory Guide 3.12. "HEPA filter systems should be tested after filter installation using a 'cold DOP' test. Acceptance should be based on an efficiency of $99.95 \%$ or better for DOP having a light-scattering mean diameter of approximately 0.7 microns." 
References for Section 5

1. Fed. Regist. 39, 16901 (1974).

2. Fed. Regist. 40, 23424 and 23425 (1975). 


\section{PRINCIPLES OF AEROSOL BEHAVIOR}

\subsection{Introduction}

Aerosols are essentially a special form of matter for which the formation, movement, and collection follow principles different from those of bodies of macro size (larger than $1 \mathrm{~mm}$ ). Until recently, lack of knowledge of these principles made the design of filters and other aerosol control devices a rather mysterious art. Even today, the application of filter theory is limited in practical design, and personnel involved in design evaluation do not make use of the large body of principles that are understood. In this section, a brief outline of aerosol collection principles is given in order to provide a rational basis for discussing empirical filtration data and design capabilities of filters presented in other sections of this report, with respect to both normal filtration and behavior of plutonium aerosols during accidents.

The characteristic sizes of particles that form aerosols of various types are summarized in the chart prepared by Lapple ${ }^{l}$ and reproduced here as Fig. 6.1. Aerosols are constantly produced naturally over land and oceans by wind action and evaporation of seawater spray. The small size limit is provided by the increasing tendency of particles to coagulate as size decreases; also, the smaller sizes serve as condensation nuclei. The large size limit is provided by sedimentation.

\subsection{Surface Adhesion Forces and Coagulation of Aerosols $\mathrm{s}^{2}$}

The limited size range and concentrations of aerosols that are stable is basically determined by (1) coagulation and (2) contact adhesion forces of small particles; these effects are not found in macrobodies. Microbalance measurements of the surface-contact adhesion of individual Pyrex spheres on a Pyrex optical flat at one-atmosphere pressure and a relative humidity of $25 \%$ and $95 \%$ have been summarized in the following formula, which gives the force required for removal of a particle of diameter, d:

$$
\text { Contact adhesion force }(\mathrm{g})=1.7 \times 10^{-5} \mathrm{~d}(\mu \mathrm{m})
$$

For reference, the force $W$ exerted by gravity is approximately:

$$
W(g)=1.7 \times 10^{-12} \mathrm{~d}^{3}\left(\mu \mathrm{m}^{3}\right)
$$

The ratio of adhesion force to weight is $10^{7} \mathrm{~d}^{-2}$. Thus, a sphere of $1-\mu \mathrm{m}$ diameter is held by a force many times greater than its weight; it is evident that small particles are held relatively more strongly than large particles. This surface adhesion effect means that once contact is made, it is not easily broken. Related effects are associated with the agglomeration of particles and the deposition of particles on fixed surfaces (such as ducts and filters).

Particle agglomeration is described by the fundamental equation

$$
\frac{\mathrm{dn}}{\mathrm{dt}}=-\frac{\mathrm{K}}{2} \mathrm{n}^{2} \text {, }
$$




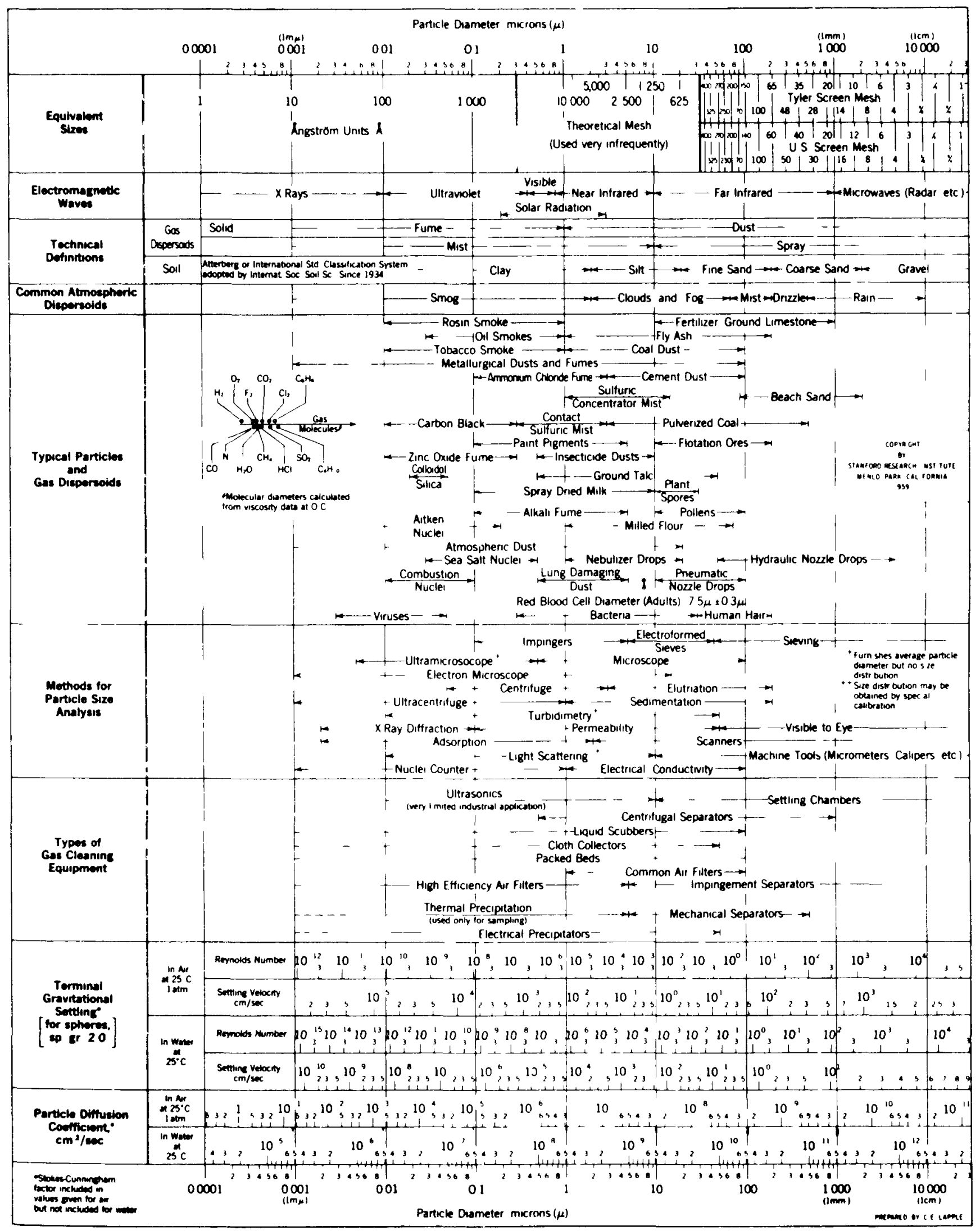

Fig. 6.1. Characteristics of Particles and Particle Dispersoids ${ }^{1}$ 
where $\mathrm{n}$ is the number of particles per unit volume of air $\left(\mathrm{cm}^{3}\right)$, $t$ is the time (sec), and $\mathrm{K}$ is the coagulation rate constant $\left(\mathrm{cm}^{3} / \mathrm{sec}\right)$. The time $t_{h}$ for the number of particles to be reduced by one-half by agglomeration is $t_{h}=\frac{2}{\mathrm{Kn}_{0}}$ where $n_{0}$ is the original number of particles per unit volume $\left(\mathrm{cm}^{3}\right)$.

For an aerosol of uniformly sized particles, $d_{0}(\mu \mathrm{m})$, the relation between the mass concentration $\mathrm{C}\left(\mathrm{mg} / \mathrm{m}^{3}\right)$ and the number of particles per unit volume, $n_{0}\left(\right.$ particles $\left./ \mathrm{cm}^{3}\right)$, is

$$
\mathrm{C}=\frac{\pi}{6} \mathrm{~d}_{0}^{3} \rho \times 10^{-3}
$$

where $\rho$ is the density $\left(\mathrm{g} / \mathrm{cm}^{3}\right)$. Solving for $\mathrm{n}_{0}$ and substituting in the above equation for $t_{h}$, one obtains

$$
t_{h}=\frac{\pi d_{o}^{3} \rho}{3 \mathrm{CK}} \times 10^{-3}
$$

For $\rho=4 \mathrm{~g} / \mathrm{cm}^{3}$

$$
t_{h}(\mathrm{sec})=\frac{\left(4 \times 10^{-3}\right) \mathrm{d}_{0}^{3}}{\mathrm{CK}}
$$

The value of $\mathrm{K}$ is determined for a pair of particles of specified diameters. For a pair of the same size in the range of diameters of 0.001 to $1.0 \mu \mathrm{m}$, the value of $\mathrm{K}$ (corrected for the gas kinetic effect) is about $1 \times 10^{-9} \mathrm{~cm}^{3} / \mathrm{sec}$. Where the particles in a pair are of unequal size, the value of $\mathrm{K}$ is larger; $e . g$. , for $1.0-\mu \mathrm{m}$ and $0.01-\mu \mathrm{m}$ particles, $\mathrm{K}=2 \times 10^{-7}$. Table $6.1 .^{2}$

Values of $\mathrm{K}$ (including the gas kinetic correction) are shown in

TABLE 6.1. The Coagulation Constant $K\left(r_{1}, r_{2}\right)=$ $K_{o} f\left(10^{-10} \mathrm{~cm}^{3} \mathrm{sec}^{-1}\right)^{a}$

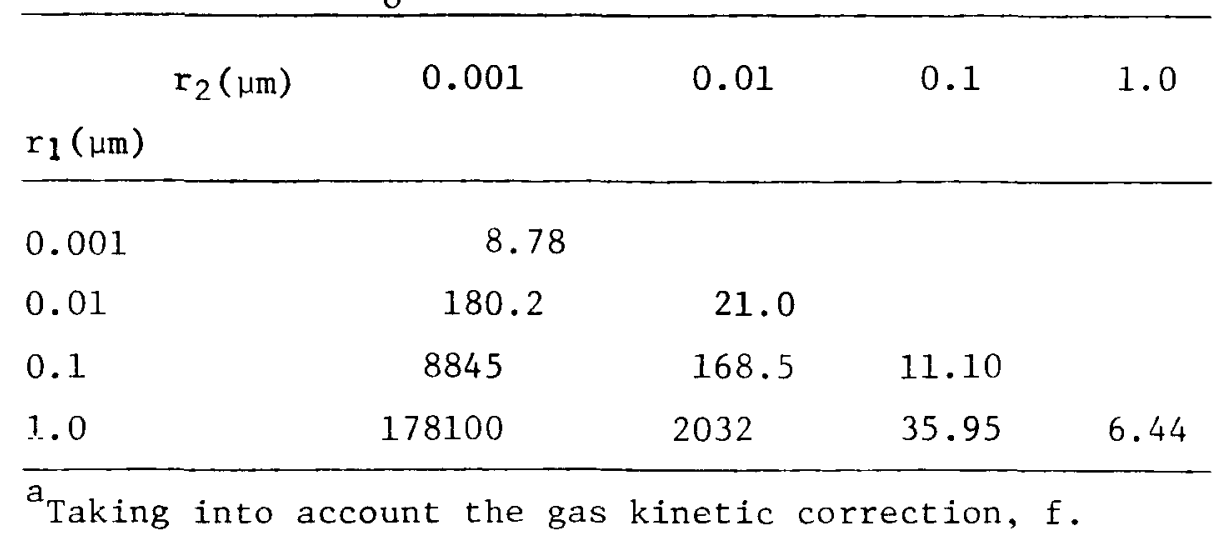


On the above basis, the relative stability of aerosols against coagulation is illustrated by the calculated values (Table 6.2) of $t_{\text {h }}$, the time (sec) for the number of particles to be reduced by one-half. The value of $C=10 \mathrm{mg} / \mathrm{m}^{3}$ corresponds to that of a stable fog. Other values of $C$ are given to show the effect of mass concentration on the half-time. As shown in the table, particles as small as $0.001 \mu \mathrm{m}$ are very unstable even in dilute concentrations. Particles of about $0.1 \mu \mathrm{m}$ are stable at low concentrations but agglomerate rapidly at high concentrations. For an aerosol of particles of a wide range of diameters, the small particles are "eaten up" rather rapidly by the large particles, due to the large value of $k$. This is illustrated by the last four entries of Table 6.2, which shows the rapidity with which small particles agglomerate with large particles having a diameter of $1 \mu \mathrm{m}$.

TABLE 6.2. Calculated Half-Times for Coagulation

\begin{tabular}{|c|c|c|c|}
\hline $\begin{array}{c}\text { Mass } \\
\text { Concentration, } \\
\mathrm{C}\left(\mathrm{mg} / \mathrm{m}^{3}\right)\end{array}$ & $\begin{array}{c}\text { Original } \\
\text { Diameter, } \\
\mathrm{d}_{\mathrm{o}}(\mu \mathrm{m})\end{array}$ & $\begin{array}{l}\text { Coagulation } \\
\text { Constant, } \\
\mathrm{K}\left(\mathrm{cm}^{3} / \mathrm{sec}\right)\end{array}$ & $\begin{array}{c}\text { Half-Time, } \\
t_{h} \text { (sec) }\end{array}$ \\
\hline 1 & 0.001 & $1 \times 10^{-9}$ & $4 \times 10^{-3}$ \\
\hline 10 & 0.001 & $1 \times 10^{-9}$ & $4 \times 10^{-4}$ \\
\hline 100 & 0.001 & $1 \times 10^{-9}$ & $4 \times 10^{-5}$ \\
\hline 1 & 0.1 & $1 \times 10^{-9}$ & $4 \times 10^{3}$ \\
\hline 10 & 0.1 & $1 \times 10^{-9}$ & 400 \\
\hline 100 & 0.1 & $1 \times 10^{-9}$ & 40 \\
\hline $10^{a}$ & $1 / 1^{b}$ & $6.4 \times 10^{-10}$ & $6.2 \times 10^{5}$ \\
\hline $10^{a}$ & $0.1 / 1_{\mathrm{b}}^{\mathrm{b}}$ & $3.6 \times 10^{-9}$ & $1.1 \times 10^{2}$ \\
\hline $10^{a}$ & $0.01 / 1_{b}^{b}$ & $2.0 \times 10^{-7}$ & $2.0 \times 10^{-3}$ \\
\hline $10^{a}$ & $0.001 / 1^{b}$ & $1.8 \times 10^{-5}$ & $2.2 \times 10^{-8}$ \\
\hline
\end{tabular}

The above adhesion and agglomeration effects of aerosols are crucial to the estimation of aerosol behavior, as incorporated, for example, in the accident analysis of ORNL (see Section 8).

\subsection{Basic Mechanisms for Collection of Airborne Particles}

Moving particles make contact with fixed surfaces (e.g., filter fibers) by three major mechanisms:

(1) flow interception

(2) inertial impaction

(3) thermal diffusion 
Although these three mechanisms are universal, they are discussed here coucretely in relation to the surface configuration commonly found in filters, namely, a cylindrical fiber of small diameter fixed transversely in the path of an airborne particle. To illustrate the basic behavior of particles, only a single fiber is considered, as in Fig. 6.2. The three removal processes are discussed below.

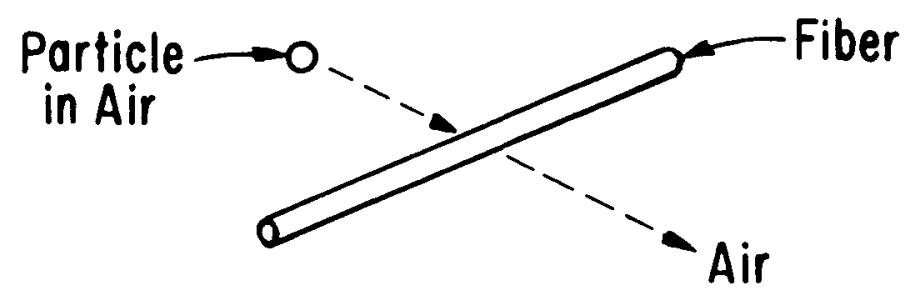

Fig. 6.2. Single-Fiber Model of Filtration

Flow interception can be best understood for the ideal case of a fiber of infinitely small diameter, fixed in the path of flowing air containing airborne particles. (Such fibers are approximated by the smaller fibers in fiber filters.) In Fig. 6.3, this case is illustrated for two positions of the particle. In position A, the particle is approaching the fiber; in position $\mathrm{B}$, the particle contacts the fiber. The cross section of the fiber is represented as a dot (point).

\section{A. PARTICLE APPROACHING FILTER}

\section{B. PARTICLE CONTACTS FILTER}
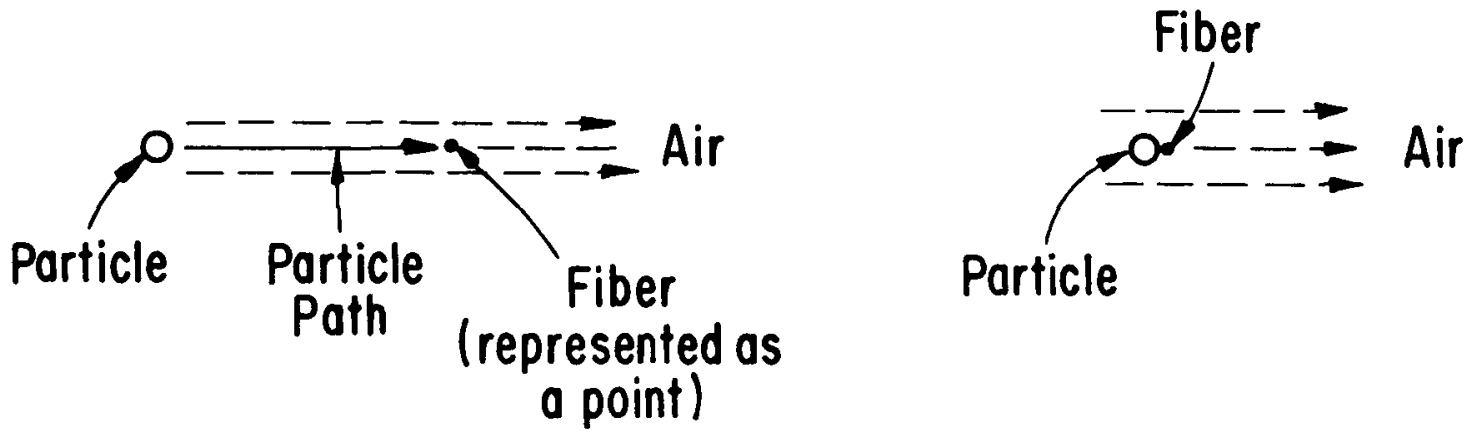

Fig. 6.3. Particle Removal by Flow Interception

Since the fiber is of infinitely small cross section, it does not deflect the air path. If the fiber is in the flow path of the particle, the particle strikes the fiber and adheres to it, while the air passes on. 
The reason for assuming the ideal case of a fiber with an infinitely small cross section is that the larger the diameter of the fiber, the more the fiber disturbs the air flow. A disturbance in air flow is likely to carry the particle around the fiber, preventing the particle from striking it. The effectiveness of this mechanism of removal is thus dependent on fiber cross section and on the number of fibers in the path of the particle. Also, larger size particles favor removal. This is an effective removal mechanism by small fibers and for particles with diameters of 0.1 to $5 \mu \mathrm{m}$.

Inertial impaction effects removal by the particle striking a fixed fiber in its path (Fig. 6.4). Unlike the mechanism discussed above, this mechanism depends on the inertia of the particle (i.e., its mass) to keep the particle in its original path even when the air is deflected around the fibers, which now may be of any size. The mechanism of inertial impaction is relatively more important for the more massive (larger) particles having diameters greater than $5 \mu \mathrm{m}$.

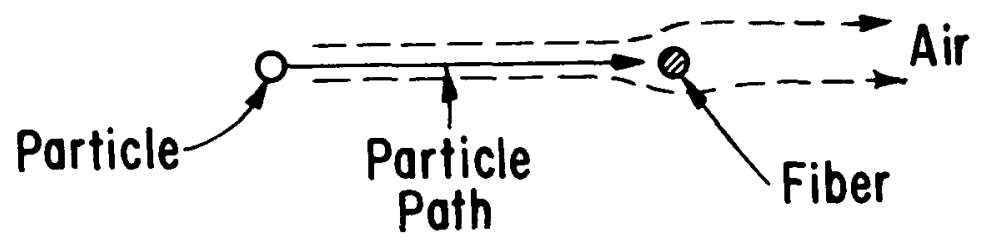

Fig. 6.4. Particle Removal by Inertial Impaction

Thermal diffusion is the random motion of a small particle that is independent of the motion of its supporting medium (air). It is the same as Brownian motion, the zig-zag path of a particle under the bombardment of air molecules, which themselves are in agitated motion as a manifestation of their kinetic-molecular motion in the gaseous state. The higher the temperature, the greater the speed and energy of the thermal vibrations of the air molecules and the higher the speed of the random translational motions imparted to the particle. A small particle in thermal diffusion motion has a much higher probability of striking a nearby surface than if it is simply carried along a single line of flow of the air medium. Figure 6.5 illustrates this particle removal mechanism. Thermal diffusion is relatively more prevalent for particles less than $0.5 \mu \mathrm{m}$ in diameter and is the only filtration mechanism that increases in effectiveness as particle size decreases. The contact effectiveness is measured by the mean square displacement of a particle (in the $x$ direction):

$$
\overline{x^{2}}=2 D t,
$$

where $t$ is the time and $D$ is the particle diffusivity. Also,

$$
\mathrm{D}=\frac{\mathrm{CkT}}{3 \pi \mu \mathrm{d}}
$$


where $T$ is the absolute temperature, $\mu$ is air viscosity, $d$ is particle diameter, $k$ is Boltzmann's constant, and $C$ and $\pi$ are numerical constants. ${ }^{3}$ Thus, for a given time and other conditions, the effective cross-sectional area of a particle moving through a filter is inversely proportional to the particle diameter and the velocity.

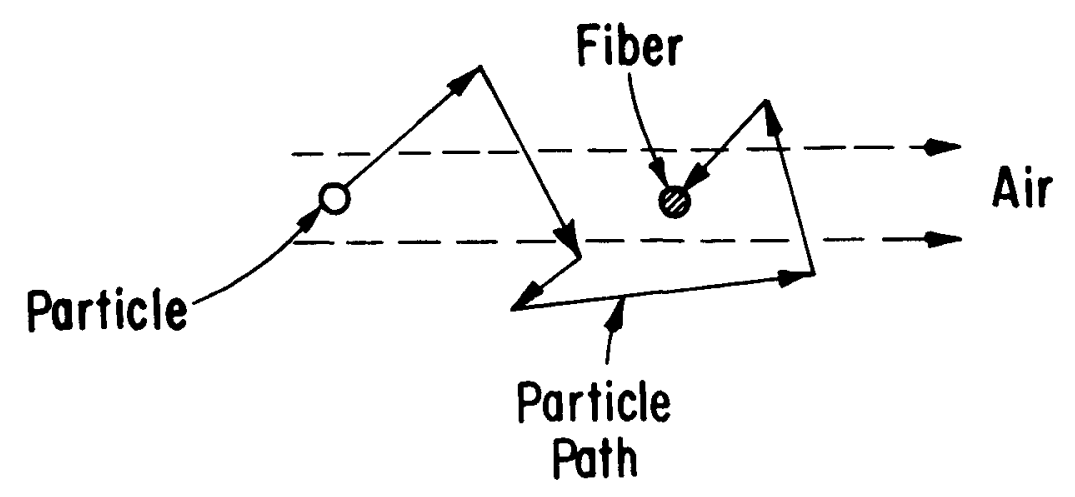

Fig. 6.5. Particle Removal By Thermal Diffusion

The relative effectiveness of the three filtration mechanisms is rather well defined with respect to particle diameter, as shown in Table 6.3. The effects of fiber diameter and air velocity are given as related to the ideal single-fiber cases discussed above. However, actual effects of fiber diameter, air velocity, fiber density, filter depth, and pressure drop are too complicated aerodynamically to be simply characterized quantitatively with respect to removal effectiveness for a wide range of particle sizes. Practical penetration probabilities have been measured down to the limit of detection for particles in the $1-\mu \mathrm{m}$ size range.

As the particle size decreases below about $0.5 \mu \mathrm{m}$, the thermal diffusion mechanism predominates and the particle density is rapidly reduced by both filtration and agglomeration. Since this mechanism of particle removal depends on residence time, a reduction in residence time by increasing the air velocity reduces the removal efficiency for a given filter installation. Air velocity per se is not important in diffusion.

Another representation of the way in which particle size and air velocity affect filter penetration via the three filtration mechanisms is shown in Fig. 6.6.4 Although the figure is oversimplified (especially as regards the inertial effect), it does illustrate the major variables of filter design.

The theory described above clearly indicates a maximum penetration as a function of particle size. It was early established, experimentally and theoretically, that particles of larger size penetrate less easily than those of smaller size, down to $0.3 \mu \mathrm{m}$, but there has been much argument as to whether particles smaller than this penetrate less easily because of increases in Brownian motion. The main reason for the lack of agreement has been the difficulty of the experimental work. ${ }^{4}$ A carefully designed series of 
experiments with sodium chloride aerosol shows the theoretically predicted decrease in penetration as the mean size of particles is reduced from 0.2 to $0.02 \mu \mathrm{m}$; the results are shown in Fig. 6.7. The decrease in penetration with sizes above about $0.5 \mu \mathrm{m}$ is well known. Tests showing critical size for HEPA filters are discussed in Section 7.

TABLE 6.3. Relative Effectiveness of Filtration Mechanisms

\begin{tabular}{|c|c|c|c|}
\hline \multirow[b]{2}{*}{ Variable } & \multicolumn{3}{|c|}{ Process } \\
\hline & $\begin{array}{c}\text { Flow } \\
\text { Interception }\end{array}$ & $\begin{array}{l}\text { Inertial } \\
\text { Impaction }\end{array}$ & $\begin{array}{c}\text { Therma1 } \\
\text { Diffusion }\end{array}$ \\
\hline Particle Size & $\begin{array}{l}\text { Effective Removal } \\
\text { for } 0.1 \mu \mathrm{m} \text { to } 5 \mu \mathrm{m} \\
\text { Diameter Particles }\end{array}$ & $\begin{array}{l}\text { Effective for } \\
\text { Particles } \\
\text { Larger than } \\
5 \mu \mathrm{m}\end{array}$ & $\begin{array}{l}\text { Increasing } \\
\text { Effectiveness as } \\
\text { Particle Size } \\
\text { Decreases Below } \\
0.5 \mu \mathrm{m}\end{array}$ \\
\hline Fiber Diameter & $\begin{array}{l}\text { Effective for } \\
\text { Small Fibers }\end{array}$ & $\begin{array}{l}\text { Effectiveness } \\
\text { Not Dependent } \\
\text { on Fiber Size }\end{array}$ & $\begin{array}{l}\text { Effectiveness } \\
\text { Not Dependent on } \\
\text { Fiber Size }\end{array}$ \\
\hline Air Velocity & $\begin{array}{l}\text { Effectiveness } \\
\text { Not Dependent } \\
\text { on Velocity }\end{array}$ & $\begin{array}{l}\text { Effectiveness } \\
\text { Increases with } \\
\text { Increasing } \\
\text { Velocity }\end{array}$ & $\begin{array}{l}\text { Effectiveness } \\
\text { Decreases with } \\
\text { Increasing Air } \\
\text { Velocity }\end{array}$ \\
\hline
\end{tabular}

These results are indicative of the soundness of modern filtration theory. In many practical areas, however, commercial aerosols and filters have not been studied systematically enough or measured carefully enough to distinguish whether problems are due to design principles or to poor operating procedures.

Particles are not trapped in a fiber filter because they are too small to pass through the "mesh" formed by the interstices, but rather are trapped if they touch the surface of the fixed fibers (to which they tend to adhere strongly). Thus, penetration of a filter is proportional to the probability of a particle not contacting a fiber. If $P_{1}$, the probability of a particle penetrating a HEPA filter unit, should have the value $10^{-4}$, then the probability of its penetrating four filter units in series is $P_{1}^{4}=10^{-16}$. Such a large separation factor is very difficult to confirm experimentally under conditions where the amount of penetration is large enough to be measurable. Such tests also have to consider general aerosol stability associated with possible chemical, electrostatic, and agglomeration effects, as well as filter imperfections. 


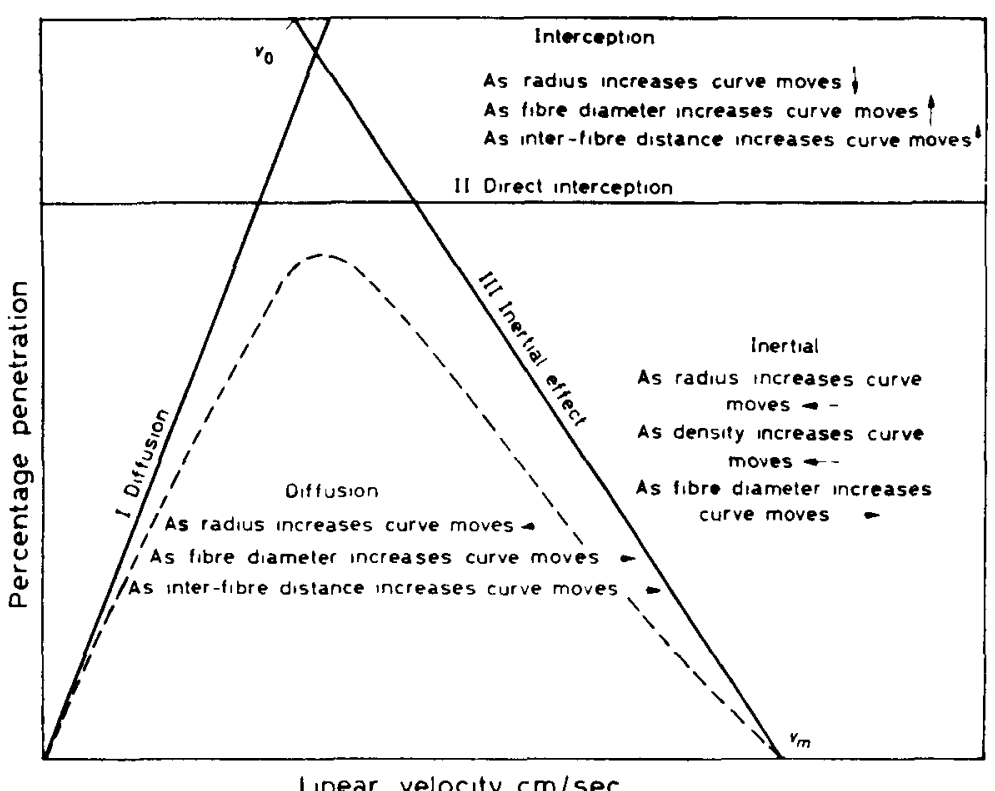

Fig. 6.6. The Effects of Inertia, Diffusion, and Interception on the PenetrationVelocity Curve ${ }^{4}$

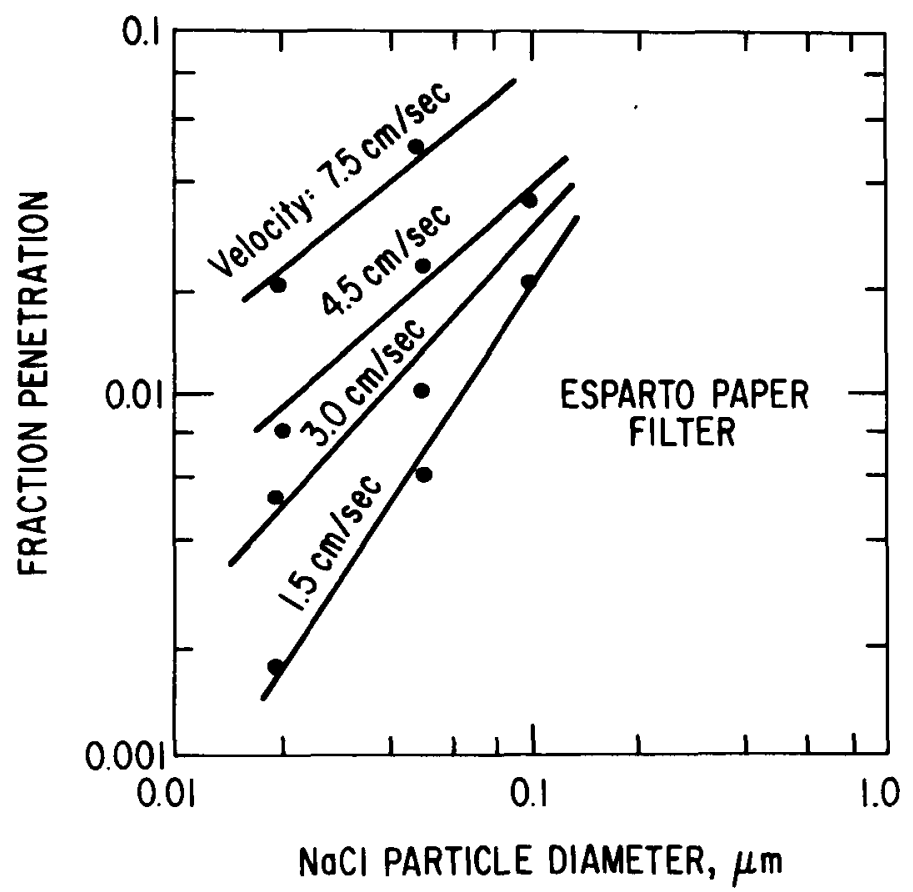

Fig. 6.7. Series of Experiments Showing Decrease of Penetration of Fiber Filter at Submicron Diameters ${ }^{4}$ 


\subsection{Measurement of Aeroso1 Emissions}

The methods used to detect and measure properties of aerosols are important to the understanding and interpretation of reported data and to establishing adequate emission controls. The types of measurements include the mass of material, the chemical constitution, the radioactivity, and the particle sizes. Because of the special nature of small particles, such methods have been considered too costly and too difficult for extensive use. However, recent advances in aerosol technology have demonstrated the practicality of methods of general and dependable use. In this section, some of the more effective measurement methods for monitoring general emissions on a test basis are reviewed. The particular features designed for routine plant control are not addressed here. The methods described could be adapted for routine use, but routine controls are optimally more specialized than the general methods discussed here.

The cascade impactor is a device that receives an air sample stream and collects particles in separate size ranges. The device consists of a train of jets; in each jet a separate size fraction of aerosol is deposited. The collected fractions can be weighed, measured for radioactivity, or otherwise analyzed. The collection efficiency of the cascade impactor is well established for a wide range of air rates, sample sizes, and particle sizes. In practice, the lower limit of particle size is about $0.5 \mu \mathrm{m}$. Its versatility makes it genera11y adequate for detecting and measuring particles of sizes greater than $0.5 \mu \mathrm{m}$. The other devices discussed below are required only to measure the smaller particles.

The Millipore filter is a chemically pure membrane filter, of very uniformly porous cellulose material. It collects very small particles, such as those smaller than $0.5 \mu \mathrm{m}$, which normally pass through the cascade impactor train. The filter can be examined microscopically to count and measure the particles. Also, the entire filter may be measured for radiation or may be chemically dissolved for analysis of contained particles. Multiple filters in series can establish the completeness of collection.

A thermal precipitator is also effective for collection of small particles (smaller than $1 \mu \mathrm{m}$ ) from a sample stream. A hot wire, usually electrically heated nichrome, establishes a thermal gradient, causing particles to be deposited on collector plates on two sides of the wire. These plates may be examined with an electron microscope, or the deposited particles may be washed off and analyzed. A thermal precipitator is cheaper and easier to control than an electrostatic precipitator for sampling.

Electrostatic precipitators are used in certain large-scale applications for particle collection, but are not considered convenient for analytical purposes.

Either a microscope or an electron microscope can be used to obtain greatly enlarged "pictures" of particles deposited on a surface. The use of a light microscope is limited to particles larger than about $0.2-\mu m$ diameter. An electron microscope can be used for particles as small as about $0.002 \mu \mathrm{m}$. 
A recent development is the scanning electron microscope, which has the advantage of using reflected electrons (instead of transmitted electrons). This type of electron microscope appears to be promising for small-particle detection and measurement.

A very effective device for measuring the absolute particle number concentration for particles of unlimited smaller sizes is the condensationnuclei detector. It is a "cloud chamber" that provides a vapor. The vapor condenses on individual particles, which serve as condensation nuclei. The particles rapidly grow to a size large enough to scatter light, and this scattering effect is measured photoelectrically. This device does not measure particle size, but it does measure the total number of particles, however small, in a sample volume of air.

The devices mentioned above can be used separately or together to characterize the particles present in aerosol emissions. Of these devices, only the cascade impactor separates the sample stream into size fractions. The others, which can be used for smaller sizes, do not separate the fractions, but give a "field" of undifferentiated particle size which must be counted and sized visually. In principle, fractional collection can be extended to particles below $0.5 \mu \mathrm{m}$ ( $e . g .$, by thermal diffusion) since the thermal force is proportional to both the thermal gradient and the particle diameter. 5

However, methods based on this principle have not been reduced to practice. 


\section{References for Section 6}

1. R. A. Juvinall, R. W. Kessie, and M. J. Steindler, Sand-Bed Filtration of Aerosols: A Review of Published Information on Their Use in Industrial and Atomic Energy Facilities, Argonne National Laboratory Report ANL-7683 (June 1970).

2. G. Zebel, Coagulation of Aerosols, Aerosol Science, Chapter II, pp. 31-58, Academic Press, London (1966).

3. R. W. Kessie and D. Ramaswami, Removal of Plutonium Hexafluoride from Cel1 Exhaust Air by Hydrolysis and Filtration, Argonne National Laboratory Report ANL-7066 (December 1965). Based on Albert Einstein (1908), Investigations of The Theory of the Brownian Movement, Dover Pub1. (1956).

4. R. G. Dorman, Theory of Fibrous Filtration, Chapter 4, High Efficiency Air Filtration, P. A. F. White and S. E. Smith, Eds., Butterworth, London, p. 67ff (1964).

5. H. L. Green and W. R. Lane, Particulate Clouds: Dusts, Smokes, and Mists, 2nd ed., E. \& F. N. Spon,, Ltd., esp. pp. 203 and 256 (1964). 


\section{REVIEW OF MAJOR EXPERIMENTAL STUDIES RELATING TO PARTICLE SIZE DISTRIBUTIONS AND EFFICIENCIES OF FIBER FILTERS}

\subsection{Analysis of Particle Size Distributions at Several AEC Facilities}

An experimental program to measure the particle size distributions of plutonium aerosols generated at five AEC facilities was carried out by experimenters at Los Alamos. ${ }^{1,2}$ The data are reported here because the study is the only one for which systematic measurements and analyses have been reported. No similar information is available for operations representative of the commercial fuel cycle.

The five facilities included in the study were two each at the Rocky Flats plant and Mound Laboratory and one at LASL. Table 7.1 1ists them by location according to the authors' coding, together with the predominant operations ( $R \& D$, fabrication, or recovery), isotopes of plutonium handled, prefilter efficiency, and relative quantities handled. The operations performed at fabrication facilities include mechanical operations such as grinding, welding, machining, and foundry; operations at the recovery plant consist of chemical conversion processes such as acid dissolution, precipitation, drying, and calcination of oxides. $R \& D$ operations include both mechanical and chemical processes that are characteristic of production operations but they are carried out on a much smaller scale and not continuously.

TABLE 7.1. Facilities and Operating Conditions at Sampling Locations for Determining Particle Size Distributions ${ }^{1}, 2$

\begin{tabular}{ccccc}
\hline Location & $\begin{array}{c}\text { Type of } \\
\text { Operation }\end{array}$ & $\begin{array}{c}\text { Pu Isotopes } \\
\text { Handled }\end{array}$ & $\begin{array}{c}\text { Prefilter } \\
\text { Efficiency }\end{array}$ & $\begin{array}{c}\text { Relative } \\
\text { Quantity } \\
\text { Handled }\end{array}$ \\
\hline 00 & R \& D & 238 and 239 & Unknown & SmalI \\
04 & R \& D & 238 & High & Moderate \\
08 & Fabrication & 238 & High & Moderate \\
11 & Recovery & 239 & Unknown & Large \\
14 & Fabrication & 239 & Unknown & Large \\
\hline authors' coding for two facilities at Rocky Flats, two at \\
Mound Laboratory and one at LASL.
\end{tabular}

The sampling stations were upstream from the exhaust HEPA filters, where aerosol concentrations were adequately high to obtain the required measurements. Where prefilters existed, the sampling points were downstream from them. Samples were obtained during the most active periods of the working day, when activity concentrations in the exhaust systems were likely to reach high values. 
Particle size characteristics were determined by radiometric analyses of (1) the material deposited on each of the stages (a total of eight stages) of Andersen impactors and (2) material deposited on a backup membrane filter that collected particles that passed through the impactor. A total of 218 sets of samples (nine samples per set) were obtained and analyzed at the five facilities. The raw data consisted of activity measurements of material that had deposited at each stage of the Andersen impactor, which in turn characterized the material at each stage as being within a certain particle size range. Since the stage at which a particle is deposited is a complex function of actual particle size, shape, and density, the unit of size measurement is the activity median aerodynamic diameter (amad).

The analysis of the data was complicated by the facts that (1) distributions were often different from sample to sample (usually attributable to changing plant operations) and (2) results did not always match the log normal probability distributions often characteristic of aerosols. An effort was made to characterize the distribution of each assuming log normal distribution. A mean diameter and geometric standard deviation for each sample was then obtained.* -'

*A $\log$ normal distribution, by definition, is a normal distribution of the logarithms of the measured values. The mean $\left(d_{k}=\mu\right)$ and standard deviation $\left(\sigma_{g}\right)$ are computed by conventional methods using $g_{\text {the }}$ logarithms of the values. Thüs:

$$
\begin{aligned}
& \log \mathrm{d}_{\mathrm{g}}=\left(\sum_{i=1}^{\mathrm{n}} \log \mathrm{d}_{i}\right) / \mathrm{n} \\
& =\frac{\log \left(d_{1} \times d_{2} \times \ldots d_{n}\right)}{n} \text {, or } \\
& d_{g}=\sqrt[n]{d_{1} \times d_{2} \times \ldots d_{n}} \quad \text {, and } \\
& \log \sigma_{g}=\sqrt{\frac{\sum_{i=1}^{\mathrm{n}}\left(\log \mathrm{d}_{i}-\log \mathrm{d}_{\mathrm{g}}\right)^{2}}{\mathrm{n}-1}}
\end{aligned}
$$

The upper and lower confidence intervals $\left(\mathrm{d}_{\mathrm{u}}\right.$ and $\mathrm{d}_{\mathrm{L}}$, respectively) of the logarithmic distribution for $2 \sigma_{\mathrm{g}}(95 \%)$ are:

$$
\begin{aligned}
\log d_{\mathrm{u}} & =\log \mathrm{d}_{\mathrm{g}}+2 \log \sigma_{g} & & \text {, and } \\
\log \mathrm{d}_{\mathrm{L}} & =\log \mathrm{d}_{\mathrm{g}}-2 \log \sigma_{\mathrm{g}} & & \text {, or } \\
\mathrm{d}_{\mathrm{u}} & =\mathrm{d}_{\mathrm{g}} \times \sigma_{\mathrm{g}}{ }^{2} & & \text {, and } \\
\mathrm{d}_{\mathrm{L}} & =\mathrm{d}_{\mathrm{g}} \div \sigma_{\mathrm{g}}{ }^{2} & &
\end{aligned}
$$

The value $d_{g}$ is termed the geometric mean, and $\sigma_{g}$ is the geometric standard
deviation. 
The simplest presentation of the results, although with considerable smoothing, is shown in Table 7.2. Overall averages of means and geometric standard deviations for each facility are presented. Note that this presentation cannot and does not reflect changes in day-to-day operations within each facility. The distributions of all sample sets for each facility from which the information in Table 7.2 was derived are shown in Figs. 7.1 through 7.5. The data are useful in determining the gross characteristics for each plant.

TABLE 7.2. Mean Plutonium Size Characteristics of Aerosols at Five AEC Facilities Upstream from Air-Cleaning Facilities ${ }^{2}$

\begin{tabular}{cccc}
\hline Location & $\begin{array}{c}\text { Particle } \\
\text { Diameter, } \\
\text { amad }(\mu \mathrm{m})\end{array}$ & $\begin{array}{c}\text { Geometric } \\
\text { Standard } \\
\text { Deviation, } \\
\sigma_{\mathrm{g}}\end{array}$ & $\begin{array}{c}\text { Range of } \\
\text { Particle } \\
\text { Sizes }\end{array}$ \\
\hline 00 & 1.8 & 2.2 & $0.4-8.7$ \\
04 & 2.3 & 3.5 & $0.2-28$ \\
08 & 4.0 & 1.7 & $1.4-12$ \\
11 & 0.34 & 5.4 & $0.01-9.9$ \\
14 & 2.7 & 2.4 & $0.5-16$ \\
\hline a & $\begin{array}{l}\text { Based on } 2 \text { o for log-normal distribution. } \\
\text { Lower and upper limits are obtained by dividing } \\
\text { and multiplying (respectively) the mean by } \sigma_{\mathrm{g}}^{2}\end{array}$
\end{tabular}

The two fabrication facilities (locations 08 and 14) exhibit the largest means of the group, 4.0 and $2.7 \mu \mathrm{m}$. The geometric standard deviations $\left(\sigma_{\mathrm{g}}\right)$ are among the narrowest of the group, indicating that the range of particle sizes is small. If one assumes that $10 \mathrm{~g}$-normal probability distributions are valid, the range of sizes ( $2 \sigma_{\mathrm{g}}$ limits) for location 08 is 1.4 to $12 \mu \mathrm{m}$, and for location $14,0.5$ to $16 \mu \mathrm{m}$. These ranges are not gross $1 \mathrm{y}$ different.

The recovery facility (location 11 ) in which chemical operations predominate has the smallest mean, $0.3 \mu \mathrm{m}$, and the largest geometric standard deviation, 5.4. Evidently, the aerosols produced in chemical operations are very much smaller than those produced by mechanical operations and also have a much broader distribution of sizes. Using $2 \sigma_{\mathrm{g}}$ limits, the range of particle sizes is 0.01 to about $10 \mu \mathrm{m}$.

The measurements made at the two $R$ \& D facilities (locations 00 and 04) are intermediate, having means of 1.8 and $2.3 \mu \mathrm{m}$. The geometric standard deviations are also intermediate, although the two values are quite different from each other, 2.2 and 3.5. The large $\sigma_{\mathrm{g}}$ for location 04 suggests that the variety of operations conducted at that location during the period of the study may have been wider than at location 00 . 


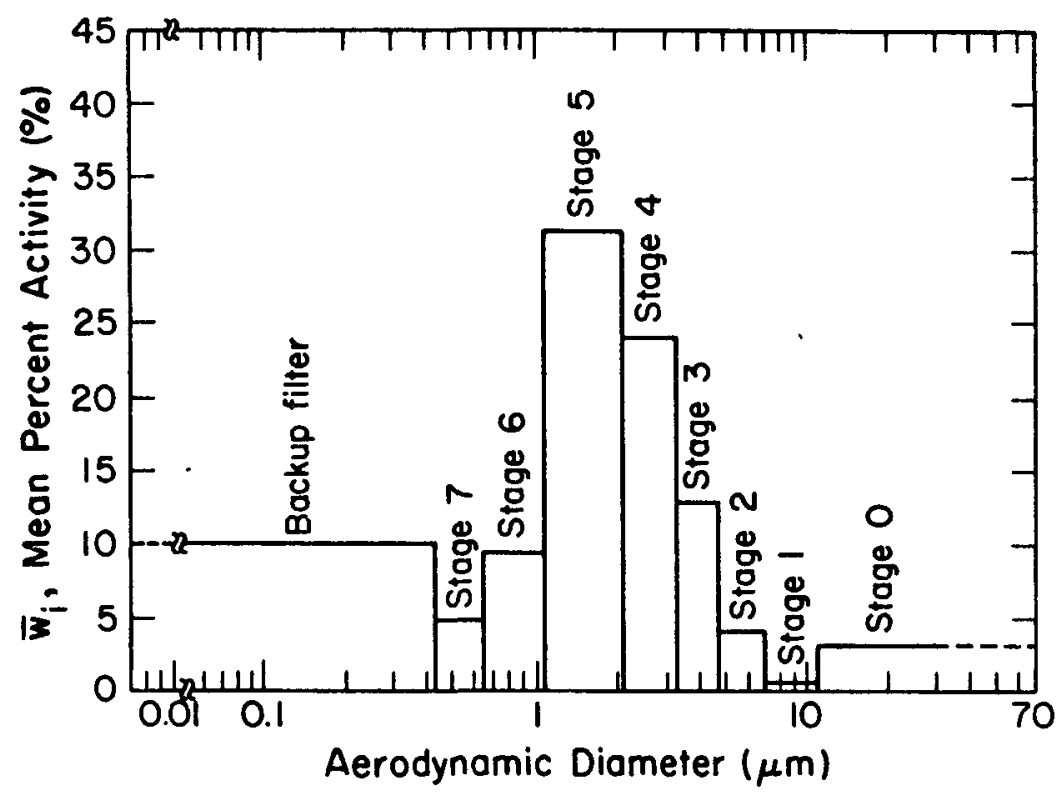

Fig. 7.1. Size Characteristics of Aerosol Containing ${ }^{238} \mathrm{Pu}$ and ${ }^{239} \mathrm{Pu}$, by Radiometric Analysis of All Impactor Samples at Location 00, a Research and Development Facility. ${ }^{2}$

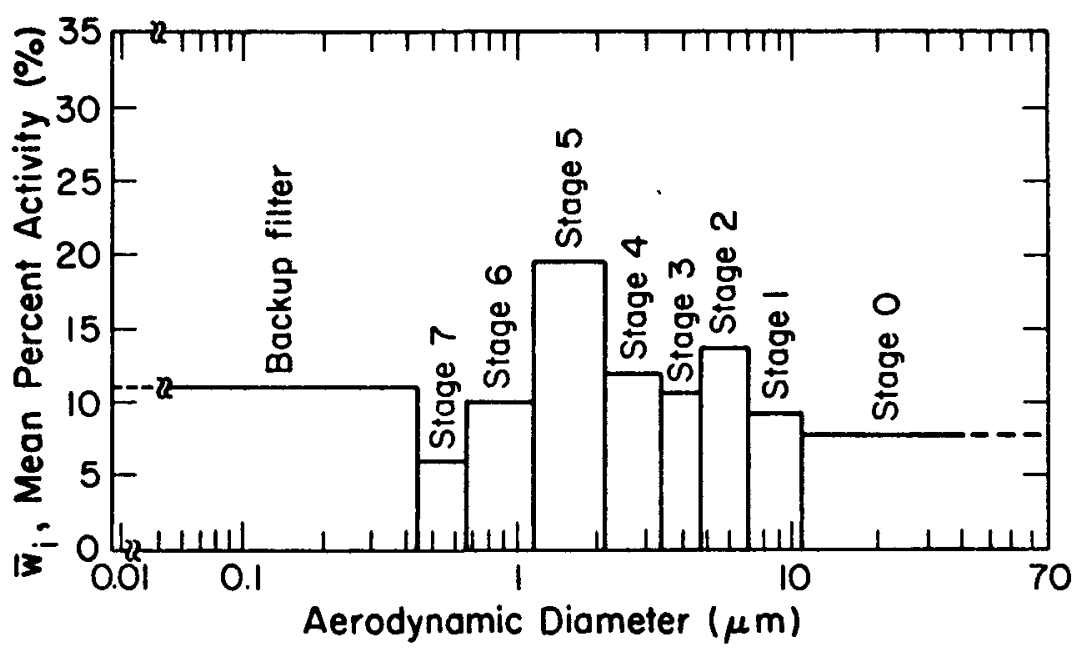

Fig. 7.2. Size Characteristics of Aerosol Containing ${ }^{238} \mathrm{Pu}$, by Radiometric Analysis of All Impactor Samples at Location 04, a Research and Development Facility. ${ }^{2}$ 


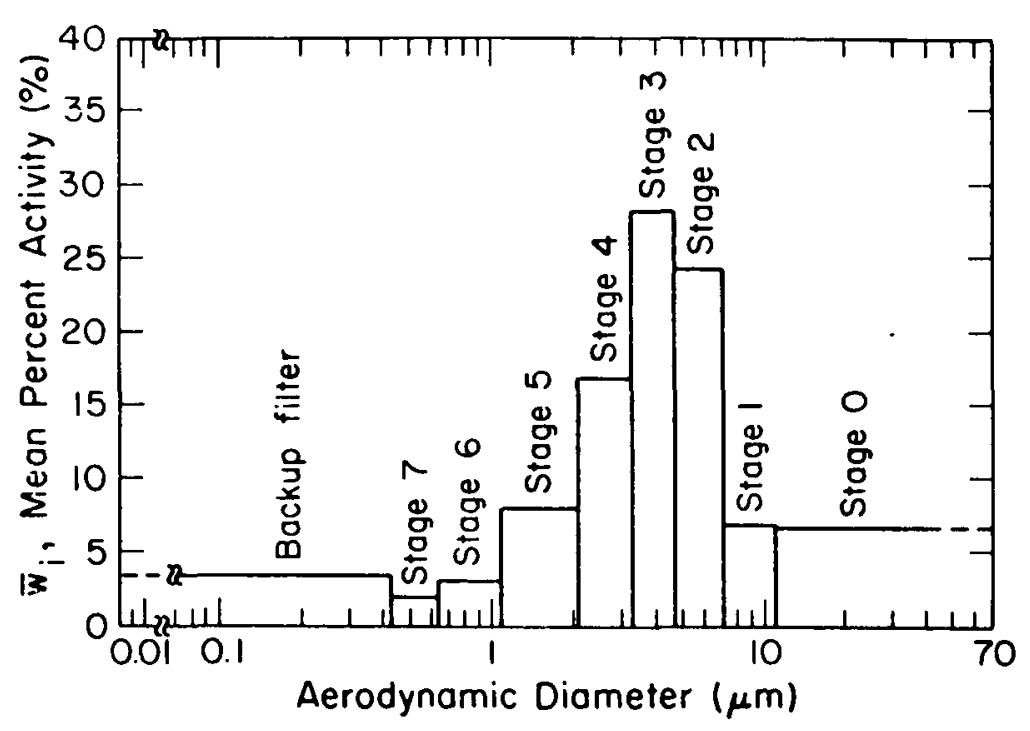

Fig. 7.3. Size Characteristics of Aerosol Containing $238 \mathrm{Pu}$, by Radiometric Analysis of All Impactor Samples at Location 08, a Fabrication Facility. ${ }^{2}$

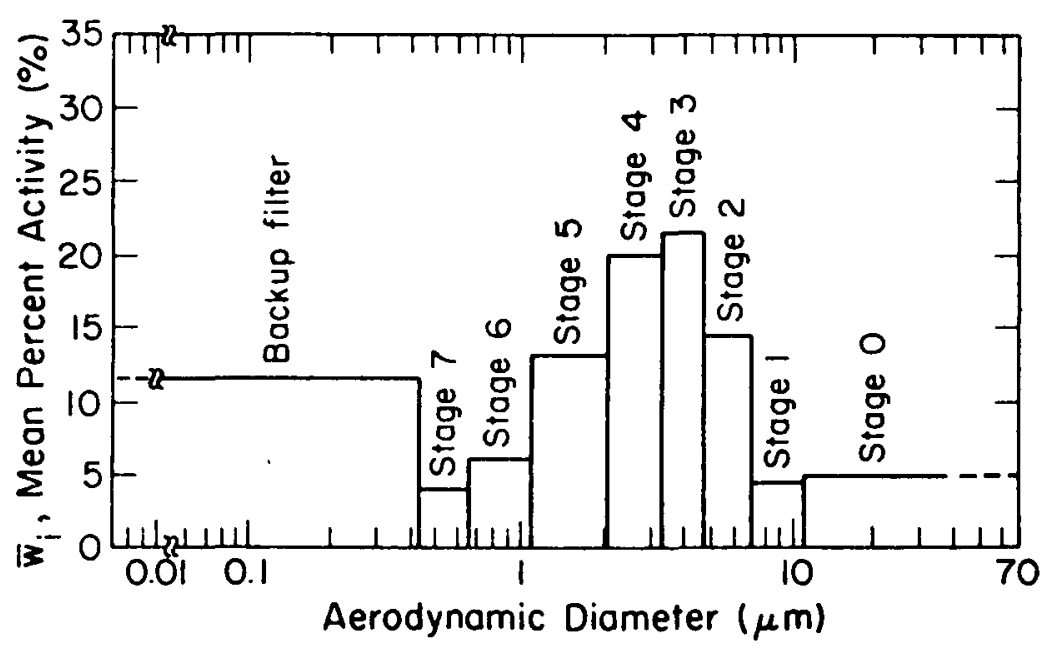

Fig. 7.4. Size Characteristics of Aerosol Containing $2{ }^{39} \mathrm{Pu}$, by Radiometric Analysis of All Impactor Samples at Location 14, a Fabrication Facility. ${ }^{2}$ 


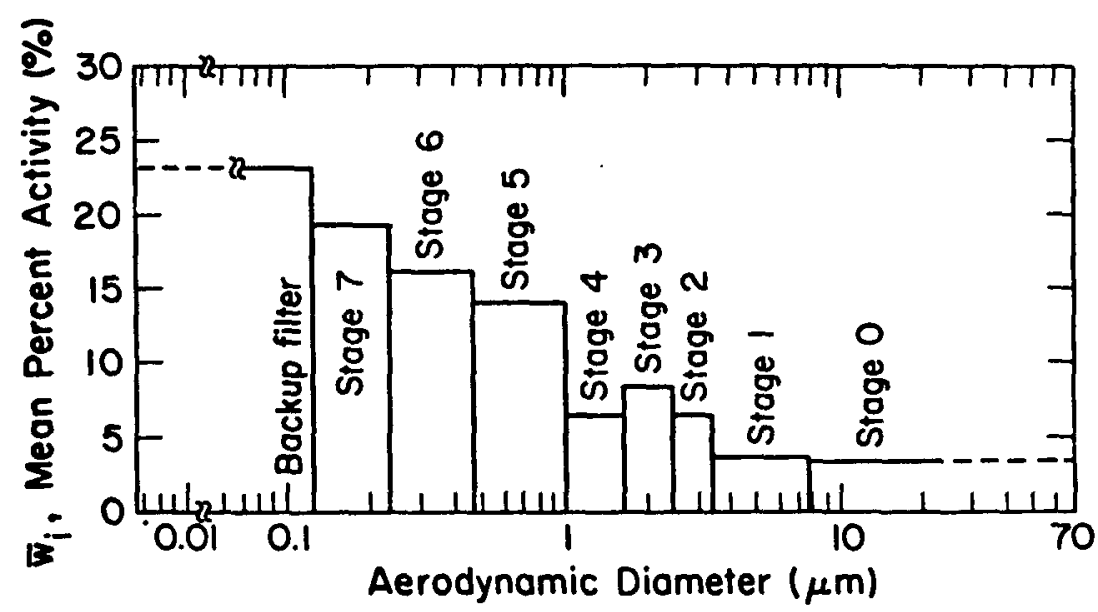

\author{
Fig. 7.5. Size Characteristics of Aerosol \\ Containing ${ }^{239} \mathrm{Pu}$, by Radiometric \\ Analysis of A11 Impactor Samples \\ at Location 11, A Chemical \\ Recovery Facility. Impactor \\ operated at $2.75 \mathrm{cfm} .^{2}$
}

A more refined method of examining the data is based on generating (for each facility) a frequency distribution of the means of all samples, and a comparable distribution for the geometric standard deviations. It would be expected that if day-to-day operations were reasonably repetitive (and other factors were reasonably constant), the distributions would be narrow in character. The distributions for the five facilities are shown in Figures 7.6 through 7.10 .

Examination of Figures 7.8 and 7.9 (for the fabrication facilities) shows that the distributions of both the means and the geometric standard deviations are quite narrow for location 08, indicating that day-to-day operation is reasonably consistent. The distributions for location 14 show more scatter; this is especially evident for the geometric standard deviation.

Figure 7.10 (for the recovery facility) shows rather narrow distributions of means centering in the small particle size region, and a broad scatter of geometric standard deviations. The narrow distribution of means may very well be characteristic of operations involving solutions and chemical conversions. Whether the wide scatter in $\sigma_{g}$ 's is attributable to a wide range of operations during the study or to some inherent characteristic of handling solutions cannot be determined.

The distributions for the two $R$ \& D facilities (Fig. 7.6 and 7.7) can be seen to be very different. Those at location 00 are suggestive of repetitive operations while the scatter in both means and $\sigma_{\mathrm{g}}$ 's for location 04 are suggestive of a wide variety of chemical and mechanical operations being performed at different times. 


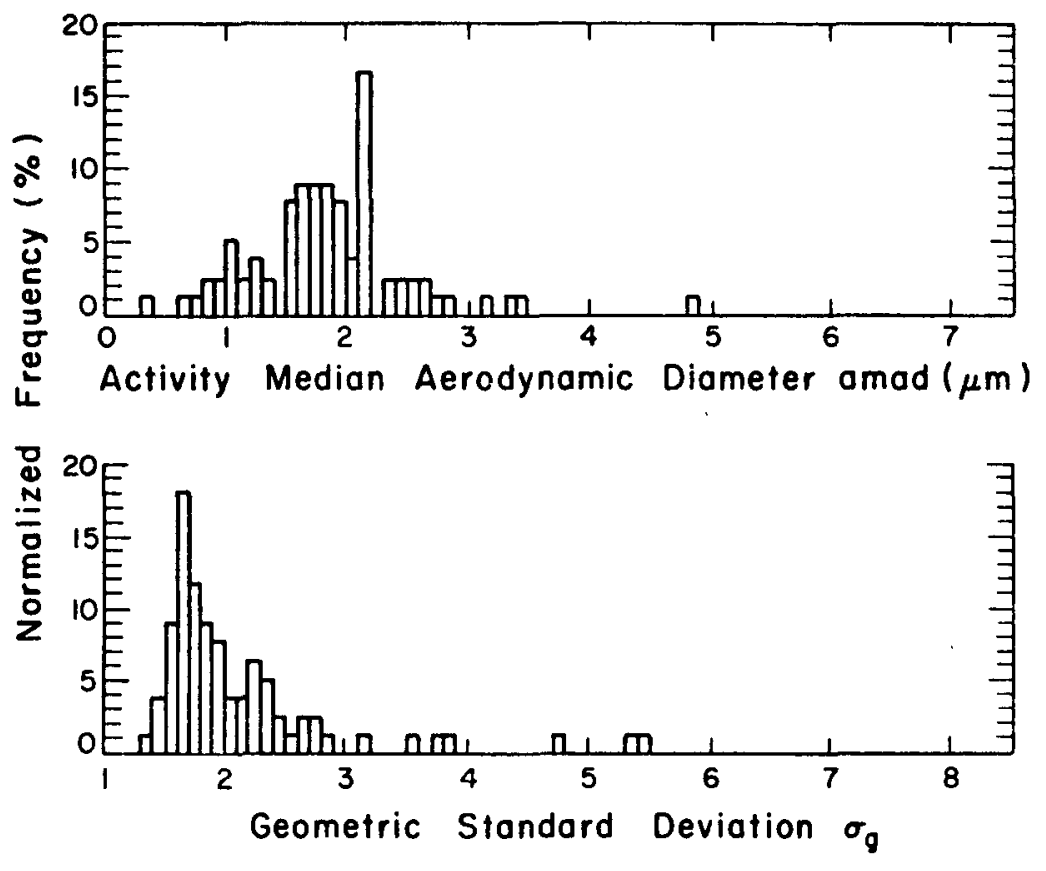

Fig. 7.6. Size Characteristics of Aerosol Containing ${ }^{238} \mathrm{Pu}$ and ${ }^{239} \mathrm{Pu}$.

Lognormally Distributed Impactor

Data from Location 00 , a

Research and Development

Facility. ${ }^{2}$

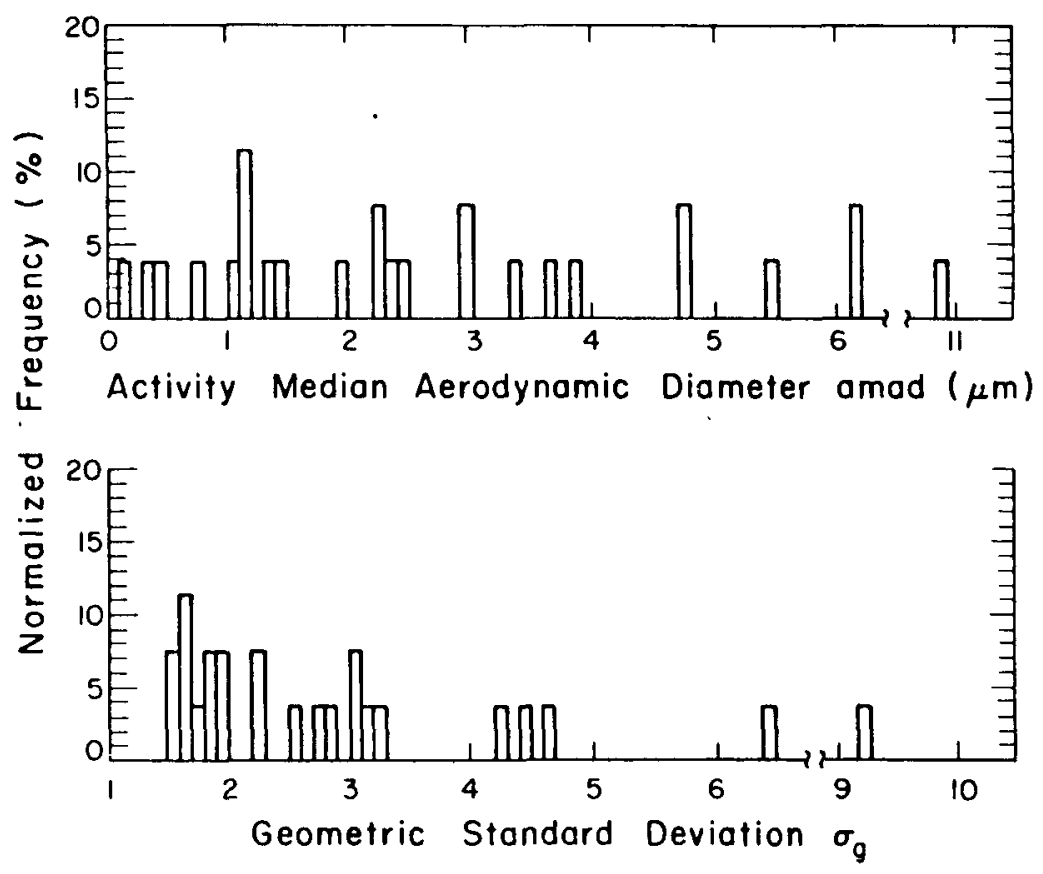

Fig. 7.7 Size Characteristics of Aerosol Containing $238 \mathrm{Pu}$. Lognormally Distributed Impactor Data from Location 04, a Research and Development Facility. ${ }^{2}$ 

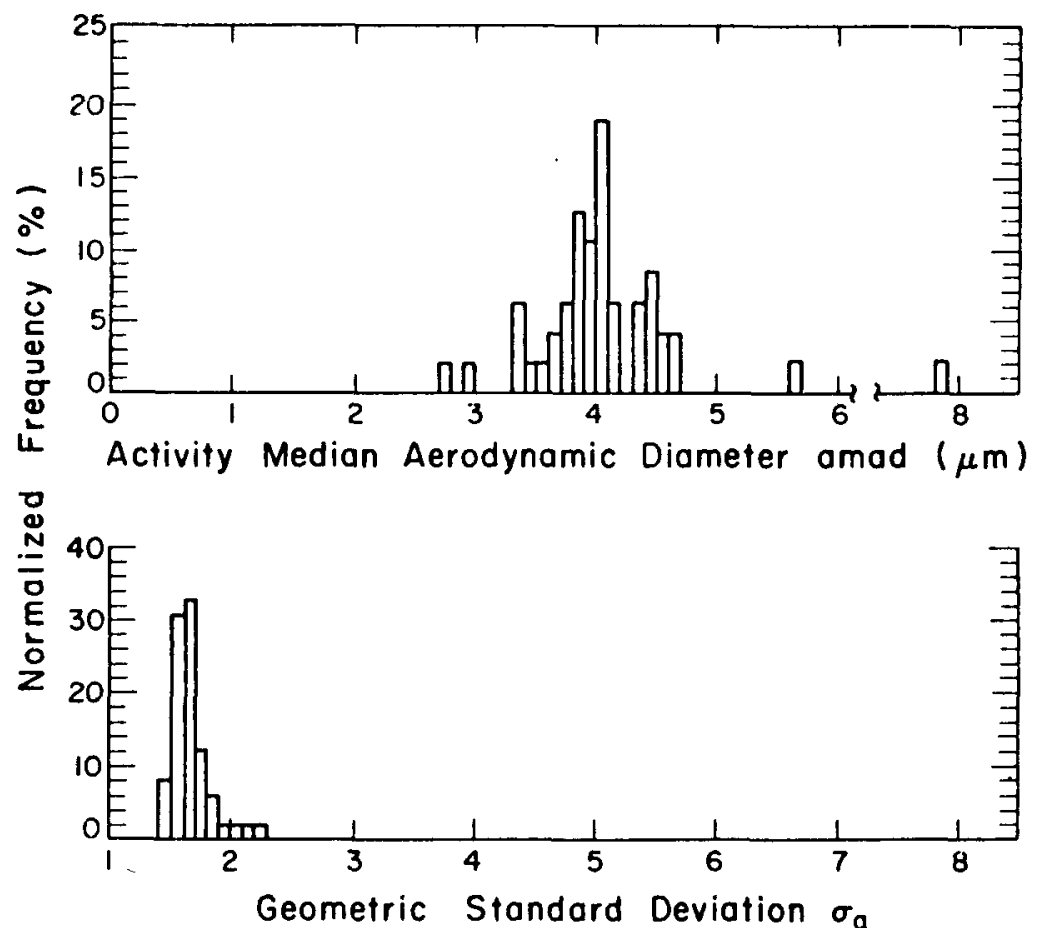

Fig. 7.8. Size Characteristics of Aerosol Containing ${ }^{238} \mathrm{Pu}$. Lognormally Distributed Impactor Data from Location 08, a Fabrication Facility. ${ }^{2}$

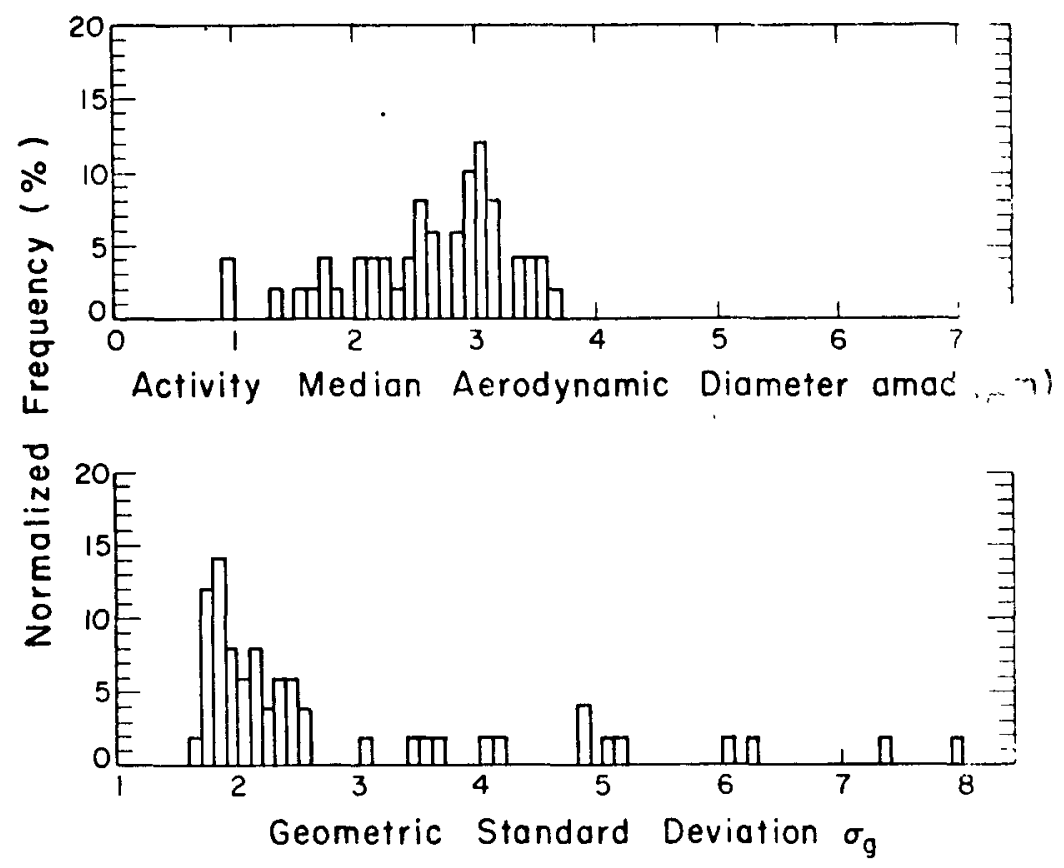

Fig. 7.9. Size Characteristics of Aerosol Containing ${ }^{239} \mathrm{Pu}$. Lognormally Distributed Impactor Data from Location 14, a Fabrication Facility. ${ }^{2}$ 


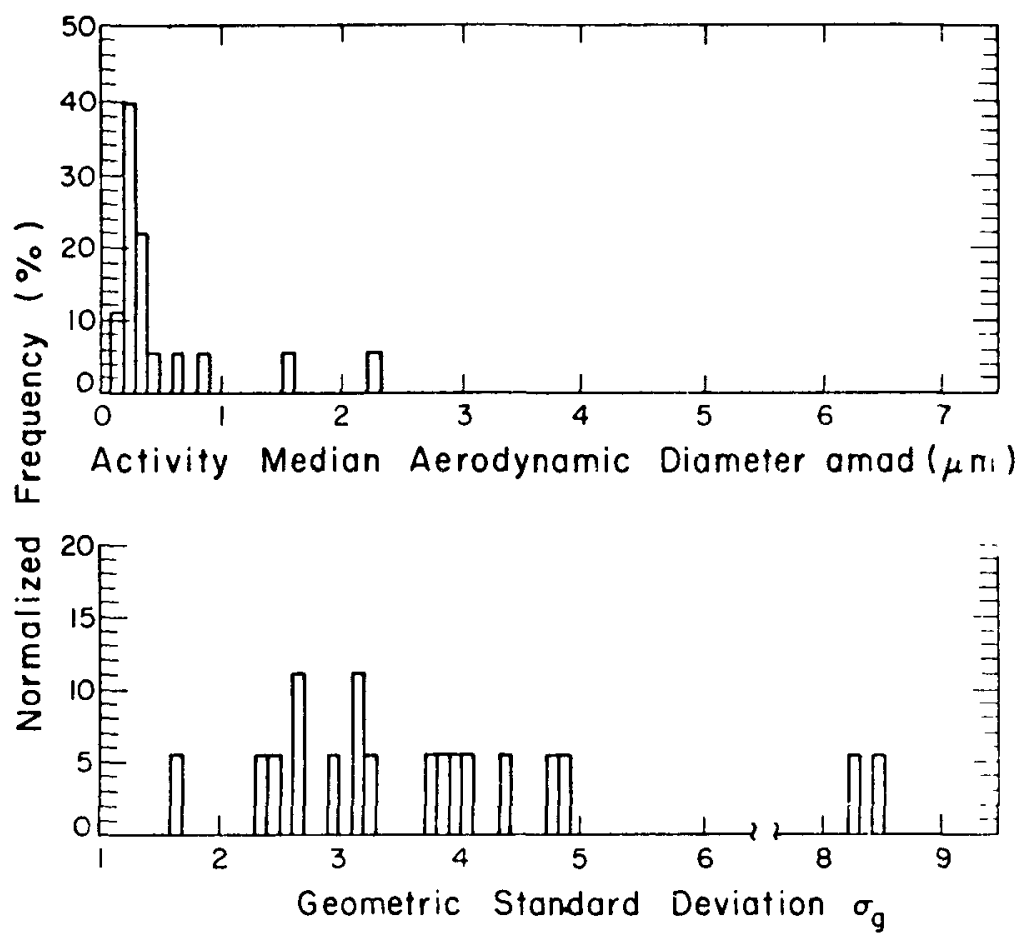

Fig. 7.10. Size Characteristics of Aerosol Containing $239 \mathrm{Pu}$. Lognormally Distributed Impactor Data from Location 11, a Recovery Facility. ${ }^{2}$

Apparently, the particle size distributions of repetitive operations, as characterized by means and $\sigma_{g}^{\prime} s$, are likely to be reasonably reproducible. Evidence for this conclusion is, however, lacking for the case in which solutions are handled or chemical conversion processes conducted. As would be expected, mechanical operations yield means of distributions that are significantly larger than those for chemical operations.

\subsection{Experimental Studies of HEPA Performance}

Experimenters at LASL have been conducting a program to establish the performance of each HEPA in a series of 3 HEPAs. $2,3,4$ The study is intended to generate information that yields filter efficiency at each stage as a function of particle size. The task is a formidable one since very high concentrations of aerosol are necessary in the input to the first stage in order to have a sufficient quantity of particulate downstream from the third stage to yield meaningful results.

To increase the capability of the measurements, the aerosols were prepared from $\mathrm{PuO}_{2}$ in which the predominant plutonium isotope was ${ }^{238} \mathrm{Pu}$, which has a high specific alpha activity. A typical procedure for generating the aerosol consists of ball-milling ${ }^{238} \mathrm{PuO}_{2}$ powder for long periods $(e . g ., 360$ $\mathrm{hr}$ ). A portion of the resulting material is suspended in water and stirred vigorously for $2 \mathrm{hr}$. A small quantity of an anionic surfactant is added, then dispersed by ultrasonics for periods up to $68 \mathrm{hr}$. The latter operation is intended to break up agglomerates; the surfactant keeps the particles well dispersed. The stability of the resulting mixture was demonstrated by an absence of observable settling over a weekend. Aerosol generation was accomplished by 
use of a RETEC nebulizer (described in reference 1). To ensure the completion of drying, make-up air was heated about $10^{\circ} \mathrm{C}$ above ambient. The resulting aerosol was then passed through the filter train. Appropriate samples were taken upstream and downstream from the train and intermediate locations.

Most aerosols generated had mean particle sizes of about $0.7 \mu \mathrm{m}$. Efforts continued during the program to produce aerosols of smaller sizes $(0.1 \mu \mathrm{m}$ being an objective); aerosols of $0.2 \mu \mathrm{m}$ were produced.

Aerosol samples were characterized by passing them through an Andersen impactor consisting of eight stages. Residual particulates not intercepted by the impactor were collected on a high-efficiency membrane filter. The total activity of the material deposited at each stage was determined. The range of particle sizes (measured as activity median aerodynamic diameter) deposited at each stage was determined by prior calibration. The authors reported mean particle size and the geometric standard deviation for each sample set obtained. Raw data was not included in the reports cited. Filter efficiencies were obtained by the authors from the raw data.

In the first series of runs (designated here as series A), reliable information was obtained on the efficiencies of the first two stages of HEPAs, but data on the third stage was regarded as questionable because counting statistics obtained on the extremely dilute aerosols discharging from that stage were very poor. In a second series of runs (designated here as series $B)$, special efforts were made to operate the experiments in a manner that would alleviate this problem. HEPAs with known lower efficiencies (but still in excess of $99.97 \%$ ) were placed in the first stage position, and efforts were made to generate aerosols having higher concentrations to challenge the first stage. This improved the counting statistics for the aerosol discharged from the system to the point where overall efficiencies of the third stage could be determined but did not improve them enough to allow efficiencies to be determined as a function of particle size.

The raw data for each run, as converted to amad and geometric standard deviations, are shown in Table 7.3 (for Series A) and Table 7.4 (for Series B), together with overall fractional penetrations for all particle sizes. The average penetration* for the first-stage HEPAs for Series A was $22 \times 10^{-7}$ as compared with $182 \times 10^{-7}$ for Series $B$. This is an expected result because the experimenters deliberately selected low-efficiency HEPAs for the first stage in Series B in order to yield improved counting statistics for the stage 3 HEPAs. Comparable penetrations for stage 2 HEPAs were $315 \times 10^{-7}$ and $722 \times 10^{-7}$ for Series $A$ and $B$, respectively. Average penetration for stage 3 HEPAs for Series $A$ is regarded as unreliable because of poor counting statistics, but for Series $B$ average penetration was $634 \times 10^{-7}$, which is quite comparable to the results obtained with stage 2 HEPAs.

A general pattern observable in the data for mean particle sizes and their geometric standard deviations is that values of both parameters tend to decrease from stage 1 to stage 2. Subsequent analysis (below) for penetrations vs particle size explains this observation.

*Average penetrations are geometric averages, i.e., the antilogarithm of the average of the logarithms of stated values. 
TABLE 7.3. Aerosol Size Distributions and Filter Penetrations in HEPA Filter Efficiency Experiments, Series $A^{3}$

\begin{tabular}{|c|c|c|c|c|}
\hline \multirow[b]{2}{*}{ Run } & \multirow[b]{2}{*}{$\begin{array}{l}\text { HEPA } \\
\text { Filter } \\
\text { Stage }\end{array}$} & \multicolumn{2}{|c|}{$\begin{array}{c}\text { Aerosol Size } \\
\text { Characteristics }\end{array}$} & \multirow[b]{2}{*}{$\begin{array}{l}\text { Overall Fractional } \\
\text { Filter Penetration } \\
\qquad \times 10^{-7}\end{array}$} \\
\hline & & $\mu(\mu \mathrm{m})$ & $\sigma_{g}$ & \\
\hline P4-1 & $\begin{array}{l}0 \\
1 \\
2 \\
3\end{array}$ & $\begin{array}{l}0.31 \\
0.31 \\
0.40 \\
--\end{array}$ & $\begin{array}{l}2.87 \\
2.01 \\
1.69 \\
--\end{array}$ & $\begin{array}{r}47 \\
16,350 \\
593^{a}\end{array}$ \\
\hline P4-2 & $\begin{array}{l}0 \\
1 \\
2 \\
3\end{array}$ & $\begin{array}{c}0.37 \\
-- \\
0.34 \\
--\end{array}$ & $\begin{array}{l}2.46 \\
-- \\
1.65 \\
--\end{array}$ & $\begin{array}{r}34 \\
201 \\
43,987^{a}\end{array}$ \\
\hline P4-3 & $\begin{array}{l}0 \\
1 \\
2 \\
3\end{array}$ & $\begin{array}{l}0.38 \\
0.37 \\
0.36 \\
--\end{array}$ & $\begin{array}{l}2.51 \\
1.76 \\
1.68 \\
--\end{array}$ & $\begin{array}{r}9 \\
236 \\
43,406^{a}\end{array}$ \\
\hline$P 4-4$ & $\begin{array}{l}0 \\
1 \\
2 \\
3\end{array}$ & $\begin{array}{l}0.34 \\
0.36 \\
0.34 \\
--\end{array}$ & $\begin{array}{l}3.00 \\
1.99 \\
1.89 \\
--\end{array}$ & $\begin{array}{r}68 \\
53 \\
6,297^{a}\end{array}$ \\
\hline$P 4-5$ & $\begin{array}{l}0 \\
1 \\
2 \\
3\end{array}$ & $\begin{array}{l}0.66 \\
0.38 \\
0.39 \\
--\end{array}$ & $\begin{array}{l}3.28 \\
2.10 \\
2.09 \\
--\end{array}$ & $\begin{array}{r}13 \\
153 \\
33,203^{a}\end{array}$ \\
\hline$P 4-6$ & $\begin{array}{l}0 \\
1 \\
2 \\
3\end{array}$ & $\begin{array}{l}0.48 \\
0.44 \\
0.42 \\
--\end{array}$ & $\begin{array}{l}3.76 \\
1.69 \\
1.66 \\
--\end{array}$ & $\begin{array}{r}2 \\
2,270 \\
3,618^{a}\end{array}$ \\
\hline $\mathrm{P} 4-7$ & $\begin{array}{l}0 \\
1 \\
2 \\
3\end{array}$ & $\begin{array}{l}0.48 \\
0.47 \\
0.42 \\
--\end{array}$ & $\begin{array}{c}2.98 \\
1.96 \\
1.68 \\
--\end{array}$ & $\begin{array}{r}55 \\
80 \\
9,381^{a}\end{array}$ \\
\hline$P 4-8$ & $\begin{array}{l}0 \\
1 \\
2 \\
3\end{array}$ & $\begin{array}{l}0.47 \\
0.48 \\
0.41 \\
--\end{array}$ & $\begin{array}{c}3.26 \\
1.70 \\
1.69 \\
--\end{array}$ & $\begin{array}{r}34 \\
85 \\
3,449^{a}\end{array}$ \\
\hline Avg (Geom) & $\begin{array}{l}1 \\
2 \\
3\end{array}$ & & & $\begin{array}{r}22 \\
315 \\
\sim 8,500^{a}\end{array}$ \\
\hline
\end{tabular}

${ }^{a}$ Data for the third stage considered unreliable. 
TABLE 7.4. Aerosol Size Distributions and Filter Penetrations in HEPA Filter Efficiency Experiments, Series $B^{4}$

\begin{tabular}{|c|c|c|c|c|}
\hline \multirow{2}{*}{ Run } & \multirow[b]{2}{*}{$\begin{array}{l}\text { HEPA } \\
\text { Filter } \\
\text { Stage }\end{array}$} & \multicolumn{2}{|c|}{$\begin{array}{c}\text { Aerosol Size } \\
\text { Characteristics }\end{array}$} & \multirow[b]{2}{*}{$\begin{array}{l}\text { Overall Fractional } \\
\text { Filter Penetration } \\
\qquad \times 10^{-7}\end{array}$} \\
\hline & & $\mu(\mu \mathrm{m})$ & $\sigma_{g}$ & \\
\hline$P 4-10$ & $\begin{array}{l}0 \\
1 \\
2 \\
3\end{array}$ & $\begin{array}{l}0.44 \\
0.53 \\
0.42 \\
--\end{array}$ & $\begin{array}{l}2.1 \\
2.3 \\
1.7 \\
--\end{array}$ & $\begin{array}{r}1,551 \\
351 \\
725\end{array}$ \\
\hline P4-11 & $\begin{array}{l}0 \\
1 \\
2 \\
3\end{array}$ & $\begin{array}{l}0.43 \\
0.47 \\
0.39 \\
--\end{array}$ & $\begin{array}{l}3.4 \\
2.4 \\
1.9 \\
--\end{array}$ & $\begin{array}{r}1,000 \\
334 \\
596\end{array}$ \\
\hline$P 4-12$ & $\begin{array}{l}0 \\
1 \\
2 \\
3\end{array}$ & $\begin{array}{c}0.33 \\
-- \\
a \\
--\end{array}$ & $\begin{array}{l}3.6 \\
-- \\
a \\
--\end{array}$ & $\begin{array}{r}79 \\
982 \\
903\end{array}$ \\
\hline$P 4-13$ & $\begin{array}{l}0 \\
1 \\
2 \\
3\end{array}$ & $\begin{array}{c}0.27 \\
-- \\
a \\
--\end{array}$ & $\begin{array}{l}3.9 \\
-- \\
a \\
--\end{array}$ & $\begin{array}{r}89 \\
985 \\
668\end{array}$ \\
\hline$P 4-14$ & $\begin{array}{l}0 \\
1 \\
2 \\
3\end{array}$ & $\begin{array}{c}0.22 \\
-- \\
a \\
--\end{array}$ & $\begin{array}{l}2.6 \\
-- \\
a \\
--\end{array}$ & $\begin{array}{l}151 \\
555 \\
780\end{array}$ \\
\hline P4-15 & $\begin{array}{l}0 \\
1 \\
2 \\
3\end{array}$ & $\begin{array}{l}0.26 \\
0.29 \\
-- \\
--\end{array}$ & $\begin{array}{l}3.2 \\
2.2 \\
-- \\
--\end{array}$ & $\begin{array}{r}81 \\
1,414 \\
884\end{array}$ \\
\hline P4-18 & $\begin{array}{l}0 \\
1 \\
2 \\
3\end{array}$ & $\begin{array}{c}0.37 \\
0.30 \\
0.22 \\
--\end{array}$ & $\begin{array}{l}3.2 \\
2.5 \\
2.5 \\
--\end{array}$ & $\begin{array}{r}45 \\
685 \\
583\end{array}$ \\
\hline$P 4-19$ & $\begin{array}{l}0 \\
1 \\
2 \\
3\end{array}$ & $\begin{array}{c}0.32 \\
0.30 \\
0.28 \\
--\end{array}$ & $\begin{array}{l}3.7 \\
2.1 \\
2.4 \\
--\end{array}$ & $\begin{array}{r}200 \\
1,213 \\
248\end{array}$ \\
\hline Avg (Geom) & $\begin{array}{l}1 \\
2 \\
3\end{array}$ & & & $\begin{array}{l}182 \\
722 \\
634\end{array}$ \\
\hline
\end{tabular}




\subsection{HEPA Efficiency as a Function of Particle Size}

Efficiencies, expressed as fractional penetrations, are reported in references 2 through 4 as a function of particle size. It was observed in reference 4 that data for the second stage HEPAs indicated increasingly high penetration as particle size decreased. This observation is inconsistent with the expected results based on filtration theory. The authors subsequently re-examined their data statistically, and now report ${ }^{5}$ revised values of penetrations (not yet published). They have identified the suspect data from individual runs, which are identified in Table 7.4. The revised results are shown in Table 7.5 .

TABLE 7.5. HEPA Filter Performance Reported by LASL (Revised, July 1975) as a Function of Aerosol Particle Size ${ }^{5}$ (Data from all runs combined).

\begin{tabular}{|c|c|c|c|}
\hline \multirow[b]{2}{*}{$\begin{array}{c}\text { Particle Size } \\
\text { Range, amad } \\
(\mu \mathrm{m})\end{array}$} & \multicolumn{3}{|c|}{ Fractional Filter Penetration ${ }^{a}$} \\
\hline & $\begin{array}{l}\text { HEPA } 1, \\
\times 10^{-7}\end{array}$ & $\begin{array}{l}\text { HEPA 2, } \\
\times 10^{-7}\end{array}$ & $\begin{array}{l}\text { HEPA } 1 \\
\text { plus } 2, \\
\times 10^{-11}\end{array}$ \\
\hline$<0.12$ & $23 \pm 19$ & $159 \pm 76$ & 3.7 \\
\hline $0.12-0.22$ & $49 \pm 45$ & $352 \pm 388$ & 17.2 \\
\hline $0.22-0.44$ & $56 \pm 60$ & $393 \pm 413$ & 22.0 \\
\hline $0.44-0.96$ & $98 \pm 95$ & $201 \pm 190$ & 19.7 \\
\hline $0.96-1.54$ & $27 \pm 38$ & c & \\
\hline $1.54-2.30$ & $1.7 \pm 1.5$ & c & \\
\hline $2.3-3.4$ & $5.2 \pm 5.8$ & $c$ & \\
\hline $3.4-5.4$ & $5.5 \pm 5.5$ & c & \\
\hline$>5.4$ & $8.6 \pm 8.6$ & $\mathrm{c}$ & \\
\hline
\end{tabular}

Because the revised values by the authors lumped the results obtained from both Series A and Series B (see Section 7.2), the data reported for individual runs (see Tables 7.3 and 7.4) were reviewed in this work, and penetrations for the two series were determined separately. Data identified as suspect by LASL were not used. The reviewers' reconstructed particle size distributions from the means and $\sigma_{\mathrm{g}}$ 's are shown in Tables 7.3 and 7.4 ( $10 \mathrm{~g}$ normal distributions were assumed). This information, together with LASL data 
of overall penetration, allowed penetrations to be computed as a function of particle size. The results together with the currently revised values of LASL are shown in Table 7.6.*

Considering the first-stage HEPAs only, the LASL data for all runs show peak penetration--98 $\times 10^{-7}$--in the particle size range of 0.44 to $0.96 \mu \mathrm{m}$. Penetrations fall off rapidly for both larger and smaller sizes. The reviewers' analysis of data, shown in Table 7.6, indicate peak penetrations-$79 \times 10^{-7}$--for the next smaller particle size range of 0.22 to $0.44 \mu \mathrm{m}$. The peak occurs at the same size range for both Series A and Series B; however, there is an order of magnitude difference associated with the deliberate selection of low-efficiency filters for Series $B$. These differences were recognized and taken into consideration in developing the source term in Section 9. It should be noted that the decrease in fractional penetration is less pronounced for the next larger particle size range $\left(70 \times 10^{-7}\right.$ for the range of 0.44 to $0.96 \mu \mathrm{m})$ than for the next lower one $\left(53 \times 10^{-7}\right.$ for the range of 0.12 to $0.22 \mu \mathrm{m}$ ). Thus it can be inferred that the peak penetration occurs close to the $0.44 \mu \mathrm{m}$ particle size.**

Examination of all data for the second-stage filters, LASLs as well as reviewer's, shows the highest penetrations in the 0.22 to $0.44 \mu \mathrm{m}$ particle size range. Penetrations calculated by the reviewers indicate about $60 \%$ greater penetration for Series A than for Series B. Again the decrease in penetration with larger and smaller particles is evident.

For completeness, combined penetrations for the two stages of HEPAs in series are also shown in Table 7.5 .

The results are generally in conformity with what would be expected from filtration theory. Penetration varied with particle size, with the peaks occurring in the ranges indicated; in most LASL runs, the mean size and the breadth of aerosol distributions decreased from the upstream side of the HEPAs to the downstream sides. Multiple stages in series enhanced this effect.

Also notable in the Series B runs (see Table 7.4) is that penetration values for stage 3 HEPAs were no higher than those of the stage 2 HEPAs. [Comparable data for the Series A runs (Table 7.3) is not considered reliable.] Based on the Series B runs (and consistent with filtration theory), a fourth stage of HEPA would be expected to perform similarly to the second and third stages.

\footnotetext{
*An example of the procedure used to obtain fractional penetration as a function of particle size is shown in Appendix A.

**The authors of the LASL reports have reported to us ${ }^{5}$ that their final report (to be published) will show maximum penetration in the range of 0.4 to 0.7 $\mu \mathrm{m}$. Their results will be more reliable than ours because their calculations of fractional penetrations will be based on their raw data of particle size distributions of aerosols, while our analysis was based on a reconstruction of distributions from the published $\mu$ 's and $\sigma_{g}$ 's. The raw data has not been published.
} 
TABLE 7.6. HEPA Filter Penetrations vs Aerosol Particle Size

for LASL Series A and B Experiments

Series A: No preselection of filters made for experiments

Series B: Stage 1 filters selected for low efficiency but exceeding $99.97 \%$

Unless indicated otherwise, results were calculated by reviewers from means and $\sigma_{g}$ 's given in Tables 7.3
and 7.4

Fractional Filter Penetration

Particle Size Range, amad, $(\mu \mathrm{m})$
Series A Runs P4-1 to P4-8
Series B Runs P4-10, 11, $15,18,19$
Revised LASL

Data (a11 runs $)^{5}$

$$
\begin{gathered}
\text { Stage } 1 \text { HEPA: } \\
<0.12 \\
0.12-0.22 \\
0.22-0.44 \\
0.44-0.96 \\
0.96-1.54 \\
>1.54
\end{gathered}
$$

Stage 2 HEPA:

$$
<0.12
$$

$0.12-0.22$

$0.22-0.44$

$0.44-0.96$

$0.96-1.54$

$>1.54$

Combined Stages 1 and 2:

$$
<0.12
$$

$0.12-0.22$

$0.22-0.44$

$0.44-0.96$

$0.96-1.54$

$>1.54$

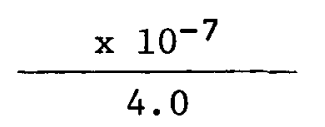

18.1

$32.8^{\mathrm{a}}$

28.1

12.1

2.5

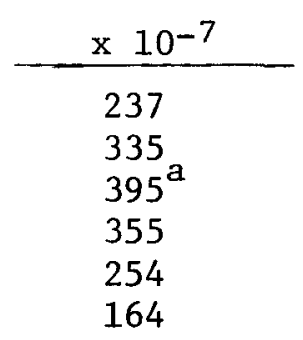

\begin{tabular}{c}
$\times 10^{-7}$ \\
\hline 154 \\
292 \\
$327^{a}$ \\
297 \\
219 \\
103
\end{tabular}

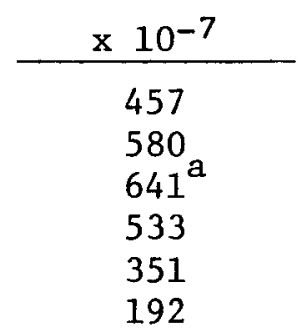

192

\begin{tabular}{c}
$\times 10^{-11}$ \\
\hline 98 \\
222 \\
$272^{a}$ \\
209 \\
105 \\
31
\end{tabular}

Series A Plus Series B

\begin{tabular}{cc}
$\times 10^{-7}$ & $\times 10^{-7}$ \\
\cline { 1 - 2 } 16 & 23 \\
53 & 49 \\
$79^{a}$ & 56 \\
70 & $98^{a}$ \\
37 & 27 \\
10 & --
\end{tabular}

\begin{tabular}{l}
$\times 10^{-7}$ \\
\hline 295 \\
402 \\
$464^{\mathrm{a}}$ \\
406 \\
283 \\
173
\end{tabular}

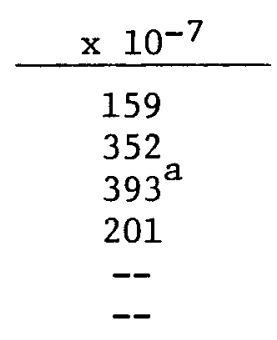

\begin{tabular}{c}
$\times 10^{-11}$ \\
\hline 0.99 \\
6.2 \\
$12.8^{a}$ \\
9.6 \\
2.8 \\
0.36
\end{tabular}

\begin{tabular}{c}
$\times 10^{-11}$ \\
\hline 4.5 \\
20 \\
$35^{a}$ \\
26 \\
9.4 \\
1.6
\end{tabular}

$\times 10^{-11}$

3.7
17
$22^{a}$
20
--
--

17

$22^{\mathrm{a}}$

20

a Maximum penetration. 
The principal observation to be made from the analysis of these results is that maximum penetration of $\mathrm{PuO}_{2}$ particles occurred in a diameter range of 0.22 to $0.44 \mu \mathrm{m}$ for all three stages of HEPA filtration. These maximums were greater for the second and third stages $\left(2450 \times 10^{-7}\right)$ than for the first stage ( $35 \times 10^{-7}$ when filters were not preselected for low efficiency). For all other particle sizes (both larger and smaller than the range of 0.22 to 0.44 $\mu \mathrm{m})$, fractional penetrations were even lower.

These data are used as major input in developing the source term in Section 9. 


\section{References for Section 7}

1. H. J. Ettinger, J. C. Elder, and M. Gonzales, Performance of Multiple HEPA Filters Against Plutonium Aerosols for Period July 1 through December 31, 1972, Los Alamos Scientific Laboratory Report LA-5170-PR.

2. H. J. Ettinger, J. C. Elder, and M. Gonzales, Performance of Multiple HEPA Filters Against P1utonium Aerosols for Period January 1 through June 30, 1973, Los Alamos Scientific Laboratory Report LA-5349-PR, July 1973.

3. H. J. Ettinger, J. C. Elder, and M. Gonzales, Performance of Multiple HEPA Filters Against Plutonium Aerosols for Period July 1 through December 31, 1973, Los Alamos Scientific Laboratory Report LA-5544-PR, March 1974

4. H. J. Ettinger, J. C. Elder, and M. Gonzales, Performance of Multiple HEPA Filters Against Plutonium Aerosols for Period January 1 through June 30, 1974, Los A1amos Scientific Laboratory Report LA-5784-PR, November 1974.

5. J. C. E1der, personal communication. 
8. REVIEW OF ANALYSES OF NORMAL AND ACCIDENTAL RELEASES FROM EX-REACTOR FUEL CYCLES

\subsection{Introduction}

A general review of safety considerations in radiochemical plants in the U.S. ${ }^{l}$ has identified the primary hazards of fire, explosion, and criticality in terms of potential uncontrolled releases of the major radioactivity associated with fission products. Emphasis was placed on Purex solvent extraction and storage of aqueous waste solutions. The basic safety-related problem is to ensure confinement. The major concern in normal operation is equipment reliability. With proper designs, releases can be controlled to very low levels. Accidental criticality or explosion has a high potential for causing releases, and the aim of design is to prevent such occurrences, as well as to limit their consequences.

The review of accidental plutonium releases (Section 4.4) showed that plant exhaust filter systems were effective in accidents in which normal in-plant containment was impaired and in-plant dispersion of process material occurred as a result of equipment failure, explosions, etc. The measured data on releases was largely presented in terms of exterior air samples; some additional information was presented on material collected on filters and on total material involved in an accident. Even where substantial amounts of material were involved in explosions of plutonium solutions and in burning of plutonium metal--processes which, in theory, can produce large amounts of very small-sized aerosols--the overall fractions of aerosols penetrating the filters or otherwise released from the building were so small that no appreciable personnel exposures occurred. It is important for accident analyses to characterize quantitatively the steps of release from the initial disruption of the process material and to account for the transport of material by air through openings in the plant system, both normal pathways and through damaged barriers. Although air cleaning systems are in general involved in actual cases, the concern here is not with filters, but with generalized transport of particulates in air, i.e., the release source strengths outside a particular enclosure due to releases within the enclosure. This "freerelease" source strength is the quantity (or fraction) of material that becomes airborne and reaches the filter or escapes from the building in the absence of a filter. For example, the releases in the accident cases reviewed in Section 4.4, especially in the accidents involving the largest quantities of plutonium, were believed to be small because of agglomeration, gravitational settling, and deposition of initially airborne particles on exposed surfaces. ${ }^{2}$

A calculational model of free-release source strength was developed by Hunt ${ }^{3}$ on the basis of a theoretical analysis. Its application was discussed in terms of a parametric analysis of releases from oxidation of plutonium metal in an enclosure having an air leak. The principal variables were:

(1) Leakage paths (number, length, size distribution, variation with overpressure, etc.).

(2) Mass, particle size, surface to mass ratio, and rate of particle release. 
(3) Mechanisms of particle transport to the walls (gravitational, diffusional, etc.).

(4) The type of thermal equilibrium in the enclosure and the duration of the release.

The analysis shows the release source term maxima as a function of plutonium quantity and type of thermal equilibrium. At these maxima, the model showed releases in excess of the MPC leve1. ${ }^{3}$

In general, the analysis supports the standard designs for handling large quantities of plutonium in small enclosures by the continuous exhausting of air through a series of fire-resistant HEPA filters. The exhaust air flow must be sufficient to prevent static pressure buildup associated with the release, but the flow must be low enough to avoid augmenting the release rate at the source.

\subsection{Theoretically Possible Major Accidents of Nuclear Fuel Cycle Plants}

\subsubsection{Introduction}

In 1962, the AEC requested ORNL to prepare a study ${ }^{4}$ of the theoretical possibilities and consequences of major accidents in plants which process and fabricate ${ }^{233_{\mathrm{U}}} \mathrm{U},{ }^{239} \mathrm{Pu}$, and radioisotopes. Previously (1959), the Commission had requested a similar study of enriched uranium by the Corvair Division, General Dynamics Corporation, 5 and in 1956 the Joint Committee on Atomic Energy had requested BNL to study nuclear power plants (WASH-740). A continuing reason for such studies was that despite the excellent safety record of nuclear facilities, the possibility of liability claims was believed to constitute a major deterrent to industrial participation. In all of these studies, the request was made to evaluate upper-limit, theoretically possible accident events, sometimes referred to as the "maximum credible accidents." Identification of such accident events was considered useful in defining indemnity and insurance requirements but not useful as a safety analysis. The ORNL study was published in 1964,4 and relevant excerpts are quoted below.

8.2.2. Reference Design Features to Minimize the Occurrence and Consequences of Accidents

The following reference design features were identified by ORNL:

(1) Radioisotopes are processed and handled in batches of 1 imited size; extraordinary precautions are taken to ensure their confinement in intended locations.

(2) Most processes are carried out behind heavy shielding, within sealed cells or glove boxes.

(3) Ventilation systems are so planned that the spread of contamination is minimized; recirculated air is frequently filtered; all exit process streams are filtered and monitored and are released only if concentrations are below preset levels.

(4) Plant design and operations are so arranged that at least three, and usually more, independent mishaps, malfunctions, or misoperations must occur before an accident can occur. 
(5) The containment system is always designed to retain the radioactive materials resulting from the maximum credible accident.

(6) There must always be at least two independent barriers between the normal locations of radioactive materials and the environment.

\subsubsection{Dispersal and Release Mechanisms}

Extensive off-site contamination can result only if radioactive materials are dispersed and released from the facility to the atmosphere. Fires and explosions were identified by ORNL as the primary types of accidents that could furnish sufficient energy for the release and off-site dispersal of radioactive materials.

Most plants contain adequate supplies of combustible materials for a sustained fire, but efforts are usually made to deliberately minimize such quantities. Efficient fire detection and specialized extinguishing techniques are available and have been shown to be reliable. Similarly, the dispersive strength of chemical explosions requires that careful control of fuel be practiced. Attention to the nature of combustion products and formation of explosive mixtures can be made adequate by design.

Criticality accidents provide relatively modest dispersal energies for fissile material. For example, a criticality excursion in 100 $\mathrm{kg}$ of solution liberates only about $3.5 \%$ of the instantaneous energy (29.5 MJ) liberated by a vapor explosion in a $225 \mathrm{~m}^{3}$ room ( $844 \mathrm{MJ}$ ). The major off-site hazards from criticality excursions is due to the liberated short-lived gaseous fission products.

Once radioactive material is dispersed as a fine smoke or mist in a cell or glove box, it is theoretically possible for it to be released to the atmosphere (1) through the ventilation systems or (2) by successive leaks from the laboratory, room, or cell (primary containment) to the building (secondary containment) and then through leaks in the building walls.

It was assumed in the ORNL study ${ }^{4}$ that filters have removal efficiencies of $99 \%$ for particles smaller than $0.05 \mu \mathrm{m}, 87 \%$ for particles between 0.05 and $0.1 \mu \mathrm{m}, 95 \%$ for particles between 0.1 and $0.3 \mu \mathrm{m}, 99.95 \%$ for particles between 0.3 and $5 \mu \mathrm{m}$, and $100 \%$ for particles larger than $5 \mu \mathrm{m}$. It was also assumed that smokes from fires of metal, solid carbonaceous materials, or organic liquids (which are predominantly 0.01 to $0.1 \mu \mathrm{m}$ in diameter when initially produced, but agglomerate rapidly) are $99 \%$ removed in filters.

When radioactive liquid aerosols are formed by an explosion in a tank of radioactive solution in a cell, the concentration of solution in the air entering the ventilation system is not expected to exceed that in rain or drizzle, i.e., 100 to $1000 \mathrm{mg}$ of solution per cubic meter of air.

On the basis of other work, the ORNL study indicates that in the event of an accident, the activity released from successive leaks through the primary and secondary containment walls would be insignificant, compared with the possible release through the ventilation filters. In a contained accident, the blast effects of an explosion are confined to the region of primary containment (glove box, laboratory, storage room, or cell). Although a 
radioactive aerosol may leak through cracks or penetrations in the primary containment wall and become mixed with the air in the secondary containment zone (building) during the period when the primary containment zone is pressurized, the quantity of leaked air is ordinarily not sufficient to raise the secondary containment pressure above atmospheric. In the event that flow from the secondary containment to the atmosphere is possible (perhaps because of a lee vacuum induced on the building by a high wind), the leak rates and ventilation rates in typical plants are still such that the predominant release of activity would be through the primary and secondary containment ventilation filters.

The fiber filters that are widely used in radiochemical plants are the weakest link in the containment of accidents. The susceptibility of the filters to both physical and chemical degradation necessitates that their integrity and efficiency be ensured by routine in situ testing or by replacement testing plus careful installation and operation. The filters must be protected from excessive corrosion and excessive loadings of dust and water, and they must be located so that they can withstand the blast wave from credible explosions without rupture. In typical facilities, the tortuous path and expansions and contractions of the ventilation duct are sufficient so that the blast wave from a credible explosion is reduced to a tolerable level at the filters. ${ }^{4}$

The assumed plant concept and fissile inventory ${ }^{4}$ for nuclear fuel fabrication are shown in Table 8.1, along with the calculated theoretically possible accident releases. It is emphasized that the ORNL study focused on the maximum possible accident associated with (a) burning of plutonium metal or carbide and (b) criticality explosion from an aqueous solution, rather thar on a realistic assessment of the probabilities of accidents in reference fuel cycle facilities.

\subsection{Routine and Accidental Releases of Plutonium in Purex Reprocessing} Plants Estimated in a 1970 Siting Study ${ }^{6}$

\subsubsection{Introduction}

This study was prepared as technical background for siting considerations for spent-fuel reprocessing plants and waste-management facilities. It incorporates basic information published previously but reviewed and revised for the present purpose. Much new information on health and safety aspects is included.

The basic design concept assumed in the ORNL work ${ }^{6}$ is that confinement of radioactive material is provided by three barriers: the primary container or equipment, the secondary vault or cell ventilation system, and the tertiary barrier offered by the building. The design, testing, and operation of a plant are so accomplished that the secondary and tertiary barriers will be maintained after exposure to any credible internal forces. Further, the process and confinement systems are designed and operated so that credible external events or forces (e.g., loss of power, earthquakes, tornadoes, floods, hurricanes, impaction by moving vehicles, etc., but not including acts of war) will not impair the ability to shut down the plant safely and to maintain safe shutdown conditions. Also, although it is considered credible that accidents may circumvent preventive administrative 
and instrumental procedures, it is not considered credible that practical remedial measures for mitigation of the consequences would not be instituted within a reasonable time (hours) of the occurrence of an accident.

TABLE 8.1. Assumed Fissile Inventory and Calculated Accidental Releases of Fissile Material in a Nuclear Fuel Fabrication Plant ${ }^{4}$

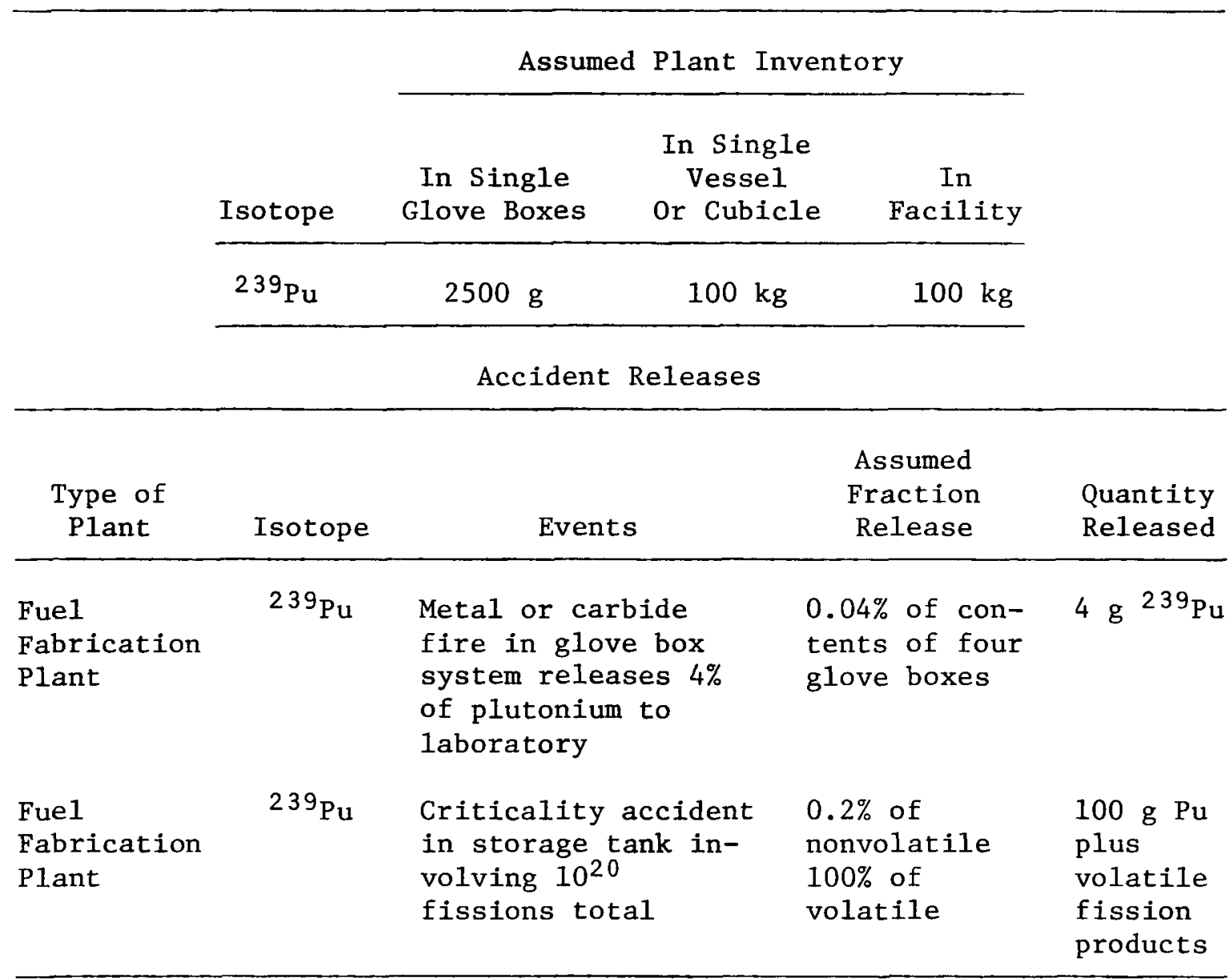

Pertinent key issues addressed in the ORNL study were these:

(1) Are routine or accidental releases controlling the siting?

(2) Are there technical and safety factors indicating that a few largecapacity plants would be preferable to more numerous small-capacity fuel reprocessing plants?

(3) Are the hazards of economics of shipping spent fuels, solid wastes, and fissile materials of such magnitude that (a) these shipments should be limited to specific routes within regional boundaries or (b) shipping offsite should be precluded?

(4) Is governmental ownership for fuel cycle facilities required? Can such facilities be decontaminated to the extent that they may be safely abandoned, i.e., need no surveillance after they are closed? 


\subsubsection{Conclusions}

Pertinent principal conclusions of the ORNL study were:

(a) On the basis of current technology of air cleaning, routine releases tend to control the location of the site boundaries. On-site waste storage facilities do not materially increase either the rate of routine release of radioactive material or the likelihood of release of such material as a result of accidents. These conclusions are based on the design assumption that containment (and filtration systems) would remain intact after exposure to internal or external forces.

(b) The study indicated that confinement barriers of fuel processing plants (including their waste storage facilities) in the size range of interest can be maintained when credible internal or external accident forces are exerted. Plants of various sizes can be made equivalently safe by applying common design criteria.

(c) Shipping of all radioactive materials except liquid high-level wastes can be conducted safely and economically.

These conclusions show both greater realism and optimism than the earlier report ${ }^{4}$ does, reflecting a different aim and context. Also, the technology of air cleaning had become better established between reports. It should be noted, however, that the conclusions are based on the assumption of strict regulation and quality assurance for the confinement and air cleaning systems. Cost considerations are essentially based on an "as low as practicable" strategy, given the present assessment of radiological hazard.

\subsubsection{Routine Plant Releases from Reprocessing Plants}

Absolutely leak-tight containment of process streams (with or without recycle of air and wastes) in reprocessing plants is impractical. The complete removal of all radioactivity from effluent streams is also impractical. Releases are controlled to acceptable levels by effluent treatment facilities. For present purposes, only the release of plutonium is of interest; the estimate from this ORNL study ${ }^{6}$ is that using current technology of processing, ventilation, and air cleaning, the release in effluent air from a 1 MT per day plant would be $3 \times 10^{-5} \mathrm{Ci} / \mathrm{day}$, based on a fractional release of LWR fuel of $1.2 \times 10^{-8}$.

It was assumed in the ORNL work ${ }^{6}$ that routine release of radioactive particulates to the environment increases in direct proportion to the process vessel off-gas flow rate in plants having large throughput rates. The fuel inventory in individual process vessels does not increase in direct proportion to the production rate because of the necessity for multiple equipment lines to permit continuity of operation and the use of progressively more continuous equipment. The ORNL work considers that the routine release to the off-gas system is roughly proportional to the area of the interface between the radioactive solid or solution and the gas. Radioactive aerosols are entrained in off-gas streams primarily by sparging (at about $1 \mathrm{scfm} / \mathrm{ft}^{2}$, and also by diffusion and recoil from surfaces. As a first approximation, the greater surface-to-volume ratio of continuous equipment will offset the effect of larger process vessels. 


\subsubsection{Mechanisms of Particulate Formation}

At ORNL, it has been found that the off-gases from process vessels in aqueous fuel reprocessing operations contain particles of aqueous solution at a concentration of about $10 \mathrm{mg} / \mathrm{m}^{3}$ (fog), with an equal weight in the size ranges of 0.1 to $0.4 \mu \mathrm{m}, 0.4$ to $1.3 \mu \mathrm{m}, 1.3$ to $5 \mu \mathrm{m}$, and $5 \mu \mathrm{m}$ and larger. This distribution differs from that observed by LASL (see Section 7.1). Sand bed or HEPA filters remove $100 \%$ of the particles larger than $3 \mu \mathrm{m}$ and about $99.98 \%$ of the particles smaller than $3 \mu \mathrm{m}$ having the above size distribution. This data differs from that presented in the earlier ORNL study (see Section 8.2). From these data, it is estimated that the aerosol concentration in the filter effluent is on the order of $0.0012 \mathrm{mg} / \mathrm{m}^{3}$ of process vesse1 off-gas. If it is assumed that the radioactive solutions contain $300 \mathrm{~g}$ fuel/liter and have a specific gravity of 1.2 , the estimated concentration of fuel in the filter effluent is $0.3 \times 10^{-12}$ MT of fuel per $\mathrm{m}^{3}$ of air. From this and assuming a combined dissolver and process-vessel offgas flow of $1000 \mathrm{cfm}$, ORNL obtains a fractional release of $1.2 \times 10^{-8}$ for the plant.

\subsubsection{Plutonium Releases in Plant Accidents}

Upper-limit accidental releases of plutonium from fuel reprocessing plants were estimated by ORNL as a function of capacity. These are summarized in Table 8.2 .

TABLE 8.2. Upper Limit Accidental Releases of Plutonium from Fuel

Reprocessing Plants in Relation to Plant Capacity

\begin{tabular}{lcc}
\hline & \multicolumn{2}{c}{ Plutonium Released (g) } \\
\cline { 2 - 3 } Capacity & LWR Plant $^{\mathrm{a}}$ & LMFBR Plant \\
\hline $1 \mathrm{MT} / \mathrm{d}$ & 0.36 & 2.4 \\
$6 \mathrm{MT} / \mathrm{d}$ & 2.2 & 4.8 \\
$36 \mathrm{MT} / \mathrm{d}$ & 2.2 & 7.2 \\
\hline a Assumes LWR fuel that contains $8 \mathrm{~kg} \mathrm{Pu} / \mathrm{MT}$. \\
$\mathrm{b}_{\text {Assumes LMFBR fuel that contains } 150 \mathrm{~kg} \mathrm{Pu} /}$ \\
MT.
\end{tabular}

These estimates are derived from detailed assumptions, given in reference 6, regarding limiting accident events and particulate behavior. The details are too complex to be summarized here, but the rationale on aerosol behavior is consistent with the basic principles discussed in Section 6. 
8.4. Risks of Effluents from Mixed-Oxide Fuel Fabrication P1ants: 1973 PNL Study ${ }^{7}$

Routine and accidental releases of plutonium from proposed mixed-oxide fuel fabrication plants were studied by PNL. The reference plant has the following features pertinent to this study:

(1) $\mathrm{UO}_{2}-\mathrm{PuO}_{2}$ fuel for light-water reactors.

(2) Design capacity of $1 \mathrm{MT} / \mathrm{day}$.

(3) Fuel composition: 2 to $4 \%$ (wt) $\mathrm{PuO}_{2}$ in $\mathrm{UO}_{2}$ (no radiological significance attached to uranium).

(4) Isotopic composition of plutonium equivalent to that of Yankee spent fuel at 35,000 MWd/MT (see Table 8.3).

(5) Design features consistent with minimum (1973) AEC criteria for new plutonium facilities.

(6) All glove boxes have HEPA filters and discharge to the final filter system of the building, which has two stages of HEPA filters. Aggregate penetrations of the 2- and 3-stage filters used in this study were $1 \times 10^{-5}$ and $6 \times 10^{-7}$, respectively.

\begin{tabular}{lr} 
TABLE 8.3. & $\begin{array}{l}\text { Reference Isotopic } \\
\text { Composition of } \\
\text { Plutonium for PNL } \\
\text { Study }\end{array}$ \\
\hline Isotope & wt \% \\
\hline $2{ }^{38} \mathrm{Pu}$ & 1.9 \\
$2{ }^{39} \mathrm{Pu}$ & 63.3 \\
$2{ }^{40} \mathrm{Pu}$ & 19.0 \\
$2{ }^{21} \mathrm{Pu}$ & 12.0 \\
$242 \mathrm{Pu}$ & 3.8
\end{tabular}

Source terms were developed by PNL for normal operation (continuous releases) and for five postulated accidents (short-duration releases). Norma1 operation of the $1 \mathrm{MT} /$ day facility is expected to result in a plutonium source term of $5 \times 10^{-6} \mathrm{~g}$ per year. For accidents analyzed, a maximum of $10^{-2} \mathrm{~g}$ of respirable plutonium was assumed to be emitted from the two-stage HEPA filter systems. Emission of both soluble and insoluble plutonium of this magnitude was deemed credible.

Probabilities of accidental releases were estimated from historical data on accident occurrences and equipment failure-rate statistics for fuel fabrication facilities and related industries. It was recognized that there 
is a difference between (a) the probability of events leading directly to releases and (b) probability of events which cause a release only if there is a simultaneous occurrence of other events. (A third consideration, the propagation of events resulting in common mode failures, is treated implicitly in the PNL study.)

Accidental releases and their estimated probabilities are summarized in Table 8.4.

Possibly significant process alternatives identified in the report are: (1) coprecipitation as an alternative to the reference blending of pure $\mathrm{UO}_{2}$ and $\mathrm{PuO}_{2}$ powders; (2) vibratory compaction for loading fuel elements as an alternative to the reference pellet-making process; and (3) adaptation of the plant to LMFBR fuel manufacture. The discussions presented on these alternatives are reviewed briefly below.

Coprecipitation differs in that the uranium-plutonium mixture is prepared as an aqueous solution, and the mixed oxides are precipitated as solids, dried, reduced, and calcined together. Since all subsequent steps (pelletizing, etc) are similar to those used following powder blending, the chief difference is in aqueous handling and in the elimination of a pure $\mathrm{PuO}_{2}$ powder, which is considered the plutonium-bearing material that is the greatest potential source of releasable plutonium. According to the PNL analysis, some reduction of routine and accident source terms would be expected if coprecipitation is adopted.

Vibratory compaction was not analyzed by PNL to give a definitive comparison with pelletizing, but PNL's preliminary judgment is that the source terms would not be affected significantly by substituting vibratory compaction.

Higher $\mathrm{PuO}_{2}$ concentrations ( 8 to $30 \%$ wt) for LMFBR fuel, with smaller pellet sizes, could be handled by the reference plant with minimal changes. If the plant were converted to process $1 / 6 \mathrm{MT} /$ day of $75 \% \mathrm{UO}_{2}-25 \% \mathrm{PuO}_{2}$, the plant plutonium inventory would be approximately the same, but criticality restrictions would force reduction in the amount of plutonium handled in one batch. For this case and assuming the same reference design features, the routine and accident source terms were judged by PNL to be unchanged from those of the $1 \mathrm{MT} /$ day LWR-Pu plant.

8.5. Review of Accidental Releases of Truck Shipments of Plutonium; A Risk

8.5.1. Introduction

A study by $\mathrm{PNL}^{8}$ on releases from truck shipments of plutonium has been reviewed to identify source term data for this mode of plutonium handling. The PNL study was oriented toward risk analysis and hence focused attention on probabilities of events and their consequences (measured as deaths).

The PNL study considered plutonium in solution form (nitrate)

and as oxide. The containers assumed for reference designs were those designated as L-10 for the nitrate solution and 6M for the oxide powder. Accident frequencies and analyses of container behavior were obtained from a 
TABLE 8.4. Annual Risk of an Individual in the Environs of a Plutonium Fuels Fabrication Facility ${ }^{7}$

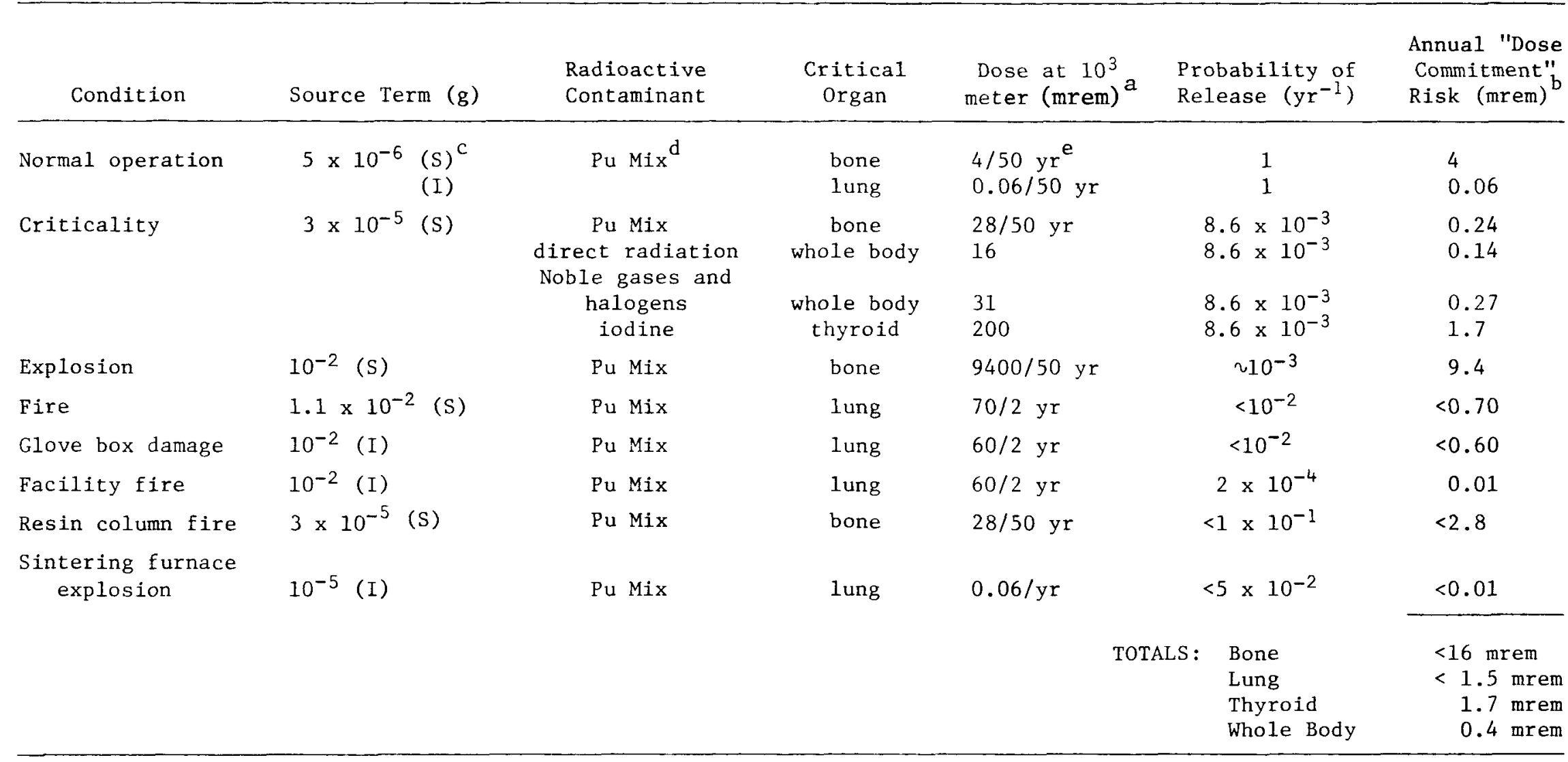

a Estimated using the ICRP Pub 2 lung mode1 (ILM).

$\mathrm{b}$ The probable dose to which an individual is annually committed to receive. This could be instantaneously received, or it could be delivered over an estimated period as in the case of the bone and 1 ung.

c $I=$ insoluble $S=$ soluble

d $\mathrm{Pu}$ Mix = reference mixture of plutonium and americium.

e 4/50 yr means that the 4 mrem is delivered to the bone over a period of 50 yr. 
Sandia study. On the basis of estimated uncertainties in the PNL report (p. 11.17), the 95\% confidence limit on the occurrence frequency is two orders of magnitude and that on the release fraction (log scale) is one-half order of magnitude; the overall product may be estimated as one order of magnitude.

It should be noted that shipment of plutonium in liquid form will be prohibited after June 17, 1978, according to current regulations (10 CFR 71.42).

\subsubsection{Basis of Analysis}

The shipment that PNL used for its evaluation consisted of the exclusive use of a "standard" van or trailer having no special provisions for containment and having adequate capacity for either 6M or L-10 packages to contain $100 \mathrm{~kg}$ of plutonium. For both oxide and nitrate shipments, four barriers between the plutonium and man's environment were considered. For the oxide powder, these were: a sample can (the primary container for the plutonium), a heavy-wall closed pipe (referred to as the $2 \mathrm{R}$ container), a 6M drum, and the van itself. For liquid nitrate, the barriers were: a polyethylene bottle, a heavy-wall closed pipe (referred to as the pressure vesse1), an L-10 drum, and the van. A release was considered to have occurred when the plutonium penetrated all four barriers. ${ }^{8}$

For shipment of plutonium as oxide, the 2R container consisted of a 5in.-dia schedule 80 steel pipewith a threaded plug and a gas-filled $0-$ ring sea1. This meets the specifications of $49 \mathrm{CFR} 178.34$. The bottom end is closed with a 1/2-in. steel cap. The oxide powder is contained in two sealed number 8 steel cans, which are placed inside the $2 \mathrm{R}$ container. Padding is used to minimize damage. The outer container is a 15-gal DOT (Department of Transportation) Specification 17C drum. Dunnage (i.e., bracing) is employed to secure the cargo during normal transport to withstand normal acceleration and deceleration. 8

For shipment of plutonium as the nitrate, the pressure vessel has a 4.8-in. ID and is sufficiently thick to withstand 3000 psi at $600^{\circ} \mathrm{F}$ $\left(315^{\circ} \mathrm{C}\right)$. The interna1 length of 52.2 in. accommodates a 10-1iter polyethylene bottle sealed in a polyvinylchloride bag and cushioned with neoprene pads. The outer container consists of two 55-gal drums welded end-to-end (DOT specification $17 \mathrm{H}$ ). The annular space is filled with vermiculite for thermal insulation. 8

\subsubsection{Estimates of Plutonium Source Term}

In the PNL study, analyses of container failures and the resulting consequences were presented as risk spectra, i.e., curves of expected fatalities (consequences) vs probability of event sequences associated with those fatalities. The methodology involved the generation of fault trees, identification of release sequences, determination of probabilities and release fractions, dispersion mechanisms of resulting releases, and evaluation of health effects. The determination of source terms (release of plutonium) is inherent in the methodology, but these were not specifically reported. The basis for the evaluation was a single shipment of 39 containers for oxide or 50 containers for nitrate $(100 \mathrm{~kg} \mathrm{Pu})$ for a distance of 1500 miles. For details of the methodology, the reader should consult the published reference. ${ }^{8}$ 
The authors of the PNL report repeated several computer runs for us in which the program was modified to yield a printout of source term data. ${ }^{9}$ The data furnished us is shown in Table 8.5. The data for oxide shipment is plotted in Fig. 8.1.

TABLE 8.5. Accident Release Fraction of Plutonium during Shipment vs Cumulative Probability (per shipment) ${ }^{9}$

\begin{tabular}{|c|c|c|}
\hline $\begin{array}{l}\text { Lower Limit } \\
\text { of Release }\end{array}$ & \multicolumn{2}{|c|}{$\begin{array}{l}\text { Estimated Cumulative } \\
\text { Probabilityb of Release } \\
\text { Fraction (F) or Greater } \\
\text { Form of Plutonium }\end{array}$} \\
\hline Fraction Range $(F)^{a}$ & Oxide & Nitrate \\
\hline $10^{-7}$ & $4.3 \times 10^{-7}$ & $1.892 \times 10^{-6}$ \\
\hline $10^{-6}$ & $3.3 \times 10^{-7}$ & $1.888 \times 10^{-6}$ \\
\hline $10^{-5}$ & $3.3 \times 10^{-7}$ & $1.876 \times 10^{-6}$ \\
\hline $10^{-4}$ & $3.3 \times 10^{-7}$ & $6.305 \times 10^{-7}$ \\
\hline $10^{-3}$ & $2.41 \times 10^{-8}$ & $6.276 \times 10^{-7}$ \\
\hline $10^{-2}$ & $2.383 \times 10^{-8}$ & $5.115 \times 10^{-8}$ \\
\hline $10^{-1}$ & $2.383 \times 10^{-8}$ & $4.954 \times 10^{-8}$ \\
\hline 0.251 & $2.38 \times 10^{-8}$ & $4.954 \times 10^{-8}$ \\
\hline 0.398 & $8.9 \times 10^{-10}$ & $2.381 \times 10^{-8}$ \\
\hline 0.631 & $8.9 \times 10^{-10}$ & $1.913 \times 10^{-8}$ \\
\hline
\end{tabular}

a Upper limit is unity.

$\mathrm{b}$

The cumulative probability $P(F)$ is defined in terms of the continuous probability density $p(F)$ by

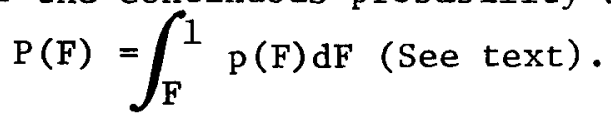

C Data obtained from the authors of BNWL-1846 (Reference 8).

The data is specifically applicable to a single container, and is valid for all containers to the extent that canister failures are independent of each other, and that, in effect, not more than one container releases its contents to the environment in any one accident. The authors did analyze the probability of two canisters failing in a single accident on the basis that the probability of each canister failure was independent. The probability of a dual failure was found to be more than two orders of magnitude lower than the probability of a single failure and could be neglected.

Two types of accidents were identified in which multiple canister failures could not be considered independent. One is criticality and the other is crush. The rationale for concluding that these events do not contribute significantly to overall consequences are given below. 


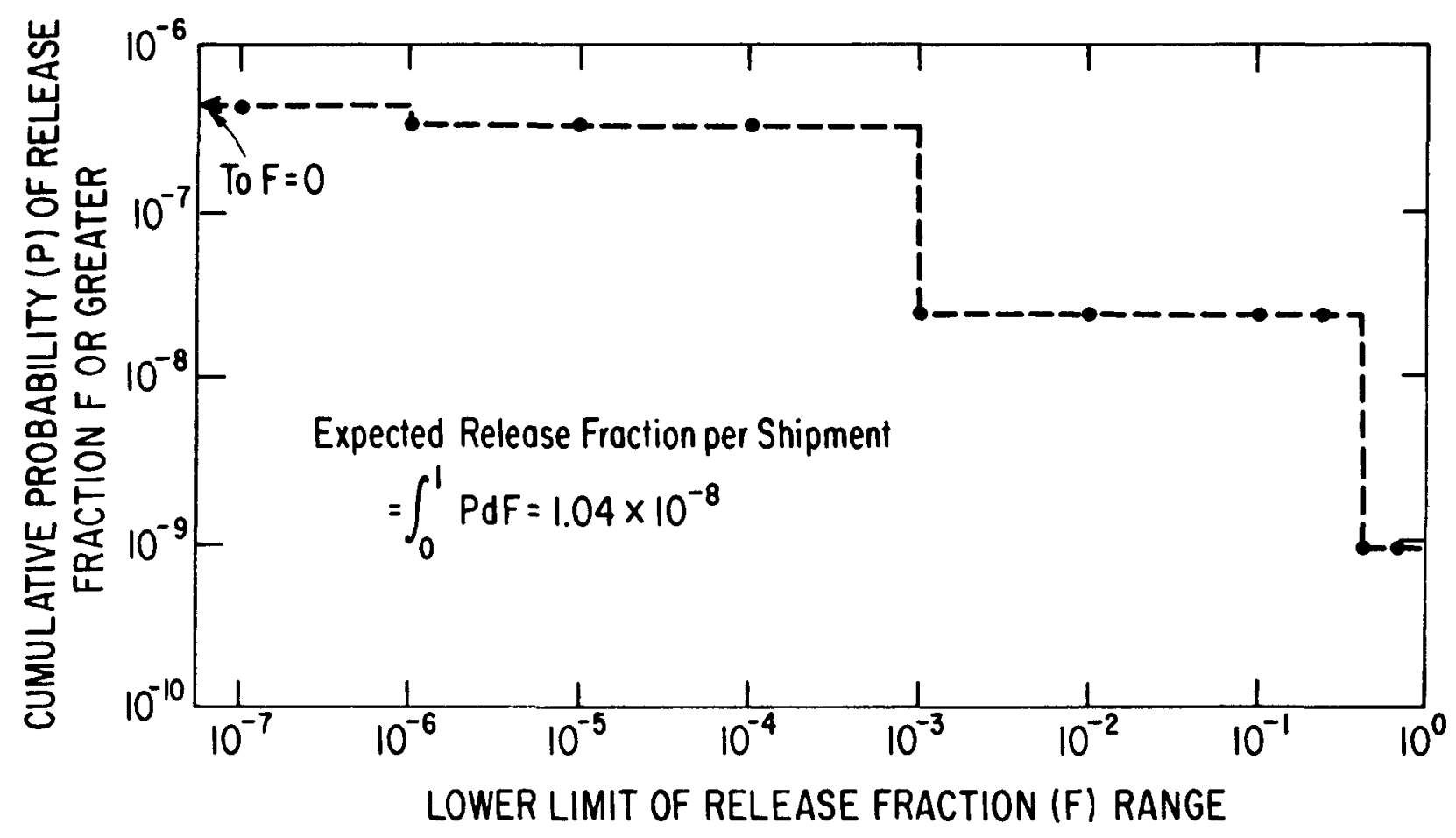

Fig. 8.1. Accident Source Term of Plutonium Oxide Shipment Expressed as Cumulative Probability (per shipment) ws. Release Fraction 
"If criticality occurs, the internal pressures generated within each container could rupture the containers. Based on the results presented in sections 7.0 and 9.0 , criticality would not be an initiating event. However, events and conditions following a severe accident in which plutonium is released could result in criticality. Nevertheless, the necessary events and conditions for criticality to occur are so limited that this stress should not significantly contribute to the risk levels.

"The crush environment of the L-10 [container] requires more detailed analysis because in accidents involving extreme decelerations, multiple containers could fail by drum lid removal. Since Sandia estimates that about $1 / 3$ of the cargo could be 1 ost in $6.8 \%$ of all accidents, more than one failed container would likely be removed from the truck in this case. Failed containers which lose vermiculite when removed from the truck are then susceptible to releasing plutonium if a fire occurs after the accident.

"The detailed evaluation of the crush environment is presented in Appendix J. The results of this supplemental evaluation are shown in Fig. 11.5 [not shown]. The evaluation presented in section 11.2 assumed that only one container failed in an accident but at an accident frequency multiplied by the number of containers in the shipment. This assumption is nonconservative by about a factor of 3 at the high consequence end of the risk spectrum, but conservative by about the same factor at the low consequence end. Since this crush-fire sequence is just one sequence out of many that determines the risk spectrum for a nitrate shipment, the overall effect of assuming individual container failures is less than the difference shown in Figure. . . Therefore, it is believed that the inclusion of multiple container failure data would not seriously distort the risk spectrum obtained from individual container failure analysis." 8

The information desired for this report is the expected release fraction of plutonium for a shipment. This is obtained by appropriate integration of the data shown in Fig. 8.1 (for shipment of plutonium oxide).*

Expected Release Fraction $=\int_{0}^{1} \mathrm{FdP}=\int_{0}^{1} \mathrm{PdF}$

where

$$
\begin{aligned}
P= & \text { cumulative probability of release fraction } F \text { or greater } \\
F= & \text { release fraction (lower limit) specific to the correspond- } \\
& \text { ing } P
\end{aligned}
$$

The integration was performed using the dashed curve of Fig. 8.1. The expected release fraction per shipment was found to be $1.04 \times 10^{-8}$. If the data furnished by the authors is connected by straight lines and the integration is repeated, the expected release fraction per shipment is reduced by about 15 percent. Note that in the release fraction range from 0 to $10^{-7}$, a cumulative probability of $4.3 \times 10^{-7}$ was assumed. The contribution of this low range of release fraction to the expected total release fraction is very small and hence is insensitive to the detailed assumptions used.

* Discussion of this integration appears in Appendix $B$. 
of possible interest is the expected release fraction per accident. The authors of the PNL report reviewed accident frequency data for the shipment of hazardous materials and determined that the value is about $2.5 \mathrm{x}$ $10^{-6}$ truck accidents per mile or 250 per $100,000,000$ miles. This translates into an accident frequency of $3.8 \times 10^{-3}$ for the reference 1500 -mile plutonium shipment or 1 accident for every 263 shipments. The expected release fraction per accident for oxide is thus $\left(1.04 \times 10^{-8}\right) /\left(3.8 \times 10^{-3}\right)=2.7 \times 10^{-6}$. This fraction is to be applied to $1.00 \mathrm{~kg} \mathrm{Pu}$ in the reference shipment.

The comparable computation for the shipment of plutonium in the nitrate form yields an expected release fraction of $3.8 \times 10^{-8}$ per shipment and $1 \times 10^{-5}$ per accident; this is about four times higher than that for oxide.

The expected release fraction per shipment for plutonium in the oxide form is somewhat greater than the expected release fraction from fabrication plants for currently applied technology and is equivalent to that for reprocessing plants. It should be noted, however, that the analysis was made for a very specific shipping model based on current designs and practices, and no advancements in technology were considered. No efforts were made for this report to estimate possible reductions of releases as a result of advancing technology.

It should also be noted that in this estimate of the plutonium source term for shipping, no effort was made to differentiate types of plutonium releases relative to potential radiological hazard. Releases that involve dispersal to the atmosphere as an aerosol are considerably more significant radiologically than releases in which oxide is simply spilled onto a highway pavement. The PNL report does take into account dispersal mechanisms in arriving at risk spectra in which the consequences are measured as fatalities.

\subsection{AEC Generic Environmental Statements}

\subsubsection{Environmental Survey of the Nuclear Fuel Cycle ${ }^{10}$}

This survey assesses the environmental impact of the currently predominant nuclear fuel cycle for uranium-fueled light water reactors (LWR-U). The portions of the cycle that contain plutonium are shipment of spent fuel, reprocessing and conversion, shipment, and waste management. The environmental discharges were normalized for a 1000-MWe model LWR-U having a plant load factor of $80 \%$. Losses of fuel were assumed to be $1 \%$ each for fabrication and processing.

The summary table shows a release of $4 \mathrm{mCi}$ (presumably $\alpha$ plus $\beta$ ) of transuranic elements as gases for the entire cycle, and none as liquids. Since the model LWR-U produces $0.8 \mathrm{GW}(\mathrm{e})-\mathrm{yr}$ of electrical energy per year, this release corresponds to $5 \mathrm{mCi} / \mathrm{GW}(\mathrm{e})-\mathrm{yr}$. All releases arise from reprocessing operations.

Five significant accidents having potential serious consequences were identified: criticality, ion-exchange resin fire, leak in the $\mathrm{UF}_{6}$ loadout system, leak in storage pool cooler, and rupture of a fuel assembly. Release of plutonium was considered only for the ion-exchange fire. A total plutonium content of $3840 \mathrm{~g}$ was assumed to be involved, and the off-gas treat- 
ment system (not described) was assumed to pass $10^{-b}$ of the plutonium. Thus the plutonium release is given as $38.4 \mathrm{mg}$ or about $26 \mathrm{mCi}(\alpha)$. Since the mode 1 reprocessing plant has the capacity to serve 26 LWR-Us, this corresponds to $1 \mathrm{mCi}(\alpha)$ per $\mathrm{LWR}-\mathrm{U}$. The $\mathrm{PuO}_{2}$ release was considered to be in the insoluble form.

Transportation of spent fuel and of high-level waste was considered; no plutonium releases were identified. Transportation of refined plutonium from the reprocessing plant was not considered.

\subsubsection{Generic Environmental Statement Mixed oxide Fuel (GESMO) ${ }^{11}$}

The GESMO statement does hot analyze the environmental effects of LWR-Pus per se but generically treats a reference mixture of LWR-Us and LWR-Pus that is likely to exist in 1990 on the assumption that plutonium recycle is introduced in the next few years. Prior to and during the year 1990 , the fraction of reactors being fueled with plutonium is assumed to be gradually increasing. Because fuel is in a reactor for up to four years, the fraction of reactors that will be discharging mixed-oxide assemblies in the year 1990 will be less than the fraction of reactors for which mixed-oxide assemblies are being fabricated.

To enable the reviewers to properly allocate plutonium discharges to either LWR-Pus or LWR-Us, they have calculated from GESMO data the fraction of reactors operating in the LWR-Pu mode.

The report states that at equilibrium, the reference LWR-Pu contains $40 \%$ of mixed-oxide assemblies. Furthermore, the total weights of fuel in mixed oxide and in all assemblies charged to the system in 1990 are calculated to be $1500 \mathrm{MT}$ and 13,800 MT, respectively. Thus, $10.9 \%$ of assemblies fabricated are mixed oxide, which is $27.2 \%$ of the $40 \%$ reached at equilibrium. Hence, it is concluded that $27.2 \%$ of the then-existing reactors (430 1000-MW(e) reactors) are being fueled in the recycle mode. The balance continue to operate as LWR-Us.

The analysis of spent fuel discharges ( $8800 \mathrm{MT}$ ) indicates that in 1990, 273 reactors will in fact be discharging fuel. Presumably, the difference between 430 and 273 will represent reactors that will have gone on stream in the preceding four years but are not yet discharging fuel. Two hundred seventy-three reactors operating only in the $L W R-U$ mode would discharge $53,000 \mathrm{~kg}$ of fissile plutonium. Two hundred seventy-three reactors operating solely in the LWR-Pu mode would discharge 8800 MT $\times 0.01059$ (fraction fissile Pu) $=93,200 \mathrm{~kg}$ of fissile plutonium. The actual stated discharge (in 1990) of $62,000 \mathrm{~kg}$ of fissile plutonium indicates that about $22.4 \%$ of the reactors are discharging fuel characteristic of an equilibrium LWR-Pu. These factors need to be considered in evaluating the environmental effects associated with LWR-Pus.

The reference mixed-oxide fuel fabrication plant for GESMO has an annual production rate of $300 \mathrm{MT} / \mathrm{yr}$. Since the fuel for a LWR-Pu (at equilibrium) consists of $40 \%$ of mixed-oxide fuel, the $300 \mathrm{MT}$ produced is ultimately charg-d to a reactor with an additional $450 \mathrm{MT}$ of slightly enriched uranium fuel for a total of 750 MT. The latter quantity [using a burnup value of 33,000 MW(t)d/MT and a reactor thermal efficiency of $32 \%$ ] will ultimately generate $21.7 \mathrm{GW}(\mathrm{e})$-yr of electrical energy. 
The stated normal environmental discharges for the eight $\mathrm{MO}_{\mathrm{x}}$ fuel fabrication plants required for the industry in 1990 is $2.2 \mathrm{mCi}(\alpha) / \mathrm{yr}$ as gaseous effluent and $3.3 \mathrm{mCi}(\alpha) / \mathrm{yr}$ as liquid $[276 \mu \mathrm{Ci}(\alpha) / \mathrm{yr}$ and $414 \mu \mathrm{Ci}(\alpha) / \mathrm{yr}$ respectively, for each plant]. This is equivalent to $12.7 \mu \mathrm{Ci}(\alpha)$ and 19.0 $\mu \mathrm{Ci}(\alpha)$ for gas and liquid discharges respectively for each GW(e)-yr of electrical energy produced.

The basis for the gaseous discharge value is an extrapolation of the experience of Westinghouse at its Cheswick facility. The release rate was obtained by multiplying the release rate at Cheswick, $11 \mu \mathrm{Ci}(\alpha) / \mathrm{yr}$, by the ratio of specific activities $[0.7 \mathrm{Ci}(\alpha) / \mathrm{g}$ at the GESMO reterence facility and $0.09 \mathrm{Ci}(\alpha) / \mathrm{g}$ at Cheswick] and by the ratio of exhaust air flows $(45,000 \mathrm{cfm}$ at the GESMO facility, and $14,000 \mathrm{cfm}$ at Cheswick). The assumption is that the gaseous effluent at the GESMO reference facility will be as clean as that at Cheswick. On the basis that the $300 \mathrm{MT}$ of production contains $1.82 \%$ plutonium, the fractional release to the stack is $7.2 \times 10^{-11}$ or a reduction factor of $1.4 \times 10^{10}$.

The GESMO report describes the reference ventilation system. All air supplied to the building passes through one stage of HEPAs, and air supplied to process enclosures passes through an additional stage. Gases from process enclosures pass through a total of three stages of HEPAs, one of them at the enclosure, the other two just upstream of the discharge stack. Building air exhausts through the latter two stages of HEPAs. This system, as described in the GESMO report, is comparable to that proposed by Westinghouse for its Anderson, South Carolina, production facility. ${ }^{12}$

The plutonium discharge in liquid streams is obtained by estimating the volume of contaminated liquid expected to be produced in the GESMO reference plant, and assuming that such liquid will be processed in a manner to obtain a plutonium concentration of $10 \%$ of that stated in 10 CFR Part 20 . The volume of contaminated liquids is estimated as $500 \mathrm{gal} / \mathrm{day}$.

GESMO considers three types of serious accidents for the $\mathrm{MO}_{\mathrm{x}}$ fuel fabrication facility, all of them stated to be unlikely to occur: criticality, a fire, and an explosion. The number of fissions in a criticality accident is estimated to be $10^{18}$; $500 \mathrm{~g}$ plutonium is assumed to become airborne in the glove box where it occurs. The filters are assumed to remain intact, and a reduced efficiency of $10^{-9}$ (penetration fraction) is taken as reasonable. Thus, $0.50 \mu \mathrm{g}$ or $0.35 \mu \mathrm{Ci}(\alpha)$ of plutonium would be released.

A major fire is assumed to destroy the HEPA filters located locally at the glove boxes affected. The remaining two HEPA stages, each assumed to be operative with an efficiency of $99.9 \%$, are protected from fire by incorporating a water spray system in the design. One hundred grams reaches the filters (plutonium loading in air is taken as $100 \mathrm{mg} / \mathrm{m}^{3}$ in a room volume of $1000 \mathrm{~m}^{3}$ ), and thus $100 \mu \mathrm{g}$ or $70 \mu \mathrm{Ci}(\alpha)$ is discharged to the stack.

The explosion considered could occur at the sintering furnace, at the clean scrap reduction operation, at the dirty scrap recycle operations, or at locations where combustible material has accumulated. The effects described are comparable to those for a fire: one set of HEPAs damaged, and $100 \mathrm{~g}$ of plutonium reaching the remaining two stages of filtration. 
If each of these major accidents occurred once a year in each reference plant (this is strictly a supposition and not an estimate), $140 \mu \mathrm{Ci}(\alpha)$ would be discharged over and above that discharged in norma1 operations. This corresponds to $6.4 \mu \mathrm{Ci}(\alpha) / \mathrm{GW}(\mathrm{e})-\mathrm{hr}$ of energy produced.

The reference processing plant will handle $1500 \mathrm{MT} / \mathrm{yr}$ of fuel of which $11 \%$ will consist of mixed-oxide fuel in 1990 . The plant processes include solvent extraction processing for the separation and recovery of urany 1 nitrate, plutonium nitrate, and fission products; conversion of the uranium stream to uranium hexafluoride; conversion of the plutonium stream to oxide; and solidification of the high-level fission product stream. GESMO states that the normal plutonium content of the gaseous effluent is expected to be 1.53 $\mathrm{mCi}(\alpha) / \mathrm{yr}$ compared with $1 \mathrm{mCi}(\alpha) / \mathrm{yr}$ if the plant were handling only LWR-U fuel. If the plant were processing only fuel from equilibrium LWR-Pu's, $40 \%$ of the fuel would be mixed oxide. By use of ratios, the discharge would be 2.93 $\mathrm{mCi}(\alpha)$ for total operation in the LWR-Pu mode. This corresponds to $27 \mu \mathrm{Ci}(\alpha) /$ GW(e)-yr of energy produced.

The fraction of plutonium processed that is released is $1.6 \times 10^{-10}$ for a reduction factor of $6.4 \times 10^{9}$.

The reference processing plant discharges no radioactive liquids to the environment.

Three principal major accidents were considered: criticality, waste concentrator explosion, and plutonium concentrator explosion. For the first two, no reference was made to plutonium releases. For the last, 13.5 $\mathrm{mCi}(\alpha)$ of plutonium penetrate the filters for the reference plant. If it is taken into account that the reference plant handles $11 \%$ mixed-oxide fuels (where $40 \%$ is the equilibrium value for an LWR-Pu) and that the same explosion would release $9.1 \mathrm{mCi}(\alpha)$ for uranium fuels, the release for LWR-Pus would be $25.1 \mathrm{mCi}(\alpha)$. For one such explosion per year, the incremental discharge (above that for normal operations) would be $231 \mu \mathrm{Ci}(\alpha) / G W(e)-y r$ of energy produced.

The transport of plutonium in the ex-reactor fuel cycle occurs in the forms of: irradiated spent fuel to the processing plant, oxide to the mixed-oxide fabrication plant, and fresh fabricated fuel to the reactor. Because of regulations that app1y to shipping packages, closures, and qualitycontrol requirements, the GESMO report regards releases of plutonium during shipment as negligible.

\subsubsection{AEC Generic Statement for LMFBR Program ${ }^{13}$}

\subsubsection{Fuel Fabrication}

The reference fuel fabrication plant produces a total of $5 \mathrm{MT} /$ day which includes about $2.54 \mathrm{MT}$ of mixed oxide for the LMFBR core, 1.75 MT of uranium oxide for the axial blanket, and 0.7 MT of uranium oxide for the radial blanket. The two compositions are fabricated in separate sections of the plant, but finished fuel elements are brought together for final assembly as required. This study is only concerned with those portions of the plant in which plutonium is present. Average burnup in the associated LMFBR is 37,100 Mwd/MT of total discharge (core, axial blanket, and radial blanket). 
The ventilation system for the mixed-oxide portion of the plant provides three stages of HEPA filtration for effluents from process containment (one stage at or near the glove box, plus two stages upstream of the discharge to the stack) and two stages of HEPA filtration from working and other building areas. Based on supplementary information provided in the report, $0.1 \%$ of the material processed becomes airborne and reaches the inlet face of the first stage of HEPA filters. Each stage of HEPA filters is considered conservatively to be $99.9 \%$ efficient. Thus the fraction of plant material that is discharged from the plant through the process system off-gas is $10^{-12}$. Similarly, the fraction of material that becomes airborne into working areas is estimated as $10^{-6}$. Two additional stages of HEPA filtration reduce this fraction to $10^{-12}$.

The rationale for arriving at the value of $0.1 \%$ of the plutonium processed that reaches the filters is as follows: Three particularly dusty operations have been identified, of which ball milling is judged the worst. At the time of charging and discharging of the ball mill with an $11.3-\mathrm{kg}$ batch of $\mathrm{PuO}_{2}$, dust loading of the surrounding air is assumed to reach $100 \mathrm{mg}$ of $\mathrm{PuO}_{2}$ per cubic meter, a level that is judged the maximum for heavy particlates. The glove box, which has a volume of $200 \mathrm{ft}^{3}$, is exhausted at the rate of $13 \mathrm{cfm}$. The dusty condition is estimated to last $20 \mathrm{~min}$. The fraction of $\mathrm{PuO}_{2}$ that becomes airborne from the single glove box is thus estimated to be $10^{-4}$. The roughing filter preceding the first HEPA stage removes about $90 \%$ of the suspended particles; as a result, the fraction reaching the HEPA is $10^{-5}$. Three similar dusty operations plus miscellaneous sources of dust increase the estimated total fraction to $4 \times 10^{-5}$. For conservatism, the fraction of $10^{-3}$ was used in the computations.

$149 \mu \mathrm{g} / \mathrm{yr}$ or $104 \mu \mathrm{Ci}(\alpha) / \mathrm{yr}$.

This analysis results in a plutonium discharge of about

Contaminated liquids are impounded for sampling and analysis. If results exceed the limits in 10 CFR Part 20 for unrestricted releases, the liquid is either processed (e.g., by evaporation or ion exchange) or incorporated into a solid matrix (e.g., concrete). If the concentrations are below the limits, the liquid is released to the environment. An estimated $1000 \mathrm{gpd}$ thus released will contain a maximum of about $10 \mu \mathrm{Ci}(\alpha)$. If this is done daily, the accumulated value will be $3570 \mu \mathrm{Ci}(\alpha) / \mathrm{yr}$.

Three types of major accidents are identified: hydrogen explosion in scrap recovery operations, criticality, and a general facility fire. Each is assumed to destroy the integrity of the HEPA filter at the process enclosure. The remaining two HEPAs are protected from heat and fire debris by water sprays, and it is assumed that they continue to function. Estimated release are listed below:

$\begin{array}{ll}\text { Accident } & \text { Estimated Release }[\mu \mathrm{Ci}(\alpha)] \\ \text { Explosion } & 29.3 \\ \text { Criticality } & 176 \\ \text { Facility Fire } & 3722\end{array}$




\subsubsection{Fue1 Reprocessing}

The reference processing plant for LMFBR fuels handles $5 \mathrm{MT} /$ day of combined core and blanket fuel. The off-gas system is fairly complex and requires absorbers and scrubbers for the removal of $\mathrm{NO}_{2}, \mathrm{I}_{2}$, and other constituents. The air-cleaning system for particulate removal from process off-gases consists of two stages of HEPAs plus a sand filter. The HEPAs are considered to be $99.9 \%$ efficient and the sand filter to be $99 \%$ efficient. The fractional penetration through the filtration system is thus $10^{-8}$. The fraction of plant material estimated to become airborne is $10^{-4}$. Thus a total fractional penetration of $10^{-12}$ is estimated. For purposes of the reference plant, this fraction was increased to $2 \times 10^{-10}$ for two reasons: (1) the aerosol particle size is expected to be much smaller than that generated in a fabrication plant, and (2) some degradation of filter media is possible due to chemical reaction with residual nitric acid in off-gases. On this basis, a normal annual plutonium discharge rate of $30,000 \mu \mathrm{g}$ or $21,000 \mu \mathrm{Ci}(\alpha)$ is estimated.

Serious accidents involving plutonium were identified and analyzed. At the time of an accident, it was assumed that the two stages of HEPAs were degraded to yield a fractional penetration of $3.6 \times 10^{-5}$ instead of $10^{-6}$. On this basis, estimated releases were as follows:

Accident

Pipe break of line containing dissolver solution

Facility Fire

Criticality

Waste Evaporator Explosion

Plutonium Evaporator Explosion

\section{Plutonium Released $[\mu \mathrm{Ci}(\alpha)]$}

1008

110

0.076

\subsection{Allied Gulf Nuclear Fuel Processing Plant, Barnwe11, S.C.}

This processing facility has a nominal capacity of $1500 \mathrm{MT} / \mathrm{yr}$ of fuel containing up to $12,800 \mathrm{~kg}$ plutonium. The off-gas treatment for this plant is relatively complex. 14 The principal process off-gases are treated for acid removal and ultimately are passed through an iodine scrubber (identified as No. 2), a heater, a prefilter (consisting of a rough filter and a final filter not identified as a HEPA), an iodine absorber, and two stages of HEPAs. The stated release rate of plutonium to the environment is $1.631 \times 10^{-10} \mathrm{Ci} / \mathrm{sec}$ [5143 $\mu \mathrm{Ci}(\alpha) / \mathrm{yr}$, which corresponds to a release fraction of $5.7 \times 10^{-10}$ based on a total plutonium content of $0.86 \%$ at discharge and a specific activity of $0.7 \mathrm{Ci} / \mathrm{g}$. No detailed analysis is presented of plutonium penetrations through various stages of the gas-cleaning equipment. The $A E C$, in preparing its independent environmental analysis, 15 arrived at the same leve1 of particulate discharge.

The applicant considered a series of serious accidents, calculating the plutonium discharges for each accident, but did not show the bases for the calculations. These are listed below:

$$
\text { Accident } \quad \text { Plutonium Release }[\mu \mathrm{Ci}(\alpha)]
$$

Solvent Fire:

Plutonium Cycle

17,813

Codecontamination Cycle 
$\begin{array}{lr}\text { Explosion: } & 24.4 \\ \text { HAW Concentrator } & 1.8 \\ \text { LAW Concentrator } & 12,268 \\ \text { Pu Product Concentrator } & -- \\ \text { Criticality } & 33.8 \\ \text { Loss of Decontamination in } \\ \quad \text { Acid Recovery and Waste Treatment }\end{array}$

8.8. Summary of Source Terms Data

Information on plutonium releases from the several environmental reports presented in the preceding sections is given in Table 8.6.

Table 8.6. Summary of Source Term Data from Environmental Reports

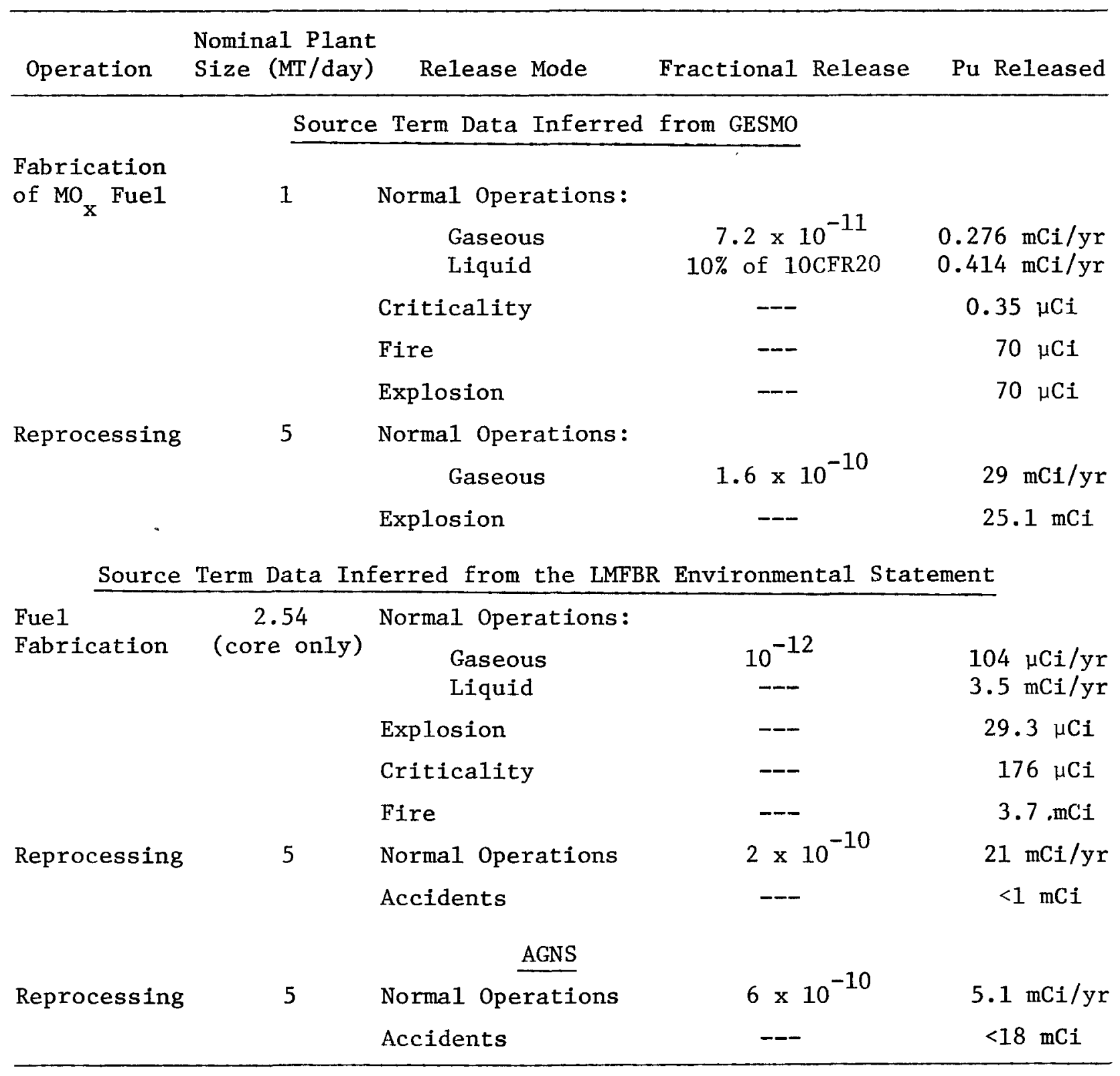


References for Section 8

1. W. E. Unger, E. V. Browder, and S. Mann, Nuc1. Saf. 12(3), 234-246 (May-June 1971).

2. D. C. Hunt, The Restricted Release of Plutonium--Part 1. Observational Data, Nucl. Saf. 12(2), 85-89 (March-April 1971).

3. D. C. Hunt, The Restricted Release of Plutonium--Part 2. Theory, Nuc1. Saf. 12(3), 203-216 (May-June 1971).

4. C. E. Guthrie and J. P. Nichols, Theoretical Possibilities and Consequences of Major Accidents in ${ }^{23}{ }^{3} \mathrm{U}$ and $23{ }^{2} \mathrm{Pu}$ Fuel Fabrication and Radioisotope Processing Plants, Oak Ridge National Laboratory Report, ORNL-3441 (April 1964).

5. H. T. Williams et $a$., Safety Analysis of Enriched Uranium Processing, Convair Report, NYO-2980, March 1960.

6. Siting of Fuel Reprocessing P1ants and Waste Management Facilities, Compiled and Edited by the Staff of Oak Ridge National Laboratory, Oak Ridge National Laboratory Report, ORNL-4451 (July 1970).

7. J. M. Selby et al., Considerations in the Assessment of the Consequences of Effluents from Mixed Oxide Fuel Fabrication Plants, Battelle Northwest Laboratory Report, BNWL-1697, Rev. 1 (June 1973).

8. T. I. McSweeney et al., The Risk of Transporting Plutonium Oxide and Liquid Plutonium Nitrate by Truck, Battelle Northwest Laboratory Report, BNWL-1846 (August 1975).

9. T. I. McSweeney, Battelle Northwest Laboratory, Personal communication, January 1976.

10. Environmental Survey of the Nuclear Fuel Cycle, prepared by the U.S. Atomic Energy Commission, Directorate of Licensing, Fuels and Materials, Report WASH-1237 (November 1972).

11. Generic Environmental Statement on the Use of Recycle Plutonium in Mixed Oxide Fuel in LWR's, U.S. Atomic Energy Commission Report WASH-1327 (August 1974).

12. Recycle Fuels Plant Environmental Report, prepared by Westinghouse Electric Company, DOCKET-70-1432.

13. Environmental Statement for LMFBR Program, WASH-1535 (1974).

14. Final Safety Analysis Report, Barnwe11 Nuclear Fuel P1ant, prepared by Allied-Gulf Nuclear Services, DOCKET-50-332.

15. Environmental Statement Related to Construction and Operation of Barnwe11 Nuclear Fuel Plant, Allied-Gulf Nuclear Services, prepared by the Staff of the Directorate of Licensing, Fuels, and Materials, U.S. Atomic Energy Commission (January 1974). 
9. CONSTRUCTION OF SOURCE TERM MODELS FOR REFERENCE FUEL CYCLES

\subsection{Ventilation Design and General Filter Characteristics}

Design criteria for ventilation systems in radiochemical plants include maintenance of directional ventilation flow (air) from areas of low contamination to areas of high contamination and flow of air from high contamination areas through air cleaning systems prior to discharge or recycle. Directional flow within the plant is required to ensure the safety of operating personnel. Directional flow through air cleaning systems ensures that the levels of contamination discharged to the environment are acceptable.

Air cleaning systems such as scrubbers or several types of filters are employed for modest-size glove box facilities, as well as for the ventilation streams of large plants. The present interest is restricted to fiber filters such as HEPA filters since these are the most commonly employed means for the efficient cleaning of ventilation streams. Commercially available HEPA filters are available in several sizes, the largest of which in common use has a nominal capacity of $1000 \mathrm{cfm}\left(28.3 \mathrm{~m}^{3} / \mathrm{min}\right)$ and is $24 \mathrm{in.} \times 24 \mathrm{in}$. $x 11.5$ in. deep $(61 \mathrm{~cm} \times 61 \mathrm{~cm} \times 29 \mathrm{~cm})$. Air flow at $1000 \mathrm{cfm}$ results in a pressure drop across the clean filter of 1 in. of water $\left(249 \mathrm{~N} / \mathrm{m}^{2}\right)$. Greater pressure drop is tolerated in service with the potential for reduction in flow, depending on the characteristics of the air-moving system.

The efficiency of HEPA filters is relatively insensitive to temperature and humidity but is related to particle size of the impinging aerosol and, to some extent, on the filter loading. The fractional penetration of a filter by aerosol particles ( 1 - efficiency) is decreased by filter loading. Tests of HEPA filters indicate a generally achieved maximum penetration of $10^{-4}$, and quality control acceptance standards are set at $3 \times 10^{-4}$. The standard test of penetration uses a nearly monodisperse $0.3-\mu \mathrm{m}-\mathrm{dia}$ 1iquid aerosol of DOP (dioctyl phthalate); this size of aerosol is very close to that for which penetration is a maximum. As indicated in Section 7, penetration of a series of HEPA filters is approximated by the product of the individual filter penetrations. Hence, for three filters, each with $\mathrm{p}=3 \times 10^{-4}$, the calculated penetration is $27 \times 10^{-12}$.

The HEPA filter, although unaffected by the normal variations in ambient conditions, is subject to destruction by pressure pulses (blast), extreme heat, and chemicals that attack the filters. These agents will result in destruction of the filters and dispersion of the contained contamination and will result in a loss of cleaning capability for air subsequently introduced into the system.

Filtration of ventilation air is the most important factor determining the attributes of contamination discharged to the environment. Particle size distributions and concentrations of contaminating aerosols will be determined largely by the properties of filters as installed in ventilation systems. For these reasons, estimates of contamination resulting from operation of nuclear plants require the identification of properties of HEPA filters as a reference. These properties are discussed in the next section. 


\subsection{Basic Ventilation Design}

\subsubsection{Introduction}

Ventilation design has the general objective of controlling air flow so that the appropriate air purity is maintained in specific zones. This is usually accomplished by arranging for a supply of fresh incoming air and by the treatment and discharge of contaminated air. Our concern is with three zones: the zones occupied by operating personnel, the zone with the source contamination, and the atmosphere zone to which the ventilation exhaust is discharged. The basic ventilation pattern concerns the direction of air flow through these zones and the provision of means of controlling the direction, flow quantity, and purity of air passing from one zone to the next.

\subsubsection{Glove Box Configuration}

The direction of flow in a glove box is maintained by the source of differential pressure, the blower.

In the process zone, which is the source of most contamination, a separate atmosphere-cleaning system may be used in a recycle mode, independent of the between-zones flow. Such systems are used in "clean rooms" where production processes require a very clean environment, especially free from contamination by dust. Filters and scrubbers are used in such recycle systems. Recycle cleaning systems are not in principle different from exhaust cleaning systems, except that performance is optimized for the processing environment rather than for the external atmosphere (as is the case with exhaust systems). The recycle system affects, and usually benefits, the exhaust cleaning system by reducing the direct load of contaminant.

In general, it is very difficult and costly to remove completely all chemical contamination in a recycle cleaning system. However, in the case of noxious contamination, the possibilities of external recycle of exhaust air to the inlet supply and the standard of contamination of the atmosphere environment may require very stringent exhaust cleanup and may also make internal recycle cleanup desirable.

\subsubsection{Removal of Contaminants from Air in AEC Filters}

The removal of contamination in either recycle or exhaust systems requires separation of the contaminants from the air. Of the two major separation processes, wet scrubbers and dry filters, we will confine our attention to filters of the modular fiber type, namely, the HEPA filter. One of the largest of the standard sizes of HEPA filters has a rating of $1000 \mathrm{scfm}$ and has overall dimensions of 24 in. $\times 24$ in. $\times 11$ 1/2 in. deep. Since there is no way of cleaning the HEPA filter unit itself, it must be replaced periodically.

The efficiency of HEPA filters is insensitive to air temperature, humidity, and barometric pressure in the practical range. The performance of the filter is measured in terms of its efficiency of collection. Fractional penetration, $p$, of the filter is related to efficiency as follows:

$$
p=1-\text { Efficiency }
$$


The penetration $\mathrm{p}$ may be thought of as the probability of a single particle penetrating through the filter. Penetration is a function of particle diameter and velocity through the filter, but is normally independent of particle concentration. HEPA filters do not function in a water-saturated environment ( $i . e .$, wet) and are not resistant to certain chemicals (e.g., HF) that attack the glass or asbestos constituents of the filter. For solid airborne particles, $p$ is not increased by higher filter loadings, although overall filtration is affected by increases in pressure drop (pressure drop increases with higher loadings).

Quality assurance uses a penetration of $3 \times 10^{-4}$ as an acceptance point for HEPA filters. These tests are with a standard (nearly) monodisperse $0.3-\mu \mathrm{m}$ liquid aerosol (dioctyl phthalate). ${ }^{1}$ It is known that the particle diameters for which $\mathrm{p}$ is a maximum are in the approximate range of 0.1 to $0.5 \mu \mathrm{m}$.

The loading on the second filter in a series is expected to be lower by a factor of $\mathrm{p}$, $i . e$, of the order of $3 \times 10^{-4}$, than the loading for the first filter when both have been in service for the same duration. If the initial filters have to be replaced every month, it is calculated that the second filters will require replacement every $275 \mathrm{yr}$.

Because of the high cost of filter replacement required as a result of loading, it is reasonable to take steps to avoid unnecessary loading due to contaminated inlet air or extraneous dust production within the process system. Inlet filters and prefilters are commonly employed.

\subsubsection{Safety and Other Considerations}

The standard HEPA filter can be damaged by pressure pulses, extreme heat, or corrosive chemicals. Thus, fire and explosion are capable of destroying the filter system and causing the release of some of the contaminants already deposited on the filter. This hazard is mainly controlled by preventive means. Also, the use of fire or pressure dampers for filter protection are possible design features.

\subsection{Reference Penetration Data for HEPA Filters}

The mechanisms by which particles contained in an aerosol are removed during passage through a fiber filter medium have been described in Section 6 . The effectiveness of the three principal mechanisms--inertial impaction, thermal diffusion, and flow interception--are dependent on particle size, density, and geometry; the nature of the filter medium (fiber size, spacing, etc.); and the velocity and temperature of the carrier gas through the filter medium. The behavior of aerosols within a filter is such that for fixed physical conditions of the filter and the flow, the fraction of particles penetrating is a function of particle size; there is a moderately narrow range of particle sizes for which penetration is maximum. This range of size has been found to be from about $0.1 \mu \mathrm{m}$ to $0.5 \mu \mathrm{m}$, depending on values of the parameters.

Data on experimental measurements of penetrations of HEPA filters at LASL by aerosols of ${ }^{238} \mathrm{PuO}_{2}$ were presented in Section 7 . These results have been used for the preparation of reference data for this review. 
The data in Table 7.5 show revised data from LASL that reflects average penetrations from all runs they've made, including data from a set of runs in which filters that had lower efficiencies were deliberately selected for stage 1. The purpose, as stated in Section 7, was to increase the penetration of the first stage and thereby obtain better counting statistics for the stage 3 HEPAs. Hence, the LASL data for stage 1 shows a bias in the direction of increased penetration. The reviewers analyzed the data for the biased runs separately from the data for all other runs. These data are shown in Table 7.6. For this review, data that excluded the results from the biased runs were used as reference for the first stage. The revised LASL penetration data, together with that adopted as a reference for the first stage, are shown in Fig. 9.1. The general shapes of the two curves are comparable, although the decrease in penetration for very small particles $(<0.22 \mu \mathrm{m})$ is somewhat greater for the reference. For large particles, the reference curve passes through the scatter of points represented by LASL data but does not show an increase at large diameters.

For the second stage filters, the LASL data was adopted as the reference in the range covered by their data: $<0.12 \mu \mathrm{m}$ to $0.96 \mu \mathrm{m}$. For larger particles, the curve was extended in such a way that the slope of the extension was comparable to that obtained by the reviewers in the extended range. Both curves are shown in Fig. 9.2.

The revised LASL data did not include penetrations for the stage three HEPA's as a function of particle size. The sma11 amount of material deposited at each stage of the impactor did not yield good counting statistics. The best data for the overall performance of the stage three filters was that series of runs--P4-10, $-11,-15,-18$, and -19 (See Table 7.4)--in which the counting statistics were the best. The average penetration for these five runs was $560 \times 10^{-7}$. Fractional penetrations for the same five runs for the second stage HEPAs averaged $670 \times 10^{-7}$. Hence, the performances of the two stages were comparable. The reviewers have assumed that the penetration characteristics of the two stages (as a function of particle size) are comparable, and have adopted for reference the penetration curve of the second stage for the third stage as well.

For application in determining source terms, it was assumed that some degradation of efficiency would occur as a result of some leaks not eliminated during installation of the filters, and that degradation would occur because of chemicals or other factors. Where two stages were required, an overall degradation factor of $10^{2}$ was used for the fractional penetration and where three stages were required, an overall degradation factor of $10^{3}$ was used.

All reference data is shown in Table 9.1.

\subsection{Particle Size Distributions of Effluents}

In this section, the reference penetration data is applied to aerosols generated within processing and fabrication plants to determine the particle size distributions of effluents. These data can then be used in conjunction with the total plutonium content of effluents to establish the absolute quantities of effluent plutonium in any particle size range of interest. 


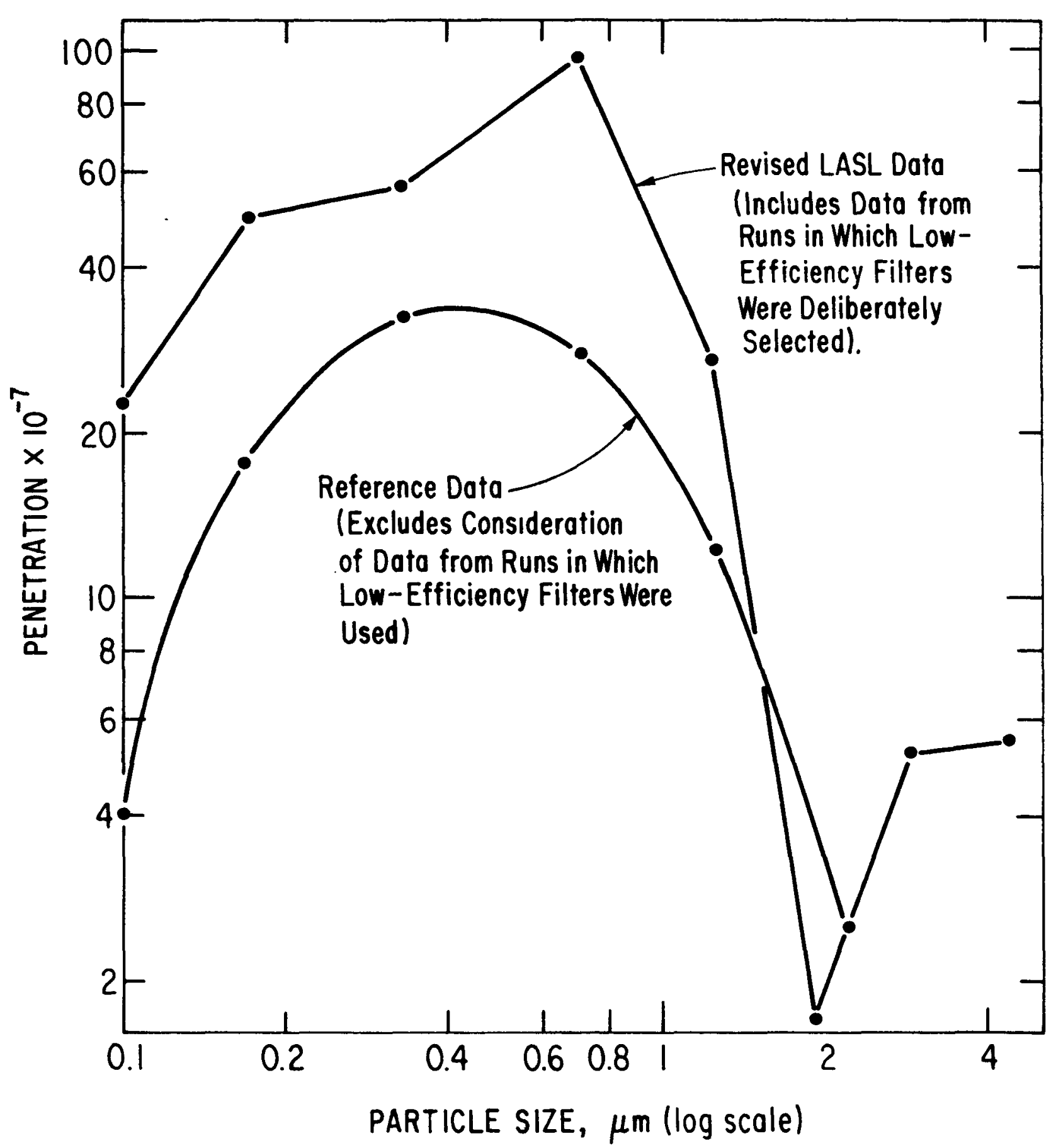

Fig. 9.1. Penetration Data for First-Stage HEPA

Filters Adopted for Reference 


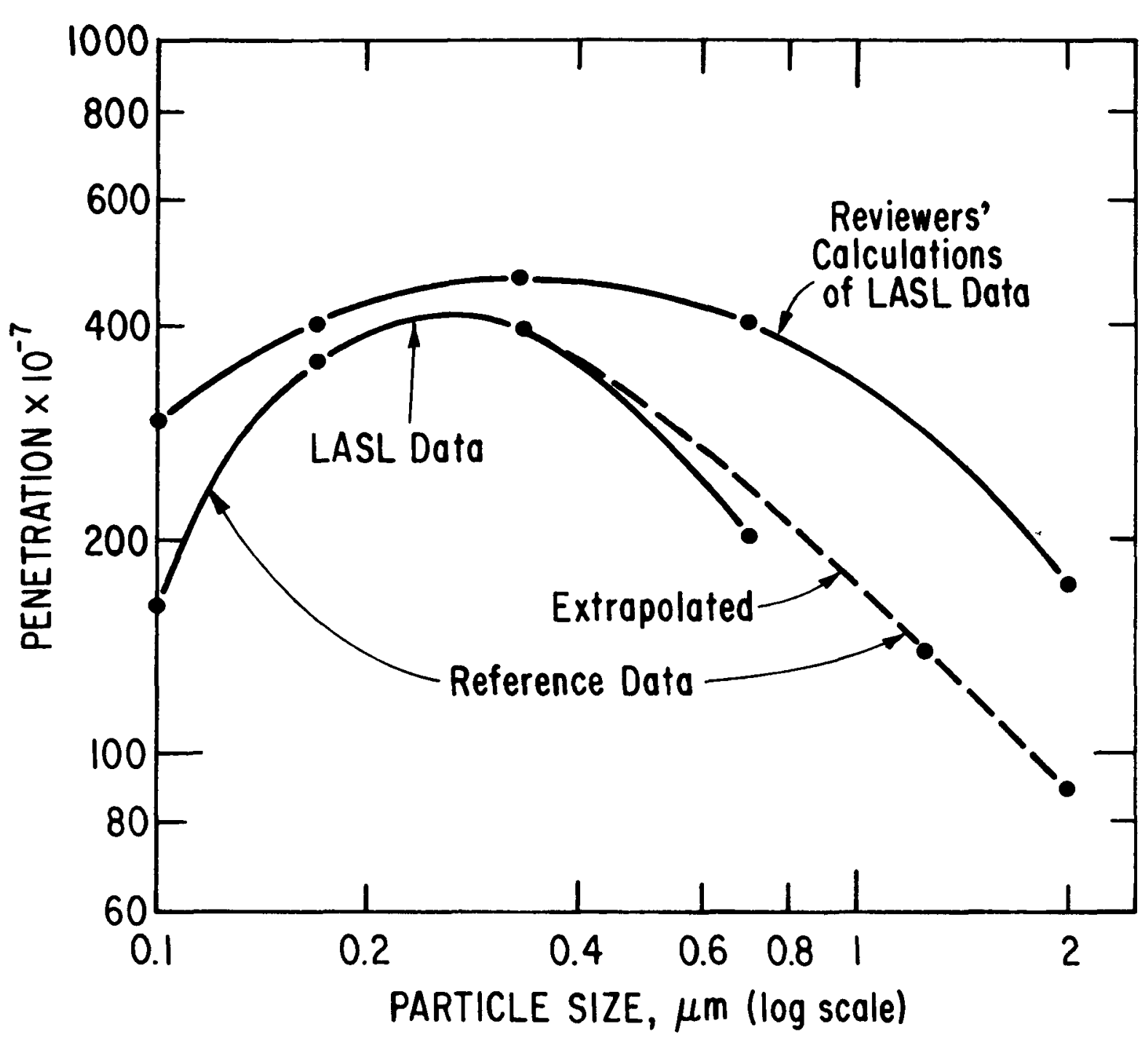

Fig. 9.2. Penetration Data Adopted as Reference For Second and Third Stages of HEPA Filters

It was shown in Section 7.1 from measurements made at AEC facilities that particle sizes from operations involving liquids are much smaller than those generated in operations that are largely mechanical in character. Also, operations of a production nature, $i . e$. , repetitive, tend to yield narrower particle size distributions than are obtained in variable operations such as those performed at research and development facilities. Also, because the reference penetration data of HEPA filters shows the efficiencies of the HEPAs to be dependent on particle size, it would be expected that the distribution of particle sizes would be altered during passage through an air cleaning system.

The calculations were performed for two air cleaning systems, one of them consisting of two HEPA filters in series and the other of three HEPA filters in series. The former is intended largely for application to existing systems, the latter to facilities yet to be constructed. To meet the new requirements for discharge limits proposed by the EPA in $40 \mathrm{CFR} 190$, facilities 
TABLE 9.1. Filter Penetration Data Used for Reference

Fractional Penetration

\begin{tabular}{|c|c|c|c|c|c|c|c|}
\hline \multirow{2}{*}{$\begin{array}{l}\text { Particle } \\
\text { Size Range } \\
\text { amad ( } \mu \mathrm{m})\end{array}$} & \multirow{2}{*}{$\begin{array}{c}\text { HEPA } 1 \\
\text { (1) }\end{array}$} & \multirow{2}{*}{$\begin{array}{c}\text { HEPA } 2 \\
\text { (2) }\end{array}$} & \multirow{2}{*}{$\begin{array}{c}\text { HEPA } 3 \\
\text { (3) }\end{array}$} & \multicolumn{2}{|c|}{ Two Stages in Series } & \multicolumn{2}{|c|}{ Three Stages in Series } \\
\hline & & & & (1) $\mathrm{x}(2)$ & Degraded by $10^{2}$ & $(1) \times(2) \times(3)$ & Degraded by $10^{3}$ \\
\hline$<0.12$ & $4 \times 10^{-7}$ & $159 \times 10^{-7}$ & $159 \times 10^{-7}$ & $0.636 \times 10^{-11}$ & $0.636 \times 10^{-9}$ & $1.01 \times 10^{-16}$ & $1.01 \times 10^{-13}$ \\
\hline 0.12 to 0.22 & $18.1 \times 10^{-7}$ & $352 \times 10^{-7}$ & $352 \times 10^{-7}$ & $6.37 \times 10^{-11}$ & $6.37 \times 10^{-9}$ & $22.4 \times 10^{-16}$ & $22.4 \times 10^{-13}$ \\
\hline 0.22 to 0.44 & $32.8 \times 10^{-7}$ & $393 \times 10^{-7}$ & $393 \times 10^{-7}$ & $12.9 \times 10^{-11}$ & $12.9 \times 10^{-9}$ & $50.6 \times 10^{-16}$ & $50.6 \times 10^{-13}$ \\
\hline 0.44 to 0.96 & $28.1 \times 10^{-7}$ & $201 \times 10^{-7}$ & $201 \times 10^{-7}$ & $5.6 \times 10^{-11}$ & $5.6 \times 10^{-9}$ & $11.3 \times 10^{-16}$ & $11.3 \times 10^{-13}$ \\
\hline 0.96 to 1.54 & $12.1 \times 10^{-7}$ & $140 \times 10^{-7}$ & $140 \times 10^{-7}$ & $1.7 \times 10^{-11}$ & $1.7 \times 10^{-9}$ & $2.37 \times 10^{-16}$ & $2.37 \times 10^{-13}$ \\
\hline$>1.54$ & $2.5 \times 10^{-7}$ & $90 \times 10^{-7}$ & $90 \times 10^{-7}$ & $0.22 \times 10^{-11}$ & $0.22 \times 10^{-9}$ & $0.20 \times 10^{-16}$ & $0.20 \times 10^{-13}$ \\
\hline
\end{tabular}


are expected to be designed with a minimum of three HEPAs in series. For some cases, it is expected that a fourth filter may be added, thus altering further the particle size distributions of effluents. The four-filter case has not been calculated.

In all cases, the particle size distribution was assumed to follow a $\log -$ normal distribution.

For a processing plant, the aerosol challenging the first filter was assumed to have a mean diameter of $0.5 \mu \mathrm{m}$ and a geometric standard deviation $\left(\sigma_{g}\right)$ of 2.2. This is consistent with the data available for 1iquid operations hating a repetitive character. The particle size range is thus established as $0.1 \mu \mathrm{m}$ to $2.4 \mathrm{~m}^{*}$ for \pm 2 standard deviations. Two additional cases were examined. In one, the distribution was broadened about the mean of $0.5 \mu \mathrm{m}$ by assuming a standard deviation of 4.4; in the other, the distribution was altered by halving the mean and retaining the reference distribution as characterized by a $\sigma_{g}$ of 2.2 .

A similar pattern was adopted in the calculations for the fabrication plants. The reference aerosol was assumed to have a mean particle size of $3.3 \mu \mathrm{m}$ and a geometric standard deviation of 2.0. This reference aerosol is also consistent with the data available for solids-handling operations. Again, two additional cases were examined in which the standard deviation was doubled and the mean was halved.

The particle size distributions for the effluents were expressed again as a mean and a geometric standard deviation. As would be expected, the particle size distributions of the effluents do not follow precisely a $10 \mathrm{~g}-$ normal distribution, but the deviations are not regarded as large.

The results are shown in Tables 9.2 and 9.3 for processing and fabrication plants, respectively.

For the reference processing case, the aerosol upstream from the first HEPA has a range $\left(+2 \sigma_{g}\right)$ of particle sizes of 0.1 to $2.4 \mu \mathrm{m}$, with a mean of $0.5 \mu \mathrm{m}$. Passage through two HEPAs reduces the mean to $0.37 \mu \mathrm{m}$ and the range of 0.15 to $0.92 \mu \mathrm{m}$. An additional HEPA yields a slight reduction to a mean of $0.33 \mu \mathrm{m}$ and a range of 0.15 to $0.73 \mu \mathrm{m}$. Doubling the $\sigma_{\mathrm{g}}$ in Case II for the input aerosol increases the range of the effluent but not substantially, especially when three HEPAs are used. Halving the input mean (Case III) reduces the means and the ranges of the effluents, but again not substantially.

The results for the processing plant indicate that the mean particle size of the effluent will be in the range of 0.25 to $0.35 \mu \mathrm{m}$, with a total range $\left(2 \sigma_{\mathrm{g}}\right.$ ) extending from about $0.1 \mu \mathrm{m}$ to $0.8 \mu \mathrm{m}$.

Comparable analyses of the data for the fabrication plant indicate that effluents will have mean particle sizes of 0.5 to $1.2 \mu \mathrm{m}$, with a total range $\left(2 \sigma_{\mathrm{g}}\right)$ extending from about 0.2 to $4 \mu \mathrm{m}$.

* Lower limit: $0.5 \div(2.2)^{2}$.
Upper limit: $0.5 \times(2.2)^{2}$.


Table 9.2. Particle Size Distributions of Effluents from Processing Plants for Air-Cleaning Systems Containing Two and Three HEPA Filters in Series

$\mu=$ mean of particle size distribution based on total activity

$\sigma_{\mathrm{g}}=$ geometric standard deviation

\begin{tabular}{lccc}
\hline & $\begin{array}{c}\text { Case I } \\
\text { (Reference) }\end{array}$ & $\begin{array}{c}\text { Case II } \\
\left(\sigma_{\mathrm{g}} \text { Doubled }\right)\end{array}$ & $\begin{array}{c}\text { Case III } \\
(\mu \text { Halved })\end{array}$ \\
\hline Upstream from Cleaning System & & & \\
$\mu, \mu \mathrm{m}$ & 0.5 & 0.5 & 0.25 \\
$\sigma_{\mathrm{g}}$ & 2.2 & 4.4 & 2.2 \\
Range $\left(2 \sigma_{\mathrm{g}}\right), \mu \mathrm{m}$ & $0.1-2.4$ & $0.02-9.7$ & $0.05-1.2$ \\
$<0.12$ & $3.9 \%^{\mathrm{a}}$ & $17.5 \%^{\mathrm{a}}$ & $17.5 \%^{\mathrm{a}}$ \\
$0.12-0.22$ & 11.3 & 12.0 & 26.5 \\
$0.22-0.44$ & 28.6 & 17.0 & 32.0 \\
$0.44-0.96$ & 35.4 & 20.2 & 19.2 \\
$0.96-1.54$ & 12.8 & 10.3 & 3.6 \\
$>1.54$ & 8.0 & 23.0 & 1.1
\end{tabular}

Downstream from Cleaning System

Two HEPAs in Series

$$
\begin{aligned}
& \mu, \mu \mathrm{m} \\
& \sigma_{g} \\
& \text { Range }(2 \\
& <0.12 \\
& 0.12-0.22 \\
& 0.22-0.44 \\
& 0.44-0.96 \\
& 0.96-1.54 \\
& >1.54
\end{aligned}
$$$$
\text { Range }\left(2 \sigma_{g}\right), \mu \mathrm{m}
$$

Three HEPAs in Series

$$
\begin{aligned}
& \mu, \mu \mathrm{m} \\
& \sigma_{g} \\
& \text { Range }(2 \\
& <0.12 \\
& 0.12-0.22 \\
& 0.22-0.44 \\
& 0.44-0.96 \\
& 0.96-1.54 \\
& >1.54
\end{aligned}
$$$$
\text { Range }\left(2 \sigma_{g}\right), \mu \mathrm{m}
$$

0.37

1.58

$0.15-0.92$

$0.4 \%$

10.8

55.1

29.8

3.3

0.3
0.33

1.77

$0.10-1.0$

$2.5 \%$

17.3

49.5

25.6

3.9

1.2

0.29

1.54

$0.12-0.69$

$1.6 \%$

23.9

58.4

15.2

0.87

0.03

a

Percentages refer to total activities in size ranges. 
Table 9.3. Particle Size Distributions of Effluents from

Fabrication Plants for Air Cleaning Systems

Containing Two and Three HEPA Filters in Series

$\mu=$ mean of particle size distribution based on total activity

$\sigma_{\mathrm{g}}=$ geometric standard deviation

\begin{tabular}{lccc}
\hline & $\begin{array}{c}\text { Case I } \\
\text { (Reference) }\end{array}$ & $\begin{array}{c}\text { Case II } \\
\left(\sigma_{\mathrm{g}} \text { Doubled }\right)\end{array}$ & $\begin{array}{c}\text { Case III } \\
(\mu \text { Halved })\end{array}$ \\
\hline Upstream from Cleaning System & & & \\
$\mu, \mu \mathrm{m}$ & 3.3 & 3.3 & 1.65 \\
$\sigma_{\mathrm{g}}$ & 2.0 & 4.0 & 2.0 \\
Range $\left(2 \sigma_{\mathrm{g}}\right), \mu \mathrm{m}$ & $0.8-13$ & $0.2-53$ & $0.4-6.6$ \\
$<0.12$ & - & $0.95 \%^{\mathrm{a}}$ & - \\
$0.12-0.22$ & $0.01 \%^{\mathrm{a}}$ & 1.85 & $0.21 \%^{\mathrm{a}}$ \\
$0.22-0.44$ & 0.2 & 4.9 & 2.89 \\
$0.44-0.96$ & 3.79 & 11.3 & 18.9 \\
$0.96-1.54$ & 10.2 & 10.5 & 24.5 \\
$>1.54$ & 85.8 & 70.5 & 53.5
\end{tabular}

Downstream from Cleaning System

Two HEPAs in Series

$\mu, \mu \mathrm{m}$
${ }_{\sigma}$ gange $\left(2 \sigma_{\mathrm{g}}\right), \mu \mathrm{m}$
$<0.12$

$0.12-0.22$

$0.22-0.44$

$0.44-0.96$

$0.96-1.54$

$>1.54$

Three HEPAs in Series $\mu, \mu \mathrm{m}$

$\sigma_{\mathrm{g}}$

Range $\left(2 \sigma_{g}\right), \mu \mathrm{m}$

$<0.12$

$0.12-0.22$

$0.22-0.44$

$0.44-0.96$

0.96-1.54

$>1.54$
1.23

1.86

$0.35-4.2$

$-$

$0.11 \%$

4.3

35.3

28.8

31.5

1.0

1.86

$0.29-3.4$

$-$

$0.24 \%$

10.7

45.2

25.6

18.3
0.54

1.85

$0.16-1.8$

$0.35 \%$

6.9

36.7

36.7

10.4

9.0

0.46

1.80

$0.14-1.5$

$0.21 \%$

9.1

54.2

27.9

5.5

3.1
0.70

1.62

$0.27-1.8$

$-$

$0.68 \%$

18.8

53.5

21.0

6.0

a Percentages refer to total activies in size ranges. 
9.5. Tota1 Penetration Factors for Processing and Fabrication Plants for Three Time Periods

The development and application of technology for the containment of plutonium within fuel cycle facilities has led to and has the prospect of continuing to lead to improvements of the quality of the effluents discharged from these facilities. Increasingly stringent criteria promulgated by the Nuclear Regulatory Commission (NRC) and the Environmental Protection Agency (EPA) provide the principal motivation for the application of new technology. It is expected that the NRC will, in the near future, issue numerical ALARA (As Low As Reasonably Achievable) guidelines for the fuel cycle similar to Appendix I of $10 \mathrm{CFR}$ Part 50 which is applicable to reactors. It is expected that the numerical guidelines will be consistent with the proposed rules issued by the EPA in 40 CFR Part 190 .

In this review, three technology references have been considered in generating plutonium source terms for the fuel cycle: current practice, current technology capability, and projected capability.

\subsubsection{Plant Retention Based on Current Practice}

In the case of reprocessing plants, the historical operating record of this country's only commercial plant is used as reference. The record was described in Section 4.2. Annual fractional releases varied from $0.7 \times 10^{-8}$ to $15.3 \times 10^{-8}$. It is judged that the original plant was capable of operating on a continuing basis at a fractional release level of $1 \times 10^{-8}$. This value is adopted here as reference.

Fabrication experience in the commercial sector has been on a small scale, and actual production figures are relatively meager. Commercial experience was described in Section 4.3. If one assumes that the Cheswick Plant of Westinghouse and the Kerr-McGee plant were operated at a level of $10 \mathrm{MT} / \mathrm{yr}$ and that the average plutonium content of the fuel was about 10 percent, the known releases translate to a fractional penetration of $2 \times 10^{-10}$ to $5 \mathrm{x}$ $10^{-10}$. The value of $1 \times 10^{-9}$ will be adopted here as a reference value for current plants.

\subsubsection{P1ant Retention Based on Current Technology Capability}

The second reference considered is that for current technology

capability. This is reflected in (1) the plans for plants under construction or proposed for construction and (2) generic environmental impact statements prepared for hypothetical facilities.

In the case of reprocessing plants, the generic statements for the recycle of mixed-oxide fuels ${ }^{2}$ and for the LMFBR Program ${ }^{7}$ provided a basis for judgment, as did the projected releases from the Barnwell fuel processing plant (construction of which is nearly completed) ${ }^{4}$ and the proposed expansion of the Nuclear Fuel Services plant at West Valley, N.Y. ${ }^{5}$ Information concerning these were presented in Sections 8.6.2., 8.6.3., and 8.7 of this report. 
In general, three stages of HEPA filtration (or equivalent) have been adopted for these plants. A sand bed filter or deep bed filter has been substituted for the third stage of HEPA in two of the reprocessing facilities (i.e., in the hypothetical plant for the environmental evaluation of the LMFBR Program and in the proposed NFS processing facility). The analyses for these facilities generally assume an installed filtration efficiency of $99.9 \%$ for.one HEPA stage, which efficiency is very much at the low end of known capabilities. In the case of processing plants, the fraction of plant material reaching the filters is about $10^{-3}$ to $10^{-4}$; on this basis, the plant release fractions would be $10^{-12}$ to $10^{-13}$. However, experience has also shown that degradation of performance occurs, principally, by reaction with residual nitric acid vapors or other chemicals.

The projected release fractions from documentation range from $1.6 \times 10^{-8}$ for the reprocessing facility described in the GESMO document ${ }^{2}$ to $5.7 \times 10^{-10}$ for the Barnwell Plant. ${ }^{4}$ Taking into account the fact that both analyses used conservative performance figures for HEPA filters (relative to known capabilities of HEPAs), a reference value of $1 \times 10^{-10}$ has been adopted.

The two fabrication plants described in GESMO $^{2}$ and in the environmental statement for the LMFBR program ${ }^{7}$ also utilize three stages of HEPA filtration, one located close to the process enclosure, the other two located just ahead of the discharge stack. The fraction of plant materials reaching the air-cleaning systems has been estimated as $1 \times 10^{-3}$ to $5 \times 10^{-4}$. Thus, a total plant pentration of $1 \times 10^{-12}$ to $1 \times 10^{-13}$ seems readily achieveable. In Sections 8.6.2. and 8.6.3. of this report, projected release rates for fabrication plants from references 2 and 7 were given as $7.2 \times 10^{-11}$ to $1 \times 10^{-12}$. Taking into account the fact that chemical degradation of filter material is not very significant for fabrication operations, a value of $1 \times 10^{-12}$ has been adopted for fabrication plants.

\subsubsection{Plant Retention Based on Future Technology Developments}

The third reference considered for plant retention is that for projected technology development. It is recognized that even current experimental filtration data obtained by LASL indicate lower penetration rates than are used in most environmental analyses. Values of $0.50 \times 10^{-16}$ appear to be achievable for three stages of HEPA filtration under optimum conditions and the addition of a fourth stage is not technology-limited. However, LASL results were obtained under laboratory conditions with exceedingly careful installations to avoid bypass leakages. The filters used were production grade, and no chemicals that could lead to degradation were involved. To exploit the full filtration characteristics will require meticulous quality control in the manufacture of such filters, standardized testing of in-place filters with very rigid requirements on installation to avoid leakage, periodic retesting, and (at least for processing plants) improved off-gas treatment systems for removal of residual chemicals (especially nitric acid). Foreseen in the future, for the third time reference, is that fractional releases of $1 \times 10^{-14}$ will be achieved routinely for processing plants and $1 \times 10^{-15}$ for fabrication plants.

Reference fractional releases are summarized in Table 9.4. 
Table 9.4. Summary of Reference Values for Plutonium Releases in Processing and Fabrication Plants for Various Time Periods

\begin{tabular}{|c|c|c|}
\hline & \multicolumn{2}{|c|}{ Reference Fractional Releases } \\
\hline & Processing & Fabrication \\
\hline Current Practice & $1 \times 10^{-8}$ & $1 \times 10^{-9}$ \\
\hline $\begin{array}{l}\text { Current Technology } \\
\text { Capability }\end{array}$ & $1 \times 10^{-10}$ & $1 \times 10^{-12}$ \\
\hline $\begin{array}{l}\text { Projected Technology } \\
\text { Capability }\end{array}$ & $1 \times 10^{-14}$ & $1 \times 10^{-15}$ \\
\hline
\end{tabular}

\subsection{Normalized Plutonium Flow for Fuel Cycles of Reference Reactors}

The reference fuel cycles for three reactors were described in section 3 . In this section, the plutonium flows for the three cycles will be determined and normalized for a gigawatt-year of electrical energy production.

Adopted as reference for both the LWR-U and LWR-Pu are the 1000-MW(e) reactors described in GESMO. ${ }^{2}$ The information needed for this study consists only of the operating plant factor and the annual rates of plutonium charge and discharge. The former is 0.80 for both reactors.

The annual discharge for the LWR-U is $275.8 \mathrm{~kg}$ of total plutonium, which corresponds to $344.7 \mathrm{~kg} / \mathrm{GW}(\mathrm{e})-\mathrm{yr}$ of electrical power generation.

The LWR-Pu described in GESMO is a 1.15 Self-Generating Reactor (SGR). A $1.00 \mathrm{SGR}$, according to this concept, is a reactor that is totally selfsufficient on its own plutonium. Plutonium is discharged, processed, and returned to the reactor with no additions or removals, except for processing and fabrication losses incurred. The 1.15 SGR reactor utilizes an additional quantity of plutonium supplied by other reactors over and above that of its own recycle plutonium. The plutonium discharge and charge numbers from GESMO will thus be somewhat higher than those for an equilibrium 1.00 SGR.

The reference LWR-Pu reactor discharges a total of $573 \mathrm{~kg}$ plutonium annually and is charged with $585 \mathrm{~kg}$ plutonium. On a normalized basis, this corresponds to 716.2 and $731.2 \mathrm{~kg}$ plutonium per gigawatt-year of electrical power generated.

The LMFBR reactor used as a reference is the Atomic International reference oxide reactor as described in a report from Oak Ridge National Laboratory. ${ }^{3}$ The plant factor is 0.80 . The annual discharges from the core, axial blanket, and radial blanket are 8.4, 4.88, and $10 \mathrm{MT}$, respectively, for a total of 23.3 MT. Averaged over all of the material discharged, the burnup is equivalent to $32,977 \mathrm{MW}(\mathrm{t}) \mathrm{d} / \mathrm{MT}$. The stated plutonium content of spent fuel is $85.9 \mathrm{~kg} / \mathrm{MT}$, which converts to $2000 \mathrm{~kg}$ for the reactor. If the plutonium charged has an isotopic composition equivalent to that discharged, the annual charge rate is $1797 \mathrm{~kg}$ total plutonium. The normalized values per gigawatt-year of electrical energy are 2500 and $2246 \mathrm{~kg}$, respectively.

The values are summarized in Table 9.5. 
Table 9.5. Normalized Plutonium Flows in Three Reference Reactors

\begin{tabular}{llc}
\hline Reactor Type & Stream & $\begin{array}{c}\text { Normalized Plutonium } \\
\text { Flow }[\mathrm{kg} / \mathrm{GW}(\mathrm{e}) \text {-yr }]\end{array}$ \\
\hline LWR-U & Charge & 0.0 \\
& Discharge & 344.7 \\
LWR-Pu & Charge & 731.2 \\
& Discharge & 716.2 \\
LMFBR & Charge & 2246 \\
& Discharge & 2500 \\
\hline
\end{tabular}

9.7. Source Term for Normal Operations

In the preceding sections, the penetration factors for processing and fabrication plants were developed, and normalized plutonium flows for three ex-reactor cycles were calculated.

In this section, these factors have been combined to yield the plutonium source terms as expressed in micrograms of plutonium released per gigawatt year of electrical energy produced. The results are shown in Table 9.6.

Table 9.6. Source Term for Normal Plutonium Releases from Three Ex-Reactor Cycles

\begin{tabular}{|c|c|c|c|}
\hline \multirow[b]{2}{*}{ Reactor Cycle } & \multicolumn{3}{|c|}{ P1utonium Release ( $\mu \mathrm{g} / \mathrm{GW}(\mathrm{e})-\mathrm{yr})$} \\
\hline & Current Practice & $\begin{array}{c}\text { Current Technology } \\
\text { Capability }\end{array}$ & $\begin{array}{c}\text { Projected Technology } \\
\text { Capability }\end{array}$ \\
\hline \multicolumn{4}{|l|}{ LWR-U } \\
\hline Fabrication & 0 & 0 & 0 \\
\hline \multirow[t]{2}{*}{ Processing } & 3,447 & 34.5 & 0.003 \\
\hline & 3,447 & 34.5 & 0.003 \\
\hline \multicolumn{4}{|l|}{$\mathrm{LWR}-\mathrm{Pu}$} \\
\hline Fabrication & 731 & 0.73 & 0.0007 \\
\hline \multirow[t]{2}{*}{ Processing } & 7,162 & 71.62 & 0.0072 \\
\hline & 7,893 & 72.35 & 0.0079 \\
\hline \multicolumn{4}{|l|}{ LMFBR } \\
\hline Fabrication & 2,246 & 2.2 & 0.002 \\
\hline \multirow[t]{2}{*}{ Processing } & 25,000 & 250.0 & 0.025 \\
\hline & 27,246 & 252.2 & 0.027 \\
\hline
\end{tabular}

If it is desired to determine the quantities of plutonium discharged as a function of particle size, the source term needs to be considered in conjunction with the particle size distributions given in Section 9.4 . 


\subsection{Fractional Release for the Shipment of Plutonium Dioxide}

In Section 8.5, a plutonium source term for the shipment of plutonium dioxide by truck was developed from a draft report prepared by Battelle Northwest Laboratories. Imperfections in human operations, accidents, and accident severities were taken into account, and it was estimated that the fractional release would be $1.0 \times 10^{-8}$.

It should be recognized that the analysis was based on a very specific containment system typical of current practices. No effort was made to determine the effect on release fractions of improvements that could be made to the system. In this review, the value of $1.0 \times 10^{-8}$ was used only in the current time period, and no efforts were made to extrapolate improvements for the near and intermediate future.

Data of a comparable nature was not available for the shipment of spent fuel to the processing plant or for the shipment of fabricated fuel from the fabrication plant back to the reactor. Intuitively, it would be expected that release fractions for these shipments due to accidents and other causes could be made substantially less than for shipment of plutonium oxide.

Estimated releases based on this information are shown for the three reactor cycles in Table 9.7. It is notable that the overall releases are about equivalent to releases occurring during normal operations of reprocessing and fabrication operations (current technology) for all reactor cycles considered.

Table 9.7. Estimated Plutonium Released during Shipment of Plutonium Oxide

(based on Risk Analysis in BNWL-1846)

\begin{tabular}{cc}
\hline Reactor Cycle & P1utonium Release $(\mu \mathrm{g} / \mathrm{GW}(\mathrm{e})-\mathrm{yr})$ \\
\hline LWR-U & 3,600 \\
LWR-Pu & 7,400 \\
LMFBR & 26,000 \\
\hline
\end{tabular}

\subsection{Accidents in Fuel Cycle Facilities}

\subsubsection{Genera1}

Accident analyses as presented in various environmental statements, both 1icensee and AEC, were reviewed. The bases for analyses vary considerably, with different factors being used for the total quantities of plutonium involved, fractions becoming airborne, and filter efficiencies. In some cases, all stages of HEPA filters were assumed to be destroyed; in other cases, all stages of HEPA filters were assumed to be intact. As a result, the quantities of plutonium estimated to be present in the gaseous effluents showed wide variations for common incidents. For example, the plutonium release shown in the applicant's Safety Analysis Report for the Barnwell fuel processing facility ${ }^{4}$ for a solvent fire is $17,800 \mu \mathrm{Ci}(\alpha)$, while 
the comparable document for the NFS plant ${ }^{5}$ indicates a plutonium release of $437 \mu \mathrm{Ci}(\alpha)$ for the same accident.

To eliminate the effect of varying assumptions about HEPA filter efficiencies, the data was normalized to reflect the quantities of plutonium upstream from the first stage of HEPA filters. The results obtained were more uniform.

In general, only accidents in the severe category were included. It is recognized that the Rasmussen type of risk analysis is needed to give a comprehensive picture of accident releases, but to date that kind of analysis has not been performed. Estimates of probabilities of accidents were presented in a BNWL report, ${ }^{6}$ and from these, the reviewers developed estimates for reprocessing plants.

\subsubsection{Fabrication Plants}

Data on the plutonium content of effluents upstream from the first stage of filtration for serious accidents in fabrication plants are shown in Table 9.8. Also shown are estimated probabilities of occurrence. These data have been combined with normalized plutonium flow data (normalized to a gigawatt-year of power production) to express plutonium discharges per gigawatt-year (Table 9.10). For current filtration practices, 7.3 and $1.3 \mu \mathrm{g}$ of plutonium are estimated to be released per GW(e)-yr for the LWR-Pu and LMFBR cycles, respectively. This compares with normal operating releases of 731 and $2246 \mu g / G W(e)-y r$.

\subsubsection{Processing P1ants}

The data for processing plants was treated similarly. Accident releases and probabilities are shown in Table 9.9. Releases normalized to a gigawatt-year of energy production are given in Table 9.10. For current filtration practices, 3.1 and $5.1 \mu \mathrm{g}$ of plutonium are released per gigawattyear for LWRs and LMFBRs, respectively. This compares with normal operating releases of 7100 and $25,000 \mu \mathrm{g}$ for the two reactor cycles.

Table 9.8. Estimated Plutonium Content of Effluents

Upstream from Air-Cleaning System for

Serious Accidents in Fabrication Plants

\begin{tabular}{|c|c|c|c|}
\hline \multirow[b]{2}{*}{ Accident } & \multirow{2}{*}{$\begin{array}{l}\text { Estimated } \\
\text { Probability }\left(\mathrm{yr}^{-1}\right)\end{array}$} & \multicolumn{2}{|c|}{$\begin{array}{c}\text { Total Plutonium Challenging } \\
\text { Air Cleaning System }(\mathrm{g}) \\
\end{array}$} \\
\hline & & LWR-Pu (1 MT/day $)^{2}$ & LMFBR (5 MT/day) 7 \\
\hline Explosion & $1 \times 10^{-3}$ & 100 & 107 \\
\hline Criticality & $8.6 \times 10^{-3}$ & 500 & 600 \\
\hline Facility Fire & $2 \times 10^{-4}$ & $\varepsilon$ & 11,700 \\
\hline Local Fire & $1 \times 10^{-2}$ & 100 & a \\
\hline
\end{tabular}

a Accident not analyzed in reference. 
Table 9.9. Estimated Plutonium Content of Effluents Upstream from Air-Cleaning System for Serious Accidents in Processing Plants

\begin{tabular}{|c|c|c|c|}
\hline \multirow[b]{2}{*}{ Accident } & \multirow{2}{*}{$\begin{array}{l}\text { Estimated } \\
\text { Probability }\left(\mathrm{yr}^{-1}\right)\end{array}$} & \multicolumn{2}{|c|}{$\begin{array}{r}\text { Total Plutonium Challenging } \\
\text { Air Cleaning System (g) } \\
\end{array}$} \\
\hline & & $\mathrm{LWR}-\mathrm{Pu}(5 \mathrm{MT} / \mathrm{day})^{2}$ & LMFBR(5 MT/day) ${ }^{7}$ \\
\hline Criticality & $10^{-2}$ & 100 & 200 \\
\hline $\begin{array}{l}\text { Explosion } \\
\text { Waste Concentrator } \\
\text { Plutonium Concentrator }\end{array}$ & $\begin{array}{l}10^{-2} \\
10^{-2}\end{array}$ & $\begin{array}{r}0.03 \\
13\end{array}$ & $\begin{array}{r}0.007 \\
1.4\end{array}$ \\
\hline Major Vessel Leak & $10^{-2}$ & a & 93 \\
\hline $\begin{array}{l}\text { Solvent Fire } \\
\text { Plutonium Cycle } \\
\text { Codecontamination Cycle }\end{array}$ & $10^{-2}$ & $\begin{array}{r}7 \\
0.06\end{array}$ & $\begin{array}{l}10 \\
\mathrm{a}\end{array}$ \\
\hline Zirconium Fire & $10^{-2}$ & 0.0037 & a \\
\hline
\end{tabular}

a Accident not analyzed in reference.

Table 9.10. Normalized Plutonium Releases for Major Accidents in Fabrication and Processing P1ants

(based on Accident Probabilities shown

in Tables 9.8 and 9.9)

Current Current Technology Projected Technology Practice Capability Capability

Assumed Filter Penetrations

$\begin{array}{llll}\text { Processing } & 10^{-4} & 10^{-6} & 10^{-9} \\ \text { Fabrication } & 10^{-5} & 10^{-8} & 10^{-10}\end{array}$

Discharges From Processing

Plants, $\mu g / G W(e)-y r$

$\begin{array}{llll}\text { LWR-U } & 3.1 & 0.031 & 0.00003 \\ \text { LWR-Pu } & 3.1 & 0.031 & 0.00003 \\ \text { LMFBR } & 5.1 & 0.051 & 0.00005\end{array}$

LMFBR

3.1

0.051

0.00005

Discharges From Fabrication

Plants, $\mu \mathrm{g} / \mathrm{GW}(\mathrm{e})-\mathrm{yr}$
LWR-Pu
7.3
0.0073
0.00007
LMFBR
1.3
0.0013
0.00001

\subsection{Conclusions}

A summary of releases of plutonium from the ex-reactor fuel cycle (except transportation) of LWR-U's, LWR-Pu's, and LMFBRs is shown in Table 9.11. 
Table 9.11. Releases Expected from Normal and Accident Situations for Ex-Reactor Fuel Cycle Operations ( $\mu \mathrm{g} \mathrm{Pu/GW(e)-yr)}$

\begin{tabular}{|c|c|c|c|c|c|c|c|c|c|}
\hline & \multicolumn{3}{|c|}{ LWR-U } & \multicolumn{3}{|c|}{ LWR-Pu } & \multicolumn{3}{|c|}{ LMFBR } \\
\hline & $\overline{\mathrm{FAB}}$ & Process & Total & $\overline{\mathrm{FAB}}$ & Process & Total & $\overline{\mathrm{FAB}}$ & Process & Total \\
\hline $\begin{array}{l}\text { Current } \\
\text { Practice }\end{array}$ & - & 3450 & 3450 & Not & t Applic & able & & Not Appli & ble \\
\hline $\begin{array}{l}\text { Current } \\
\text { Technology } \\
\text { Capability }\end{array}$ & - & 34.5 & 34.5 & 0.7 & 72 & 73 & & Not Appli & ble \\
\hline $\begin{array}{l}\text { Projected } \\
\text { Technology } \\
\text { Capability }\end{array}$ & - & 0.003 & 0.003 & 0.0008 & 0.008 & 0.009 & 0.002 & 0.027 & 0.03 \\
\hline
\end{tabular}

These data can be combined with estimates of the contribution of each of the reactor types to the total nuclear capacity to derive values for the total plutonium estimated to be discharged in any time period. This exercise was not carried out, because the significance of data on the total amount of plutonium discharged to the environment by the ex-reactor fuel cycle is not clear. It is likely that this amount, even if calculated, would be dwarfed by the amounts of plutonium in the biosphere from weapons tests. 
References for Section 9

1. C. A. Burchsted and A. B. Fuller, Design, Construction, and Testing of High-Efficiency Air Filtration Systems for Nuclear Applications, U.S. Atomic Energy Commission Report ORNL-NSIC-65, p. A-2 (January 1970).

2. Generic Environment Statement, Mixed Oxide Fuel (draft), prepared by U.S. Atomic Energy Commission, Fuels and Materials, Directorate of Licensing, Report WASH-1327 (August 1974).

3. Siting of Fuel Reprocessing Plants and Waste Management Facilities, compiled and edited by the staff of Oak Ridge National Laboratory, Report ORNL-4451 (JuIy 1970).

4. Barnwe11 Nuclear Fue1 P1ant Separations Facility, Fina1 Safety Analysis Report, Allied-Gulf Nuclear Services, Barnwell, S.C., DOCKET-50-332.

5. Safety Analysis Report, NFS Reprocessing Plant, West Valley, N.Y., Nuclear Fuel Services, Inc., Rockville, Md., DOCKET-50-201 (1973).

6. J. M. Selby et $a Z$, Considerations in the Assessment of the Consequences of Effluents from Mixed Oxide Fuel Fabrication Plants, U.S. Atomic Energy Commission Report BNWL-1697 (June 1973).

7. Environmenta1 Statement, Liquid Metal Fast Breeder Reactor, U.S. Atomic Energy Commission Report WASH-1535 (March 1974). 


\section{APPENDIX A - EXAMPLE OF METHOD USED TO CALCULATE FILTER PENETRATION AS A FUNCTION OF PARTICLE SIZE}

In Section 7.3, the results of filter penetration tests conducted by LASL with $\mathrm{PuO}_{2}$ aerosols were presented and analyzed. The data were reported in the form of (1) overall fractional penetration of a filter as determined by measurements of total activity and (2) particle size distributions upstream and downstream of a filter, expressed as a geometric mean and a geometric standard deviation.

Shown below is an example of the method used to reconstruct the particle size distributions and, more importantly, an example of how fractional penetrations as a function of particle size were obtained from LASL data.

The data selected for this example is that from the first-stage HEPA of LASL Run P4-3 (shown in Table 7.3 of the main part of this report). The data germaine to this exercise is as follows:

Overall fractional penetration of HEPA: $9 \times 10^{-7}$

Aerosol characteristics upstream of HEPA:

$$
\begin{aligned}
& \mu=0.38 \mu \mathrm{m} \\
& \sigma_{g}=2.51
\end{aligned}
$$

Aerosol characteristics downstream of HEPA:

$$
\begin{aligned}
& \mu=0.37 \mu \mathrm{m} \\
& \sigma_{\mathrm{g}}=1.76
\end{aligned}
$$

The use of $\mu$ and $\sigma_{g}$ by LASL for characterizing particle size distributions is consistent with a log normal probability distribution, for which $95 \%$ of the activity is associated with particles in a size range of $\mu / \sigma_{g}{ }^{2}$ and $\mu \cdot \sigma_{g}{ }^{2}$.

The particle size distributions of the two aerosols were reconstructed on $\log$ normal probability paper (Fig. A.1). If it is assumed that the $\log$ normal probability distribution is valid, 2.5 percent of the total activity of the aerosol is associated with particles having an amad less than $\mu / \sigma_{g}{ }^{2}$, and 2.5 percent of the total activity is associated with particles having an amad greater than $\mu \cdot \sigma_{g}{ }^{2}$. Ninety-five percent of the activity is thus included between these two values.

$$
\begin{array}{cll}
\begin{array}{l}
\text { Percent of activity associated } \\
\text { with particles having an amad } \\
\text { less than that shown }
\end{array} & \begin{array}{l}
\text { Particle Size, } \\
\text { amad, } \mu \mathrm{m}
\end{array} \\
2.5 & \begin{array}{l}
0.38 / 2.51^{2}=0.0603 \\
97.5
\end{array} & 0.38 \cdot 2.51^{2}=2.39
\end{array}
$$

These two points were plotted on log probability paper and were connected with a straight line. The line passes through $\mu=0.38 \mu \mathrm{m}$ at the median probability of $50 \%$. 


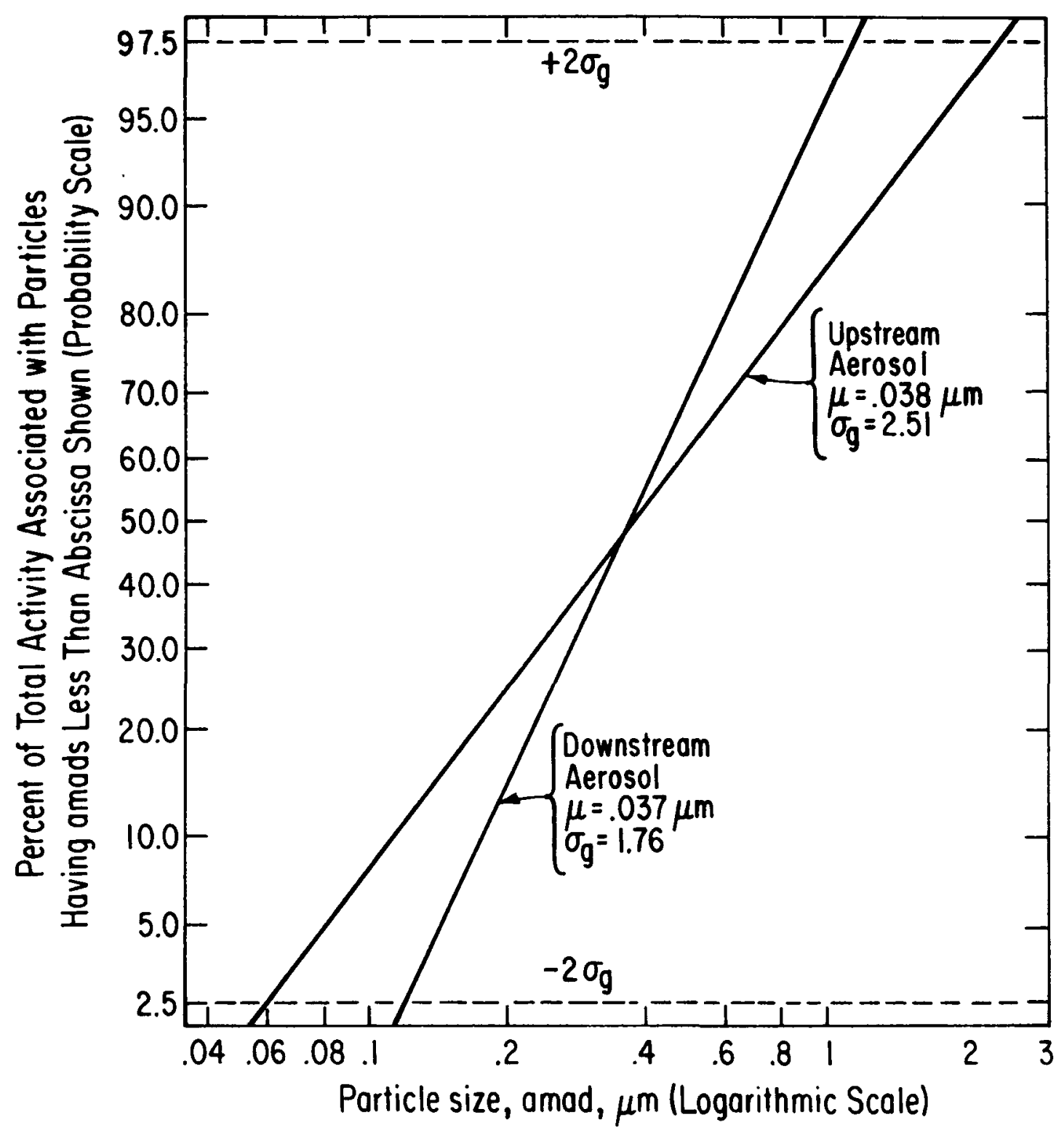

Fig. A.1. Reconstructed Particle Size Distributions for the First-Stage HEPA of LASL Run P4-3. 
fashion.

The distribution for the downstream aerosol is constructed in similar

The follwing tabulation lists the particle size ranges for which fractional penetrations are to be determined as well as the percentage of the activity associated with each range (see Fig. A.1.).

\begin{tabular}{|c|c|c|c|}
\hline & \multirow[t]{2}{*}{$\begin{array}{c}\text { Particle Size } \\
\text { Range, } \mu \mathrm{m} \\
\end{array}$} & \multicolumn{2}{|c|}{$\begin{array}{c}\text { Percent of Activity } \\
\text { Associated with } \\
\text { Range } \\
\end{array}$} \\
\hline & & $\begin{array}{l}\text { Upstream } \\
\text { Aerosol }\end{array}$ & $\begin{array}{c}\text { Downstream } \\
\text { Aerosol }\end{array}$ \\
\hline Read & $<0.12$ & 11.1 & 2.7 \\
\hline Directly & $<0.22$ & 28.0 & 18.5 \\
\hline from & $<0.44$ & 56.6 & 62.0 \\
\hline Fig A.1 & $<0.96$ & 84.0 & 95.1 \\
\hline & $<1.54$ & 93.6 & 99.35 \\
\hline Ranges & $<0.12$ & 11.0 & 2.7 \\
\hline Calculated & $0.12-0.22$ & 17.0 & 15.8 \\
\hline by Differences & $0.22-0.44$ & 28.5 & 43.5 \\
\hline of Above & $0.44-0.96$ & 27.5 & 33.1 \\
\hline Values & $0.96-1.54$ & 9.6 & 4.25 \\
\hline & $>1.54$ & 6.4 & 0.65 \\
\hline
\end{tabular}

If the total activity of the upstream aerosol is normalized at 1 unit, the total activity downstream is equivalent to the known fractional penetration of the filter $=9 \times 10^{-7}$ units. Hence, the ratio of downstream activity to upstream activity (i.e., the fractional penetration) for each particle size range is calculated as follows:

\begin{tabular}{|c|c|c|c|}
\hline $\begin{array}{l}\text { Total } \\
\text { Downstream } \\
\text { Activity }\end{array}$ & $\mathrm{x}$ & $\begin{array}{l}\text { Percent of downstream } \\
\text { activity associated } \\
\text { with range }\end{array}$ & Fractional \\
\hline $\begin{array}{l}\text { Total } \\
\text { Upstream } \\
\text { Activity }\end{array}$ & $\mathrm{x}$ & $\begin{array}{l}\text { Percent of upstream } \\
\text { activity associated } \\
\text { with range }\end{array}$ & for Range \\
\hline
\end{tabular}

As an example, for the range, 0.44-0.96 $\mu \mathrm{m}$ :

Fractional Penetration $=\frac{\left(9 \times 10^{-7}\right)(33.1)}{(1)(27.5)}=10.7 \times 10^{-7}$

Performing this operation on all particle size ranges yields the following final result:

Particle Size Range, $\mu \mathrm{m}$

Fractional Penetration

$<0.12$

$0.12-0.22$

$0.22-0.44$

$0.44-0.96$

$0.96-1.54$ for Range

$>1.54$

$2.2 \times 10^{-7}$

$8.3 \times 10^{-7}$

$13.6 \times 10^{-7}$

$10.7 \times 10^{-7}$

$3.9 \times 10^{-7}$

$0.9 \times 10^{-7}$ 


\section{APPENDIX B - CALCULATION OF EXPECTED FRACTIONAL RELEASES FROM CUMULATIVE PROBABILITY DATA}

In Section 8.5, a PNL report on accidental releases of plutonium during truck shipments was reviewed. The authors of the report furnished us supplemental information (shown in Table 8.5) that related cumulative accident probabilities (P) for stated release fractions of $F$ or greater (upper limit is unity). In Section 8.5.3, we calclulated the estimated release fraction by use of the following relationship,

$$
\text { Expected Release Fraction }=\int_{0}^{1} \mathrm{FdP}=\int_{0}^{1} \mathrm{PdF}
$$

This relation arises directly from consideration of the probability density distribution from which the cumulative probability distribution is derived. Curve (a) below is a generalized probability distribution with the specific characteristic that $\int_{0}^{1} \operatorname{pdF}=1$. Like
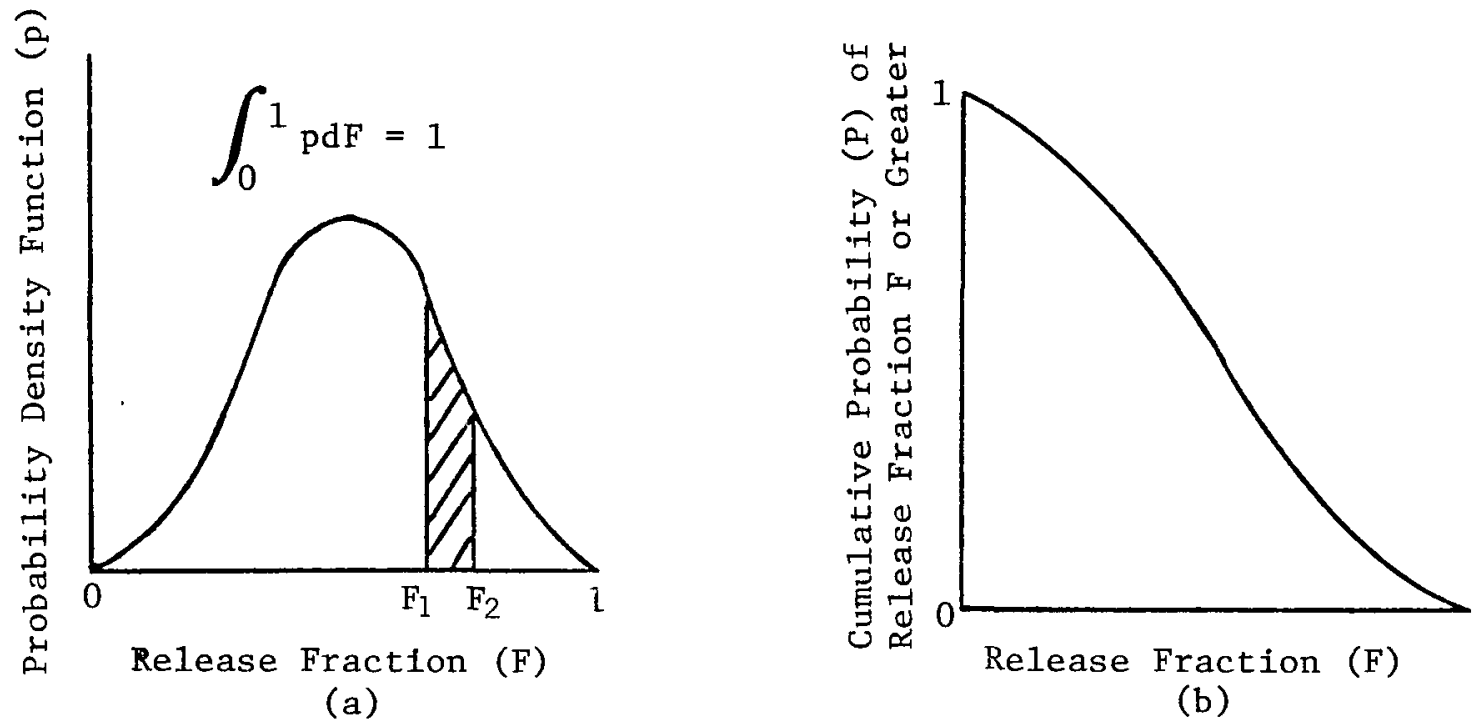

the normal distribution, the probability of release fractions occuring within a range of values, $e_{\cdot} g_{\cdot}, \mathrm{F}_{1}$ and $\mathrm{F}_{2}$, is the area under the curve between those values. (a).

Curve (b) is the cumulative probability distribution derived from Curve

$$
P=\int_{F}^{1} p d F
$$

Note that the limits of integration in (1) are consistent with $P$ being expressed as the cumulative probability of the corresponding release fraction $F$ or greater. 
(We could have selected the limits of integration in (1) as 0 (zero) to $F$ which would be consistent with expressing $P$ as the cumulative probability of the corresponding release fraction $F$ or less.)

Returning to curve (a), consider a range of values of fractional releases $F_{1}$ and $F_{2}$ as a differential element $d F$. Then the probability of fractional releases occurring in that range is $\mathrm{pdF}$, and the expected fractional release $(\mathrm{dE})$ is the product of the probability and the release fraction, thus:

$$
\mathrm{dE}=(\mathrm{pdF})(\mathrm{F})
$$

From (1), we note that

$$
\mathrm{dP}=\mathrm{pdF}
$$

Combining (3) and (2)

$$
\mathrm{dE}=\mathrm{FdP}
$$

The expected release fraction is obtained by integrating (4) between the limits of 0 and 1 .

$$
E=\int_{0}^{1} P d F
$$

It is visually evident from curve (b) that

$$
E=\int_{0}^{1} \operatorname{PdF}
$$

